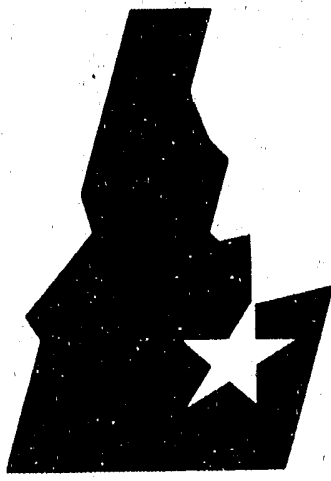

Idaho National

Engineering Laboratory

Managed

by the U.S.

Department

of Energy
EGG-WTD-10129

March 1992

APR2?. 1992;
Release Model for In Situ Vitrification Large-Field Test Off-Gas Treatment System

D. J. Pafford

V.X. Tung

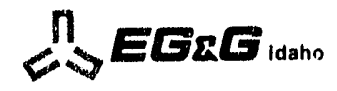

Work performed under DOE Contract No. DE-ACO7-76/D01570 
This document contains new concepts or the author(s) interpretation of new calculations and/or measurements; accordingly, EG\&G Idaho, Inc. is required by the Unised States Government to include the following disclaimer:

\section{DISCLAIMER}

This report was prepared as an account of work sponsored by an agency of the United States Government. Neither the United States Government nor any agency thereof, nor any of their employees, makes any warranty, express or implied, or assumes any legal liability or responsibility for the accuracy, completeness, or usefulness of any information, apparatus, product or process disclosed, or represents that its use 'vould not infringe privately owned rights. References herein to any specific commercial product, process, or service by trade name, trademark, manufacturer, or othenwise, does not necessarily constitute or imply its endorsement, recommendation, or favoring by the United States Government or any agency thereof. The views and opinions of authors expressed herein do not necessarily state or reflect those of the United States Government or any agency thereof. 


\title{
Release Model for In Situ Vitrification Large-Field Test Off-Gas Treatment System
}

\author{
D. J. Pafford \\ V. X. Tung
}

Published March 1992

Idaho National Erigineering Laboratory
EG\&G Idaho, Inc.
Idaho Falls, Idaho 83415 
Release Model for In Situ Vitrification Large-Field Test Off-Gas Treatment System

EGG-WTD-10129

Prepared by:
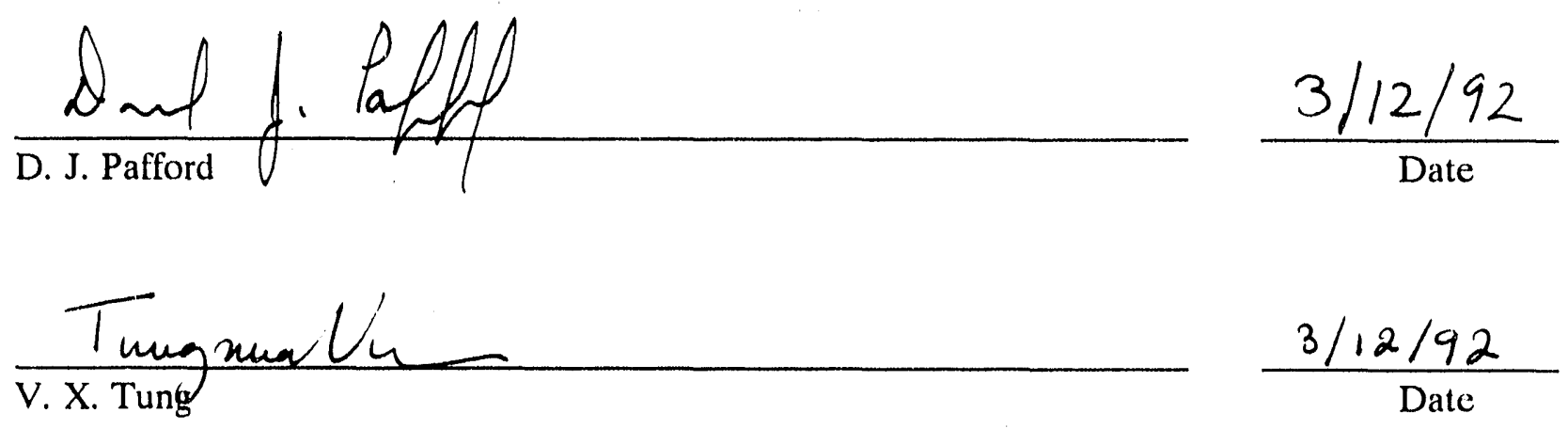

Approved by:

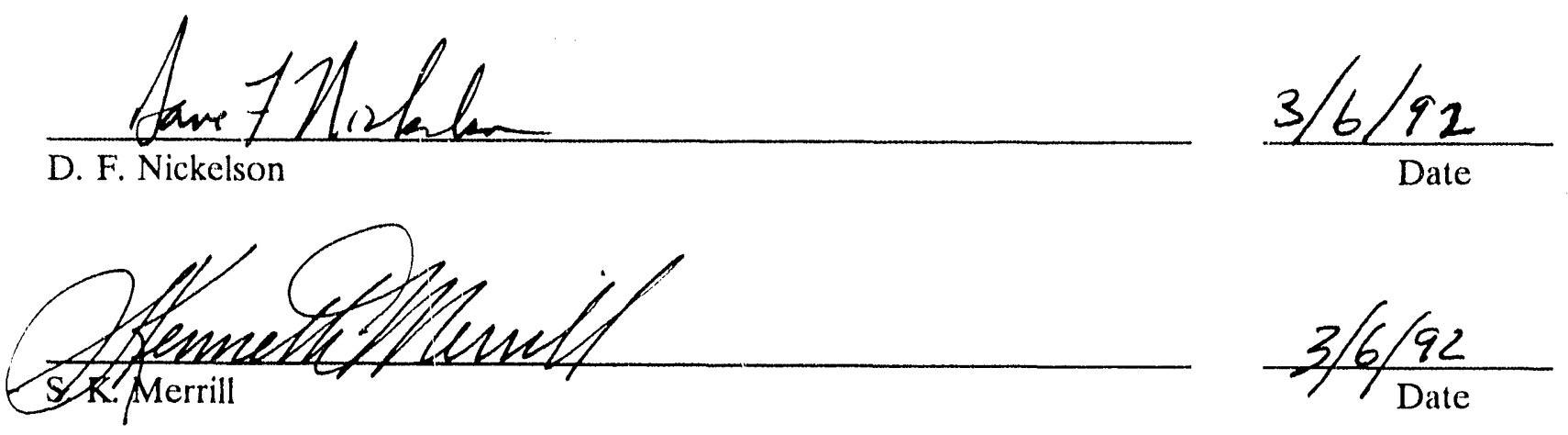




\begin{abstract}
A conceptual model for the vapor and aerosol transport and deposition in the in situ vitrification large-field test off-gas system (OGS) has been developed. This model can be used to predict the emissions from the OGS under normal and off-normal conditions. Results generated by the model can be used to evaluate design and/or procedural modifications, define tests, and predict results.

The OGS vapor and aerosol transport and deposition is modeled using the PULSE/MOD-ISV/VER 1.0.0 developmental computer code. Input data requirements for this code include the specific geometries of the OGS components; the composition, rate, and temperature of the vapors and aerosols entering the OGS; and the OGS component surface temperatures or heat fluxes. Currently, not all of these model inputs are available. Therefore, conceptual input parameters are developed. Using this input data, preliminary calculations with the code have been performed. These calculations include a demonstration that the code predicts convergent results, a comparison of predicted results with performance data for one of the OGS components, and a preliminary sensitivity study of the complete model.
\end{abstract}




\section{SUMMARY}

In support of the Idaho National Engineering Laboratory (INEL) Large-Field Test (LFT) in situ vitrification (ISV) program and integrated safety analysis, this report presents a conceptual model to predict emissions from the ISV off-gas system (OGS). This is accomplished by analyzing the vapor and aerosol transport and deposition in the OGS. Results generated by the model can be used to support consequence modeling of postulated accidents, evaluate design and/or procedural modifications, define tests, and predict test results.

ISV is a thermal treatment process that uses ohmic heating to melt in-place contaminated soil and buried wastes into a chemically inert glass or crystalline substance. The heating process pyrolyzes organic material and drives volatile compounds to surrounding soil and the aboveground area. The area above the melt zone is covered with a confinement hood. The evolved gases collect above the melt zone within the confinement of the hood, where it is mixed with fresh air inlet to the hood. The hot, evolved, combustible gases mix with the inlet air and autoignite within the hood. The OGS processing fans sweep the balance of the evolved gases, the products of combustion, and suspended aerosols from the hood to the OGS. The OGS is engineered to cool, scrub, and filter the smoke, fumes, airborne particulate matter, and gases produced by the vitrification process. This is required to produce a decontamination factor consistent with applicable environmental discharge requirements.

The conceptual design of the INEL's LFT ISV OGS is based on the basic design concepts previously demonstrated by Pacific Northwest Laboratory's (PNL) large-scale system. The OGS consists of four processing trains similar to PNL's design. Each of the processing trains will consist of the following components:

- Gas cooler

- Wet scrubber system

- Quencher

- Tandem nozzle scrubber

- $\quad$ First mist eliminator

- Condenser

- Second mist eliminator

- Reheater

- High efficiency particulate air (HEPA) filters

- Blower

- Exhaust stack

- Piping to interconnect the components.

The OGS vapor and aerosol transport and deposition is modeled using the PULSE/MOD-ISV/VER 1.0.0 developmental computer code. This code is a modified version of the TRAPMELT/PULSE code. Modifications of the TRAPMELT/PULSE code were necessary to adequately model the species, component geometries, and phenomena encountered in the ISV OGS.

The PULSE/MOD-ISV code models transient vapor and acrosol transport and deposition through circular and rectangular channels. The complex flow through the OGS is modeled by 
defining a number of discreet channels in series. The thermal boundary conditions for the channel surfaces can be specified as a time dependent surface temperature or heat flux.

Mass transport is modeled for up to 20 condensible species homogeneously mixed in a noncondensible gas packet. Each species in the packet is described by five different states-vapor, aerosol, condensate, chemisorbed mass, and deposited aerosol. Of these five states, only vapor and aerosol are considered mobile and they are assumed to travel at the speed of the gas packet. Several mechanisms couple these different states. Vapor-to-wall condensation couples the vapor in the packet with the surface condensate. Similarly, chemisorbtion couples vapor with the mass chemisorbed by the wall surface. Condensation/evaporation and nucleation couple the vapor mass with the aerosol masses. Agglomeration provides a coupling between the various aerosol sizes. Aerosol deposition couples the suspended aerosol masses and the deposited aerosol mass. In addition to these coupling mechanisms, PULSE/MOD-ISV also utilizes heat transfer correlations to calculate the bulk gas temperature.

Input data requirements for the PULSE/MOD-ISV code include the specific geometries of the OGS components; the composition, rate, and temperature of the vapors and aerosols entering the OGS; and the OGS component surface temperatures or heat fluxes. Currently, not all of these model inputs are available. Therefore, conceptual input parameters were developed as part of this project.

Using the conceptual input data, preliminary analyses of the ISV OGS relcase model using the PULSE/MOD-ISV/VER 1.0.0 computer code were performed. These analyses included a convergence test for the hood component, a comparison of code predictions with performance data for the mist eliminator component, and a preliminary sensitivity study of the overall OGS model to the inlet aerosol size.

Convergence of the hood model results were examined in two ways. First, a series of three calculations were made in which the code's differential equation solver iteration tolerances were systematically reduced from $10^{-3}$ to $10^{-4}$ to $10^{-6}$. Second, another series of calculations were made in which the number of subsegments in the hood was increased from 5 to 10 to 20 . In the first test, as the tolerance values were decreased, the precision of the results increased. Likewise, in the second test, the precision of the results increased as the spatial segmenting was increased.

The second analysis used the PULSE/MOD-ISV/VER 1.0.0 computer code to predict the efficiency of the Munters TS-5/4 mist eliminator with published performance data. The performance data provided included the limit drop size and the fractional efficiency. The limit drop size is the smallest drop which is completely removed at a specified flow velocity. Droplets smaller than the limit drop size are not completely removed. The fractional efficiency specifies the mass fraction removed for droplets smaller than the limit drop size. The predicted results compare quite well with the performance data.

The final analysis examined the sensitivity of the complete OGS model to the inlet aerosol diameter. The results of this study include the decontamination fraction (DF) for the overall ISV OGS and the release fraction (RF) for the overall ISV OGS. The DF is defined as the ratio of the total mass removed to the total mass input. The RF is defined as the ratio of the total mass released 
to the total mass input. For water, the total mass inlet to the OGS included the vapor entering the hood and the water sprey injected in the quencher and scrubber components.

Three separate calculations were made with the aerosols entering the hood as $0.2,2.0$, and $9.3 \mu \mathrm{m}$ in diameter. All of the calculations were steady state; the inlet flow conditions and thermal boundary conditions were specified as constant in time. The off-gas temperature at the entrance to the hood was specified as $854^{\circ} \mathrm{C}\left(1569^{\circ} \mathrm{F}\right)$. The condensible species considered were $\mathrm{Be}, \mathrm{Hg}, \mathrm{CsOH}$, $\mathrm{KCl}, \mathrm{KOH}, \mathrm{NaCl}, \mathrm{NaOH}, \mathrm{Pb}, \mathrm{PuO}_{2}, \mathrm{UO}_{2}$, and $\mathrm{H}_{2} \mathrm{O}$ and the noncondensible species considered were $\mathrm{CO}_{2}, \mathrm{~N}_{2}$, and $\mathrm{O}_{2}$. To simplify the presentation, the results for the eleven condensible species considered were binned into six groups. This grouping was based upon the equilibrium vapor concentration (EVC) characteristics of the species. The six groups in order of increasing EVC are:

\begin{tabular}{ll} 
Group & \multicolumn{1}{c}{ Species } \\
\cline { 2 - 2 } 1. & $\mathrm{Be}, \mathrm{UO}_{2}$, and $\mathrm{PuO}_{2}$ \\
2. & $\mathrm{KCl}, \mathrm{NaCl}$, and $\mathrm{Pb}$ \\
3. & $\mathrm{KOH}$ and $\mathrm{NaOH}$ \\
4. & $\mathrm{CsOH}$ \\
5. & $\mathrm{Hg}$ \\
6. & $\mathrm{H}_{2} \mathrm{O}$.
\end{tabular}

The calculated ISV OGS overall DF and RF as a function of the inlet aerosol size and species groups are presented in Figure S-1 and Figure S-2, respectively. The results indicate that the OGS overall DF and RF are a function of the species properties and the inlet aerosol diameter. The dominant species property observed to affect the OGS DF and RF was the EVC.

For species group one, the DF is essentially 1.0 for all three inlet aerosol diameters. The RF for this group is very small and decreases as the inlet aerosol size increases. These species have very low EVCs at the OGS operating temperatures.

For species groups two, three, four, and five, a different trend is observed. The DF values for these groups are maximum for the $2.0 \mu \mathrm{m}$ inlet aerosol size. Conversely, the RF values are minimum at this inlet aerosol size. These species groups have EVCs that range from moderate to high.

Examination of the results indicate that the RF is highest for the mercury and lowest for species group one. That is, the OGS RF is lower for species with lower EVCs. Furthermore, those species with low EVCs enter the OGS as aerosols and the RF decreases witt inlet aerosol size. This trend occurs because the OGS removal is dominated by gravitational and centrifugal deposition mechanisms and the efficiency of these mechanisms increases with increasing aerosol size.

The removal of water is virtually independent of the inlet aerosol size. This result is primarily due to the water mass being dominated by the water injected into the quencher and scrubber components.

Future work on this project should include efforts to upgrade the PULSE/MOD-ISV code from developmental status, efforts to update OGS component models as revised information becomes 


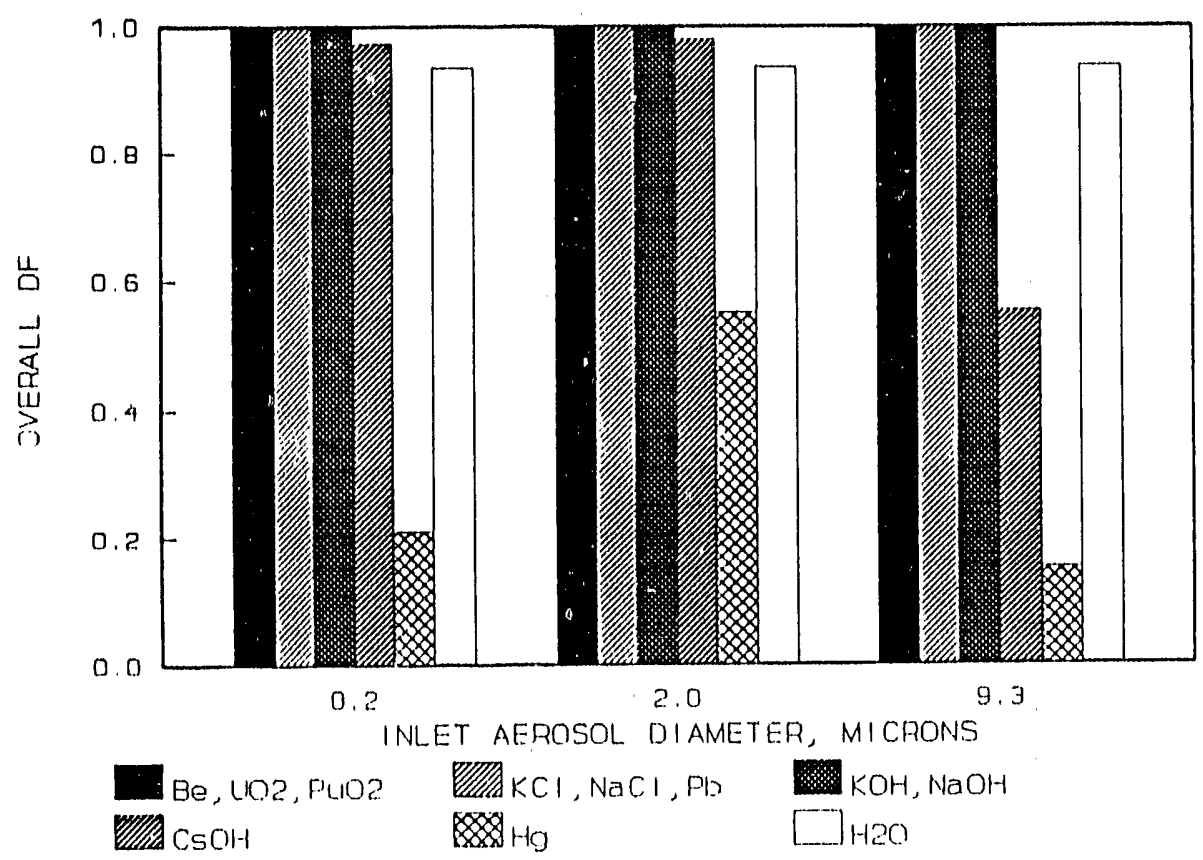

Figure S-1. ISV OGS overall decontamination fraction as a function of inlet aerosol diameter.

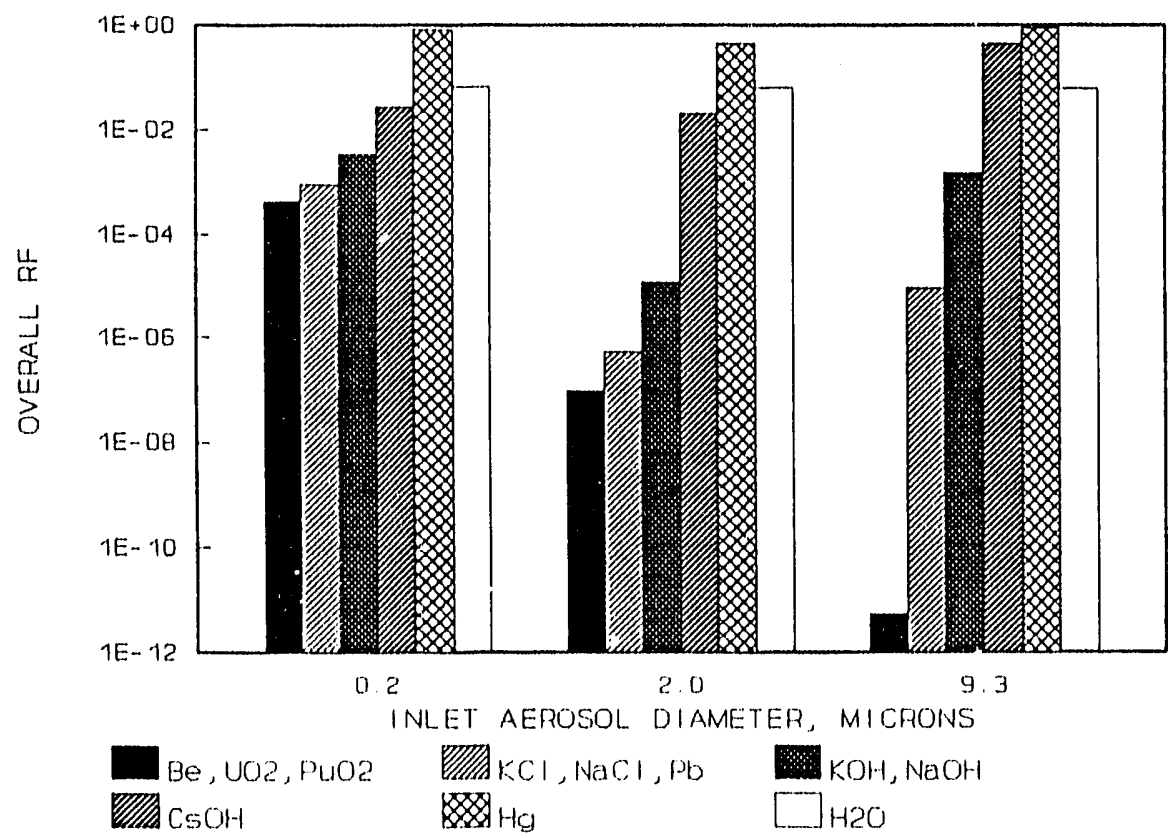

Figure S-2. ISV OGS overall release fraction as a function of inlet acrosol diameter. 
available, and additional eflorts to obtain more accurate estimates of the olligas llow conditions entering the OGS. Upgrading of the PULSE/MOD-ISV code should include a thorough verification and validation program, the development of a user's guide and code manual, and improved phenomenon models. Whether the code models need improvement should be determined by comparison of predicted results with experimental data. Proposed improvements should also be balanced with the required predictive accuracy. 


\section{ACKNOWLEDGMENTS}

We gratefully acknowledge the significant contributions made to this project by the following:

- Dave Nickelson for his support as Project Manager of the In Situ Vitrification (ISV) Project.

- Frank Purser, formerly of the Idaho National Engineering Laboratory, for his support as Technical Leader of the ISV Safety and Risk Analysis.

- Don Hagrman for his valuable assistance in and suggestions for improving the TRAPMELT/PULSE code; for his review of our code moditications; and for always making time to discuss problems.

- Dave Petıi fo: reviewing our draft report and for his many constructive suggestions.

- Rudy Bonnenberg for providing consulting and design specifications of the Off-Gas System components.

- Tom Wheeler for providing the engineering drawings of the OGS components.

- Phil West for providing the design specifications of the ISV Large-Field Test Hood.

- Dick Callow for supplying us with results of the Intermediate Field Tests at the INEL.

- Cal Slater for providing consulting and the ISV off-gas relcase rates.

- Kevin Gering and Daryl Haefner for providing insights on the OGS process.

- Dick Hobbins for his participation in the analysis reviews.

- Jim Adams for his help with the execution of the $\mathrm{F}^{*} \mathrm{~A}^{*} \mathrm{C}^{*} \mathrm{~T}$ code.

- Janalee Nelson for her assistance in document preparation.

- Marc Rumminger for his help in the property data compilation. 


\section{CONTENTS}

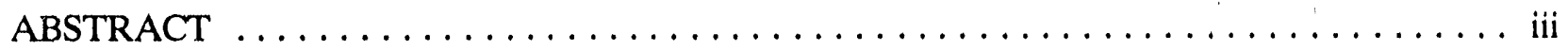

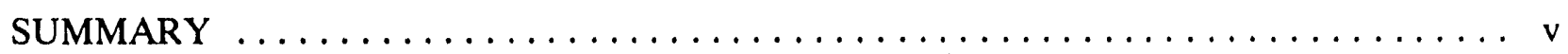

ACKNOWLEDGMENTS $\ldots \ldots \ldots \ldots \ldots \ldots \ldots \ldots \ldots \ldots \ldots \ldots \ldots \ldots \ldots \ldots \ldots$

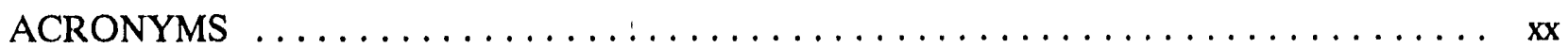

1. INTRODUCTION $\ldots \ldots \ldots \ldots \ldots \ldots \ldots \ldots \ldots \ldots \ldots \ldots \ldots \ldots \ldots \ldots \ldots$

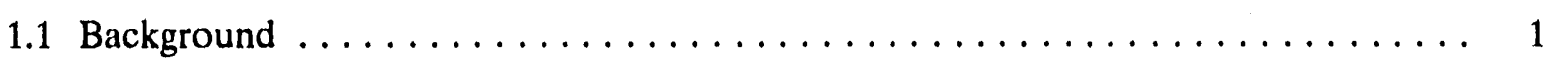

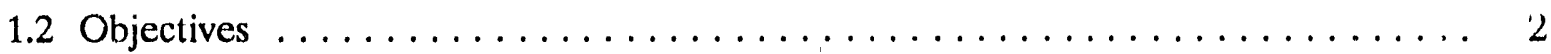

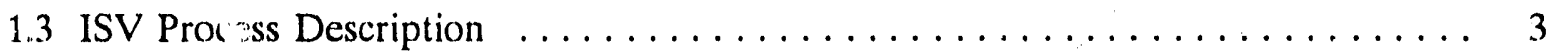

1.4 Large Field Test Off-Gas Treatment System $\ldots \ldots \ldots \ldots \ldots \ldots \ldots \ldots$

1.4.1 Component Design Descriptions $\ldots \ldots \ldots \ldots \ldots \ldots \ldots \ldots \ldots$

2. PULSE/MOD-ISV/VER 1.0 .0 COMPUTER CODE $\ldots \ldots \ldots \ldots \ldots \ldots \ldots \ldots \ldots$

2.1 Code Description $\ldots \ldots \ldots \ldots \ldots \ldots \ldots \ldots \ldots \ldots \ldots \ldots \ldots \ldots \ldots$

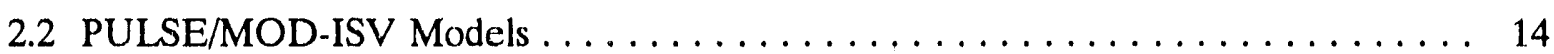

2.2.1 Vapor To Wall Condensation/Evaporation . . . . . . . . . . . . 17

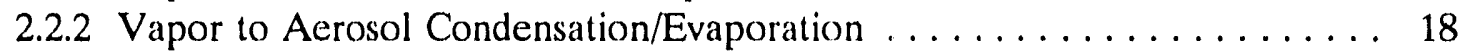

2.2.3 Aerosol Size Change Due to Condensation/Evaporation . . . . . . . . . . . . 19

2.2 .4 Aerosol Nucleation . . . . . . . . . . . . . . . . . . . . . . . . . . . . . . 19

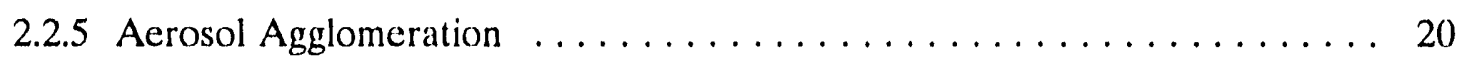

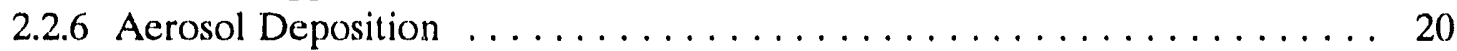

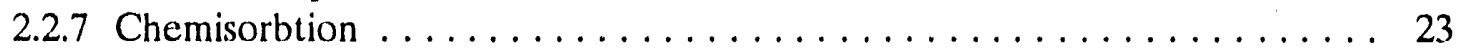

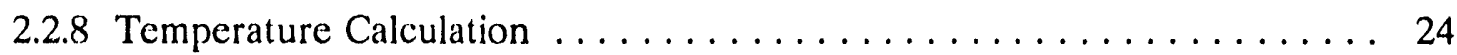

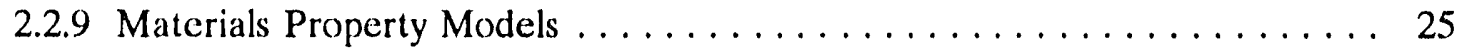

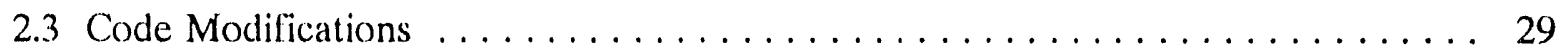

2.3.1 Rectangular Channels ... . . . . . . . . . . . . . . . . . . . . 29

2.3.2 Turbulent Nusselt Number . . . . . . . . . . . . . . . . . . . 30

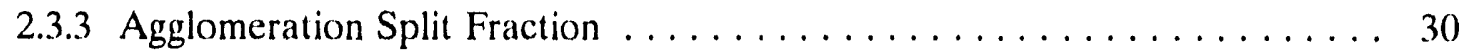

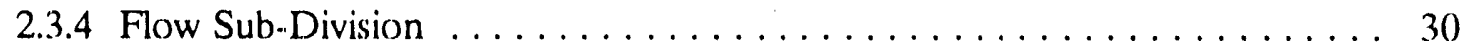

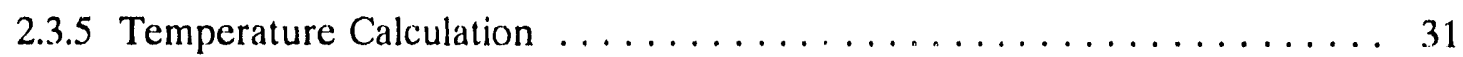




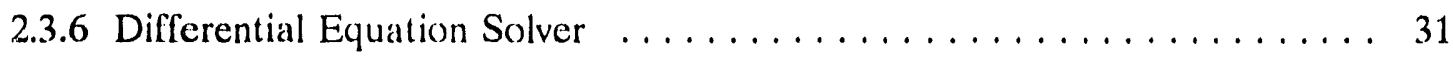

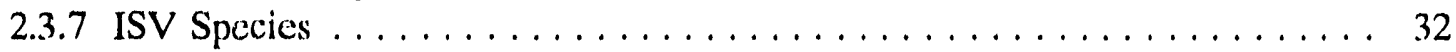

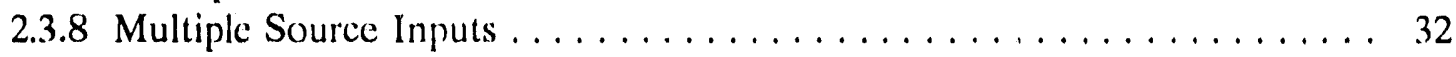

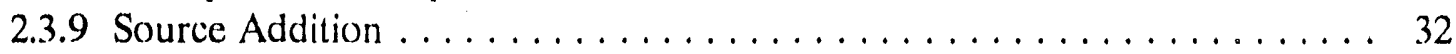

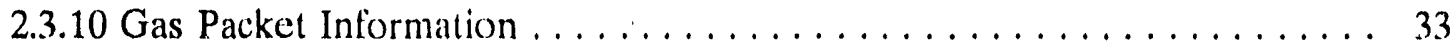

2.3.11 Maximum Number of Segments and Subsegments $\ldots \ldots \ldots \ldots \ldots \ldots 33$

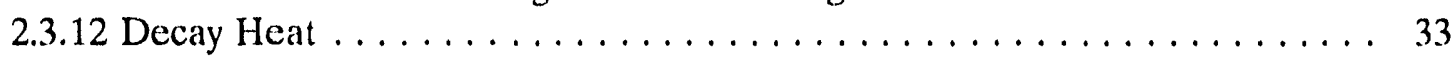

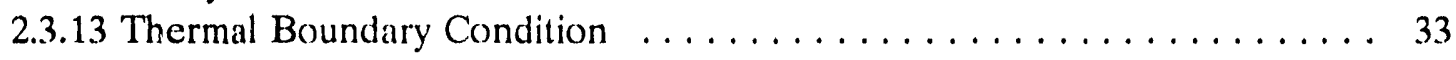

2.3.14 Restart Capability ............................ 33

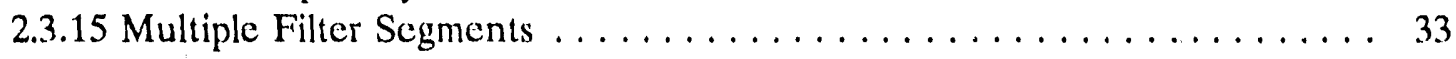

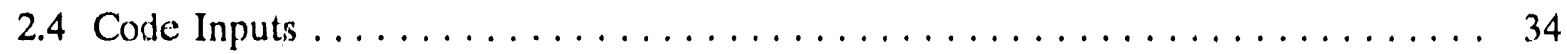

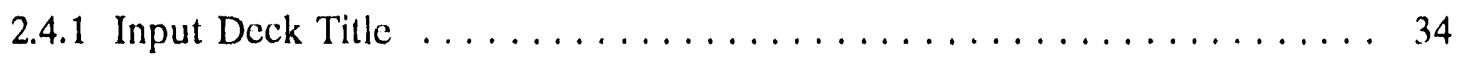

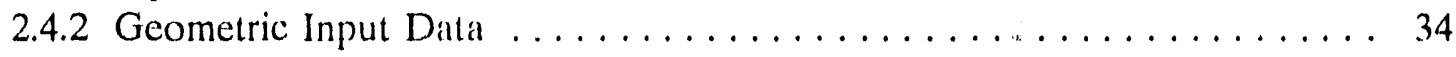

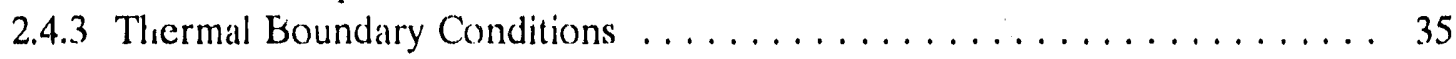

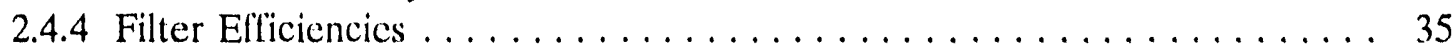

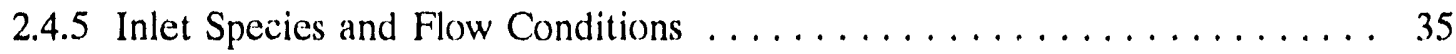

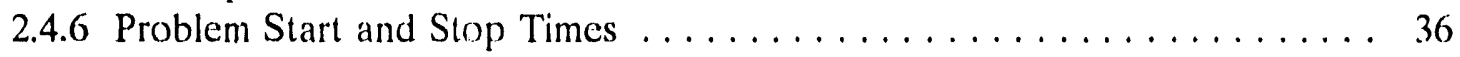

2.4.7 Convergence Tolerances and Parameter Value Limits . . . . . . . . 36

2.4 .8 Output Switches . . . . . . . . . . . . . . . . . . . 37

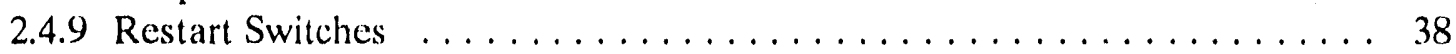

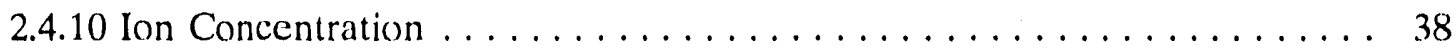

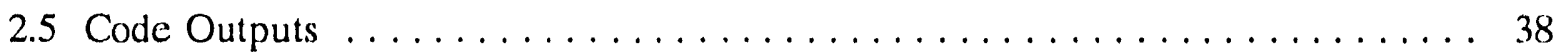

3. OFF-GAS SYSTEM MODELS $\ldots \ldots \ldots \ldots \ldots \ldots \ldots \ldots \ldots \ldots \ldots \ldots \ldots$. . $\ldots \ldots$

3.1 Component Models $\ldots \ldots \ldots \ldots \ldots \ldots \ldots \ldots \ldots \ldots \ldots \ldots \ldots \ldots$

3.1 .1 Off-Gas Hood $\ldots \ldots \ldots \ldots \ldots \ldots \ldots \ldots \ldots \ldots \ldots \ldots \ldots \ldots$. . . . . . . . . . .

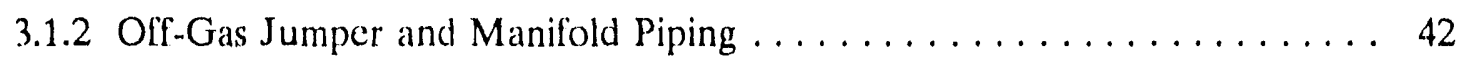

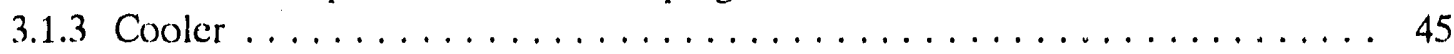

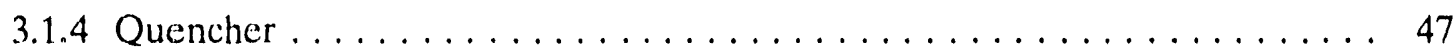

3.1 .5 Tandem Nozzle Scrubber . . . . . . . . . . . . . . . . . 49

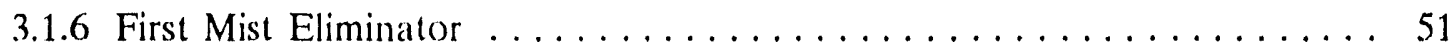

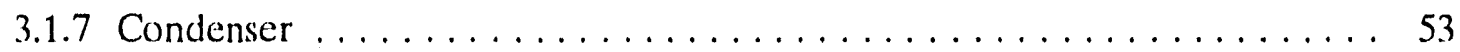

3.1 .8 Second Mist Eliminator $\ldots \ldots \ldots \ldots \ldots \ldots \ldots \ldots \ldots \ldots \ldots \ldots$

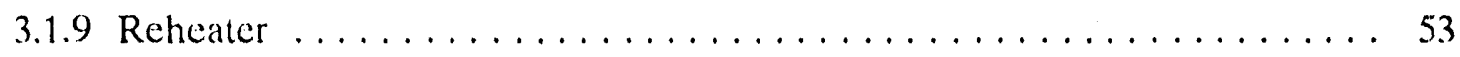

3.1.10 Piping Connecting the Reheater with the HEPA Filters $\ldots \ldots \ldots \ldots \ldots 54$

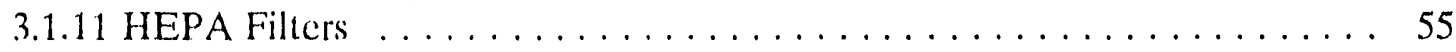

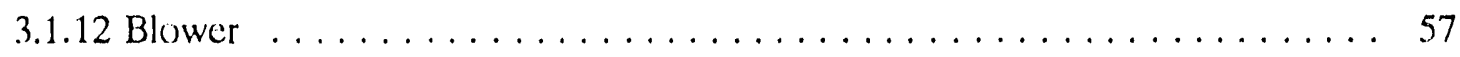

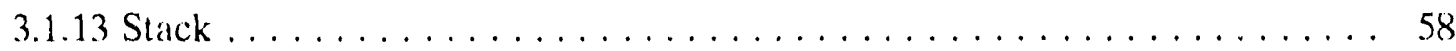

3.2 Off-Gas Inlet Flow Description $\ldots \ldots \ldots \ldots \ldots \ldots \ldots \ldots \ldots \ldots \ldots$ 


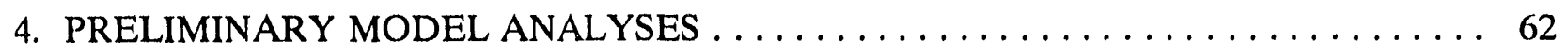

4.1 PULSE/MOD-ISV/VER 1.0 .0 Convergence Test $\ldots \ldots \ldots \ldots \ldots \ldots \ldots \ldots$

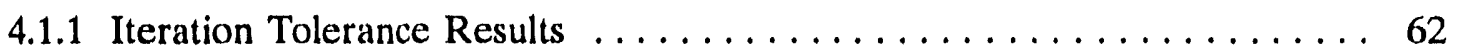

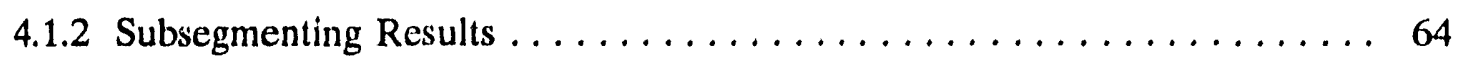

4.1 .3 Convergence Test Summary $\ldots \ldots \ldots \ldots \ldots \ldots \ldots \ldots \ldots \ldots \ldots$

4.2 Mist Eliminator Performance Comparison $\ldots \ldots \ldots \ldots \ldots \ldots \ldots \ldots \ldots \ldots \ldots \ldots \ldots$

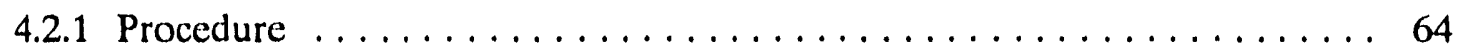

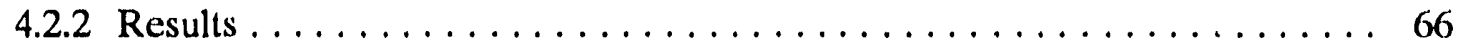

4.3 Sensitivity Study $\ldots \ldots \ldots \ldots \ldots \ldots \ldots \ldots \ldots \ldots \ldots \ldots \ldots \ldots \ldots$

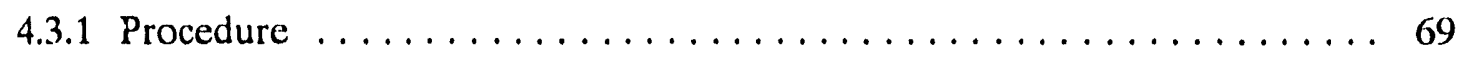

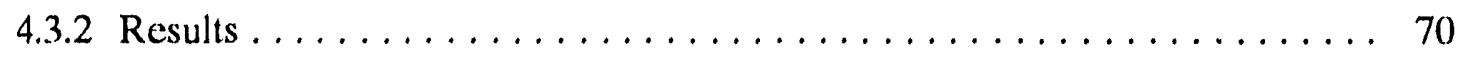

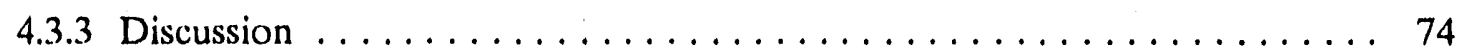

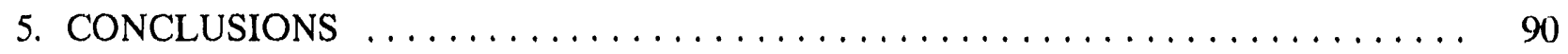

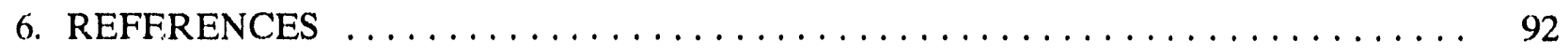

APPENDIX A - BULK GAS TEMPERATURE MODEL DERIVATION $\ldots \ldots \ldots \ldots$ A-1

APPENDIX B - PULSE/MOD-ISV MATERIAL PROPERTY MODELS $\ldots \ldots \ldots \ldots$ B-1

FIGURES

S.1. ISV OGS overall decontamination fraction as a function of inlet aerosol diameter.

S-2. ISV OGS overall release fraction as a function of inlet aerosol

diameter.

viii

1. Electrode insertion during the ISV process. $\ldots \ldots \ldots \ldots \ldots \ldots \ldots \ldots \ldots$

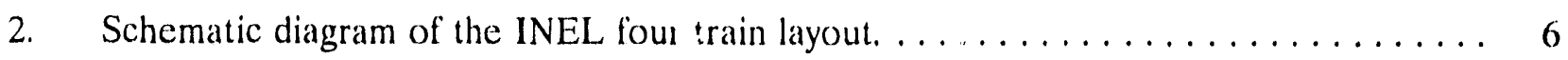

3. Schematic diagram of the INEL. ISV process trailer equipment and

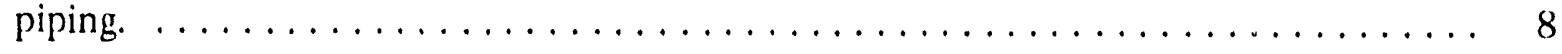

4. Schematic diagram of the INEL ISV support traile $\ldots \ldots \ldots \ldots \ldots \ldots \ldots$

5. Off-gas system main flow path. $\ldots \ldots \ldots \ldots \ldots \ldots \ldots \ldots \ldots \ldots \ldots \ldots \ldots$ 
6. The five states and mass transport modes that connect them in the PULSE computer code.

7. Equilibrium concentrations versus temperature for the eighteen condensible species modeled in the PULSE/MOD-ISV/VER 1.0.0 code.

8. Comparison of the Petukhov and Dittus-Boclter correlations predictions of the turbulent convective transfer Nusselt number.

9. Limit drop size versus inlet velocity for the Munters TS-5/4 horizontal flow mist eliminator.

10. Fractional efficiency versus droplet sizes, as expressed as a percentage of the limit drop size for the Munters TS $-5 / 4$

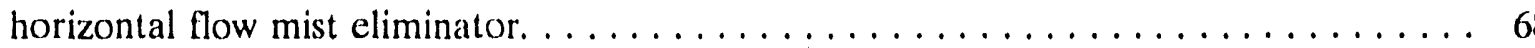

11. ISV OGS overall decontamination fraction as a function of inlet

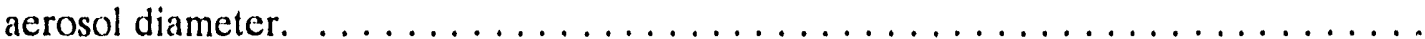

12. ISV OGS overall release fraction as a function of inlet aerosol diameter.

13. Mass fraction removed within each OGS component for an inlet acrosol diameter of $0.2 \mu \mathrm{m}$.

14. Mass weighted average aerosol diameters at the ISV OGS component exits for an inlet aerosol diameter of $0.2 \mu \mathrm{m}$.

15. Off-gas temperature at the ISV OGS component exits for an inlet aerosol diameter of $0.2 \mu \mathrm{m}$.

16. Mass fraction removed within each OGS component for an inlet aerosol diameter of $2.0 \mu \mathrm{m}$.

17. Mass weighted average aerosol diameters at the ISV OGS component

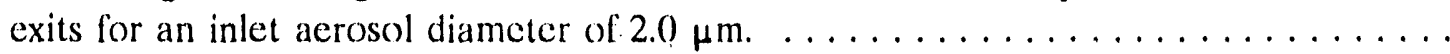

18. Olf-gas temperature at the ISV OGS component exits for an inlet aerosol diameter of $2.0 \mu \mathrm{m}$.

19. Mass fraction removed within each OGS component for an inlet aerosol diameter of $9.3 \mu \mathrm{m}$. 
20. Mass weighted average aerosol diameters at the ISV OGS component

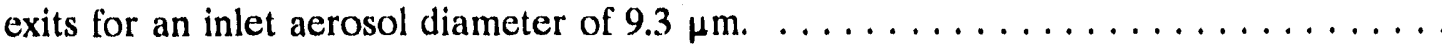

21. Off-gas temperature at the ISV OGS component exits for an inlet aerosol diameter of $9.3 \mu \mathrm{m}$.

\section{TABLES}

1. Models included in the PULSE/MOD-ISV/VER 1.0 .0 computer code. $\ldots \ldots \ldots \ldots$

2. Condensible and non-condensible species modeled in the

PULSE/MOD-ISV VER 1.0 .0 code. . . . . . . . . . . . . . . . . . . 26

3. Calculated off-gas jumper pipe surface temperatures. $\ldots \ldots \ldots \ldots \ldots \ldots \ldots \ldots \ldots$

4. Calculated gas cooler fin plate surface temperatures. $\ldots \ldots \ldots \ldots \ldots \ldots \ldots \ldots$

5. Conceptual mass flow rates of off-gas compounds entering the

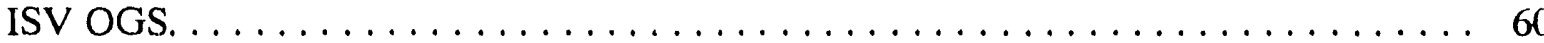

6. Inlet vapor and aerosol mass fractions for an inlet temperature

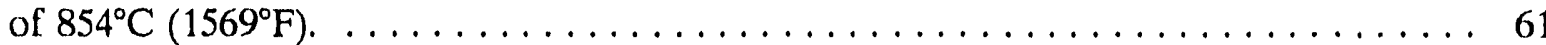

7. Mass of vapor and aerosol at the hood exit and the mass removed

in the hood as a function of the iteration tolerance.

8. Mass of vapor and aerosol at the hood exit and the mass removed

in the hood as a function of the number of hood subsegments.

9. Summary of calculated velocities and mass balance statements for specified limit

drop sizes. . . . . . . . . . . . . . . . . . . . . . . . . . .

10. Calculated mass balances for droplet sizes smaller than the limit

drop diameter of $12.1 \mu \mathrm{m}$ at a gas velocity of $4.22 \mathrm{~m} / \mathrm{s}$.

11. Predicted OGS exit mass flow rates, decontamination fractions, and release fractions for an inlet aerosol diameter of $0.2 \mu \mathrm{m}$.

12. Predicted OGS exit mass flow rates, decontamination fractions, and release fractions

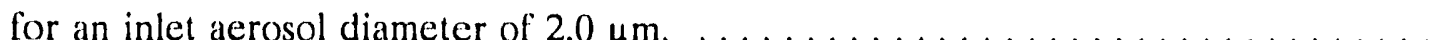

13. Predicted OGS exit mass flow rates, decontamination fractions, and release fractions for an inlet aerosol diameter of $9.3 \mu \mathrm{m}$. 


\section{ACRONYMS}

CERCLA Comprehensive Environmental Response, Compensation, and Liability Act

DF decontamination fraction

DOE U.S. Department of Energy

EPA Environmental Protection Agency

EVC equilibrium vapor concentration

HEPA high efficiency particulate air (filter)

INEL Idaho National Engineering Laboratory

ISV in situ vitrification

LFT Large-Field Test

OGS off-gas system

PNL Pacific Northwest Laboratory

RF release fraction

RFP Rocky Flats Plant

RI/FS remedial investigation/feasibility study

RWMC Radioactive Waste Management Complex

SDA Subsurface Disposal Area

TRU transuranic 


\section{Release Model for In Situ Vitrification Large-Field Test Off-Gas Treatment System}

\section{INTRODUCTION}

This report describes a conceptual model for the vapor and aerosol transport and deposition in the in situ vitrification (ISV) large-field test (LFT) off-gas system (OGS). The release model was developed in support of the LFT ISV program and integrated safety analysis. It can be used to predict OGS process emissions under normal operating conditions and for postulated accidents.

\subsection{Background}

The U.S. Department of Energy (DOE) has identified the need to remediate waste disposed between 1954 and 1970 at the Subsurface Disposal Area (SDA) of the Radioactive Waste Management Complex (RWMC) at the Idaho National Engineering Laboratory (INEL). Various contaminants and radionuclides have been detected in sedimentary interbeds and perched groundwater beneath the SDA, indicating migration away from the disposal area. ${ }^{1}$ In November 1989, as a result of these discoveries and other waste disposal activities, the INEL was placed on the U.S. Environmental Protection Agency (EPA) National Priority List under the Comprehensive Environmental Response, Compensation, and Liability Act (CERCLA). This listing has led to the need for the remedial investigation/feasibility study (RI/FS) currently being conducted at the SDA.

As part of the RI/FS, the Waste Technology Development Department of EG\&G Idaho, Inc., is conducting a treatability investigation of ISV as a remedial technology for use at the SDA. ${ }^{2}$ In situ vitrification technology was developed by Battelle, Pacific Northwest Laboratory (PNL) for the remediation of soils contaminated with transuranic (TRU) material. The process uses electric resistance heating to melt the contaminants and the surrounding soil in place. Once the melt product has solidified, the radioactive contamination is fixed into an environmentally stable glass and crystalline waste form. During the heating process the area above the melt surface is covered by a confinement hood. Evolved gases and suspended aerosols collect above the melt zone within the confinement of the hood where it is mixed with fresh air inlet to the hood. OGS processing fans then sweep the balance of the gases and aerosols from the hood to the OGS where the effluent is treated prior to discharge to the atmosphere. Successful testing by PNL has proven the general feasibility and applicability of the process for contaminated soils.

The suitability of ISV for the SDA is being assessed by a comprehensive testing and analytical program. This program has the primary mission of conducting a treatability study, which will collect data and evaluate ISV in accordance with CERCLA. The study involves a progressive series of laboratory, engineering, and field-scale tests, and related analytical studies of specific applications of ISV for remediation of buried wastes (mixed and transuranic) and the health and safety concerns.

One of the most important tools developed in the program will be a set of computer models that approximate the important physical phenomena occuring during the ISV process, both below and 
aboveground. These models will provide a capability to predict process emissions for postulated accidents and to evaluate response and mitigating action procedures. They will be used in the treatability investigation to determine the safety and risks associated with implementation of the ISV process and the suitability of ISV for treatment of various waste forms and combinations at the SDA and other INEL sites.

As part of the experimental program, the INEL has begun a LFT ISV program which will implement a large-scale, experimental ISV system. This system will be based on the basic design concepts currently demonstrated by PNL's large-scale system. Test data from experiments using the LFT ISV system will be incorporated into mathematical models.

LFT activities to date have included development of test data requirements, test siting criteria, safety and risk assessments, environmental permitting requirements, and conceptual design of the test equipment. ${ }^{3}$ In addition, requirements are being developed for the field test sites at the SDA. Several SDA test sites will be identified, including areas of contaminated soil, randomly disposed Rocky Flats Plant (RFP) drums, stacked RFP drums, intermixed INEL and RFP wastes, and special case waste sites. A site in Pit 9 of the SDA containing randomly disposed RFP drums was identified and a preliminary waste inventory developed. Conceptual modeling has been completed for the off-gas generation and release from the melt during ISV operation at this site. Sample combustion calculations have been proposed for the volatile compounds evolving from the melt.

\subsection{Objectives}

In support of the LFT ISV program and integrated safety analysis, this repert presents a conceptual model to predict OGS process emissions. This is accomplished by analyzing the vapor and aerosol transport and deposition in the LFT ISV OGS. Results generated by the model can be used to support consequence modeling of postulated accidents, evaluate design and/or procedural modifications, define tests, and predict test results.

The transient vapor and acrosol transport and deposition is modeled using the PULSE/MOD-ISV/VER 1.0.0 developmental computer code. This code is a modified version of the TRAPMELT/PULSE code. ${ }^{4}$ Modifications of the TRAPMELT/PULSE code were necessary to adequately model the species, component geometries, and phenomena encountered in the ISV OGS.

Input data requirements for the PULSE/MOD-ISV code include the specific geometries of the OGS components; the composition, rate, and temperature of the vapors and aerosols entering the OGS; and the OGS component surface temperatures or heat fluxes. Currently, not all of these model inputs are available. Therefore, conceptual input parameters were developed. Using this input data, preliminary code calculations were performed. These calculations include a demonstration that the code predicts convergent results, a comparison of code predictions with performance data for one of the OGS components, and a preliminary sensitivity study of the complete OGS model to the inlet aerosol size. It should be noted that these calculations are preliminary. The results were obtained with a developmental code, which has not been verified or validated, using conceptual input data and parameters. 
This report is organized as follows. Section 1 provides background information of the ISV process, presents the objectives of this project, and describes the LFT ISV OGS. Section 2 presents a description of the PULSE/MOD-ISV/VER 1.0.0 computer code, including the code structure, models used in the code, modifications made to the code, code input requirements, and outputs. Section 3 describes the conceptual OGS component models used as input to the PULSE/MOD-ISV/VER 1.0.0 code. The component models consist of descriptions of the component geometries and thermal boundary conditions. Also presented are the off-gas flow conditions at the entrance to the OGS. Section 4 presents the results of preliminary code calculations. Section 5 gives conclusions and describes areas for future work.

\subsection{ISV Process Description}

ISV is a thermal treatment process that melts contaminated soil and wastes into a chenically inert glass or crystalline substance. ${ }^{5}$ Electric current, conducted through electrodes to the soil, melts the contents of a buried waste pit in place. The heating process pyrolyzes organic material and drives volatile compounds to the surrounding soil and aboveground area. The area above the melt zone is covered with a confinement hood. The evolved gases collect above the melt zone, within the confinement of the hood, where it is mixed with fresh air inlet to the hood. The hot, cvolved combustible gases mix with the inlet air and autoignite within the combustion area of the hood. The OGS processing fans sweep the balance of the evolved gases, the products of combustion, and suspended aerosols from the hood to the OGS where the eftluent is cleaned, cooled, and treated prior to discharge to the atmosphere.

The process is initiated by a square array of four graphite electrodes inserted a few inches into the ground, as shown in Figure 1. Because dry soil is not electrically conductive, a mixture of flaked graphite and glass frit is placed among the electrodes to serve as a starter path. An electrical potential is applied to the electrodes to establish an electrical current in the starter path. The applied power heats, via joule (resistance) heating, the starter path and surrounding soil to approximately $2000^{\circ} \mathrm{C}$, well above the typical soil fusion temperatures of 1100 to $1400^{\circ} \mathrm{C}$. Upon melting, typical soils become sufficiently electrically conductive and become the primary conductor and heat transfer medium, allowing the process to continue beyond startup. The graphite in the starter path is eventually consumed by oxidation.

Continued application of electrical energy causes the molten volume to grow downw.ard and outward, encompassing the desired treatment volume. The melt in a large-scale test may grow to encompass a total melt mass of up to 1000 tons and a maximum width of about $9.2 \mathrm{~m} \mathrm{(30} \mathrm{fi).}$

The molten mass is typically in the 1600 to $20000^{\circ} \mathrm{C}$ temperature range; specilic temperatures are dependent on the overall chemistry of the melt. Within the melt, a vigorous, chemically-reducing environment occurs. Because unmelted soil typically has low thermal conductivity, a very steep thermal gradient (e.g., 60 to $100{ }^{\circ} \mathrm{C} / \mathrm{cm}$ ) precedes the advancing melt surface. Typically, the 100$)^{\circ} \mathrm{C}$ isotherm is less than $1 \mathrm{ft}$ away from the melt front during ISV processing and the average rate of melt is 1 to 2 in. per hour (see Reference 5). 


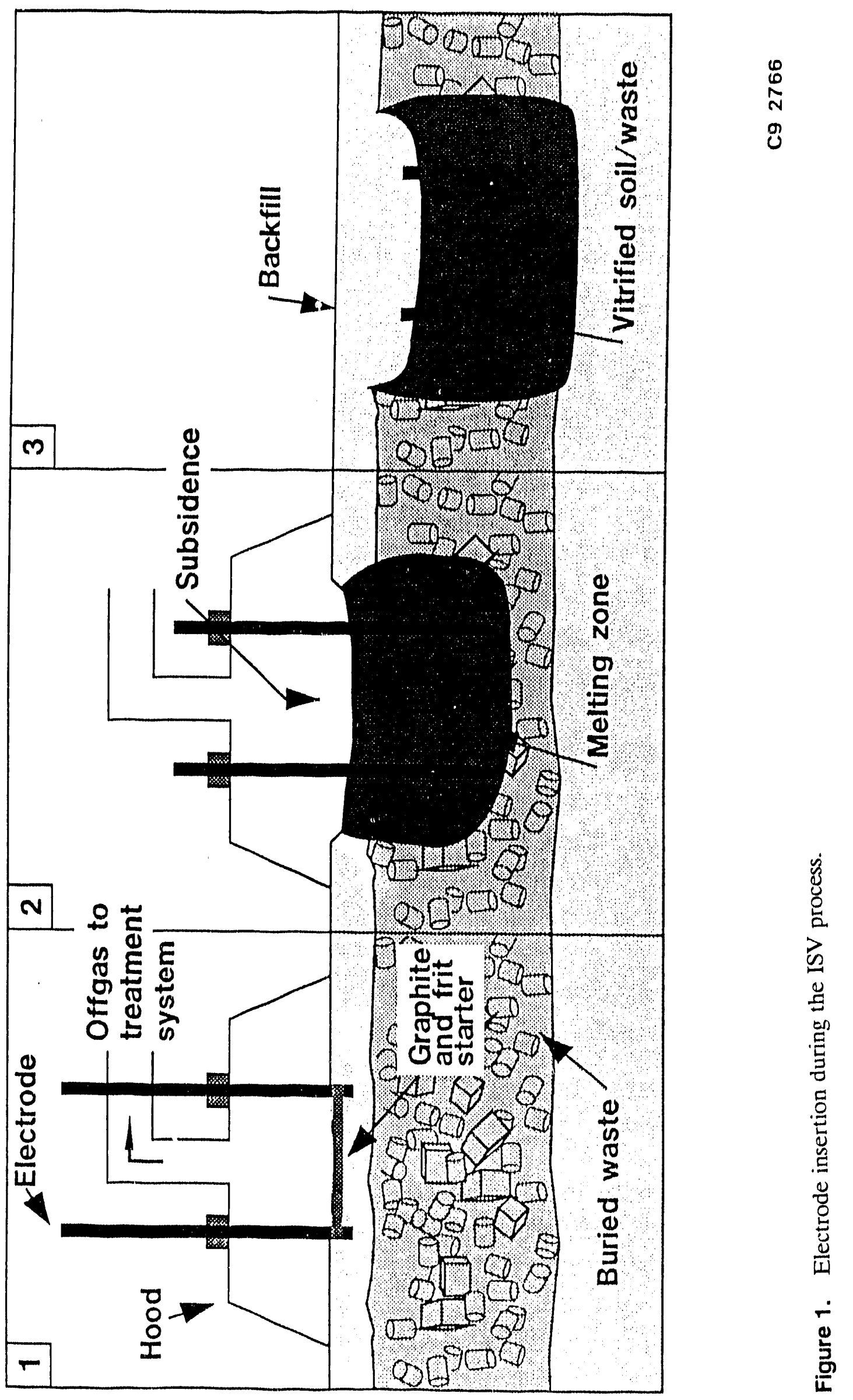


As the thermal gradient advances, solid or liquid organic materials pyrolyze (i.e., decompose in the absence of oxygen) into elemental components. For example, organic pyrolysis products are typically gaseous; these gases move slowly through and around the melt to the upper melt surlace. Some of these gases may dissolve into the molten mass; the remainder move to the surface and those that are combustible, autoignite in the presence of air. Pyrolysis and combustion products are collected in the hood and are subsequently treated to ensure process emissions meet regulatory requirements. Because of the high temperature of the melt, a negligible amount of organic contamination remains in its original compound form within the vitrilied product.

The behavior of inorganic materials, upon exposure to the advancing thermal gradient, is similar to that of the organic materials. Inorganic compounds may thermally decompose, cnter into reactions within the melt, or dissolve within the melt. For example, nitrates and sulfates yield gascous decomposition products (e.g., $\mathrm{NO}_{x}, \mathrm{~N}_{2}, \mathrm{SO}_{2}, \mathrm{O}_{2}$ ) that may dissolve into the melt or may evolve to the melt surface and be collected in the off-gas collection hood. Typically, the positively charged elements of the inorganic compounds are incorporated, in oxide form, into the vitrified residual.

Volatile heavy metals, such as mercury, will vaporize and evolve to the melt surface to be collected in the off-gas collection hood. Most of the transition metals and radionuclides are incorporated into the molten mass and are immobilized within the mass as it cools. However, some particulate matter will be carried by the evolved gases to the melt surface.

\subsection{Large-Field Test Off-Gas Treatment System}

The conceptual design of the INEL's LFT ISV OGS has been developed and is based on the basic design concepts previously demonstrated by PNL's large-scale system. ${ }^{\text {a }}$ The OGS operates in conjunction with the confinement hood to remove the evolved gases and products of combustion from the combustion area within the hood. Fresh air is drafted into the combustion area of the hood to provide safe, efficient, and controlled combustion. A slight vacuum, relative to the immediate surroundings, is maintained within the hood by the OGS exhaust flow. This vacuum also ensures inward leakage for contamination control.

The conceptual LFT ISV OGS consists of four processing trains similar to PNL's design. Each of these trains has a nominal capacity approximately half that of PNL's large-scale system. A schematic of the four train layout is shown in Figure 2. Each of the processing trains will consist of the following components:

- Gas cooler

- Wet scrubber system

- Quencher

- Tandem nozzle scrubber

- First mist eliminator

a. In Situ Vitrification Large Field Test Off-Gas System Preliminary System Design Description, attachment to letter KVB-(66-91, from Ken V. Beard, EG\&G Idaho, Inc., Idaho Falls, Idaho, June 27, 1991. 


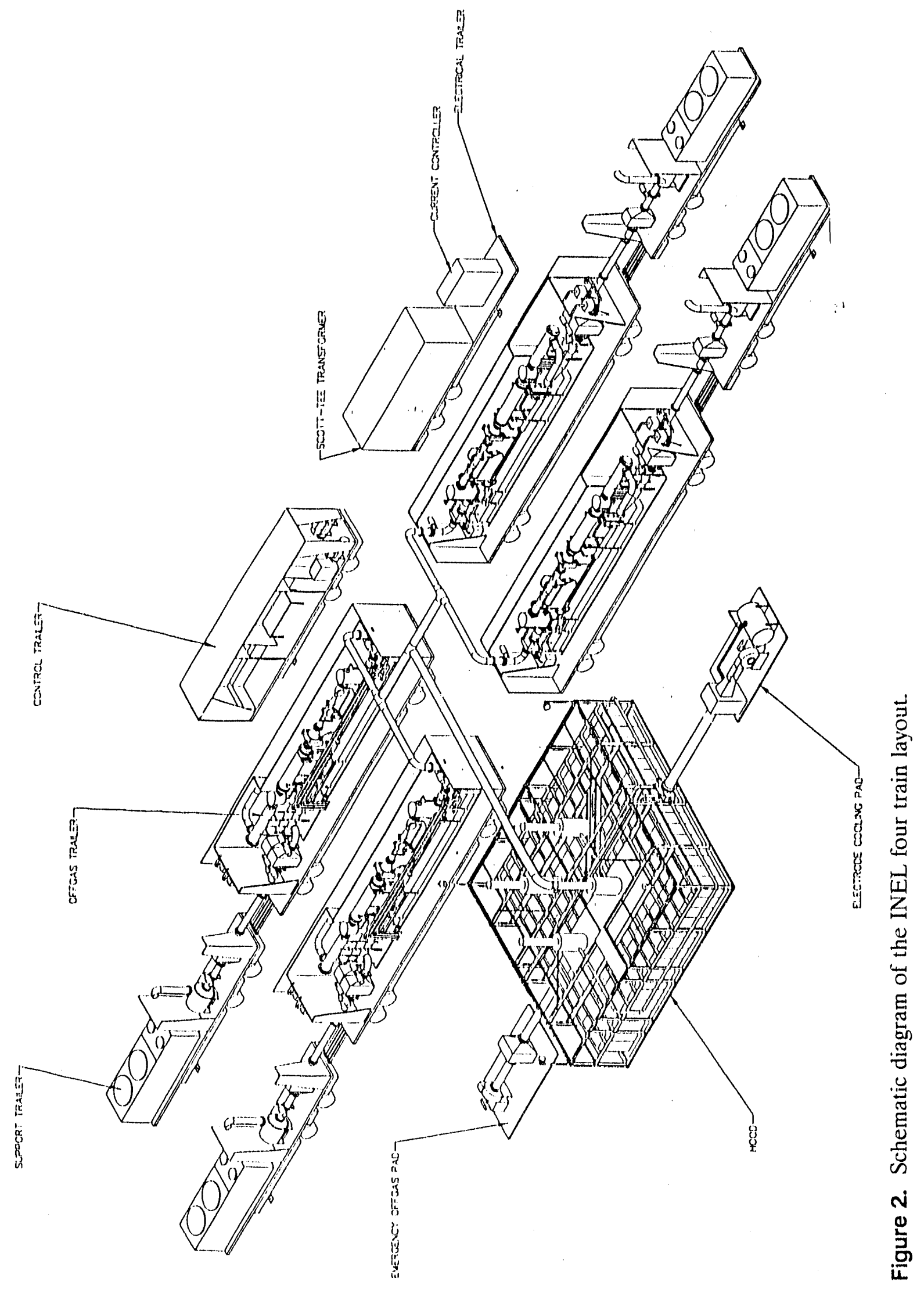




\begin{tabular}{l} 
- Condenser \\
- $\quad$ Recond mist eliminator \\
- $\quad$ High efficiency particulate air (HEPA) filters \\
- $\quad$ Elower \\
- $\quad$ Piphaust stack \\
\hline to interconnect the components.
\end{tabular}

The OGSs and support equipment are housed in trailers at the melt site. A schematic diagram of the ISV OGS process trailer equipment and piping is shown in Figure 3 and the support trailer is shown in Figure 4. Figure 5 illustrates the OGS components along each main flow path. A qualitative description of the OGS process follows.

Upon evolving from the melt, heat is removed from the off-gas via mixing with ambient air inlet to the hood and by heat losses to the cooler ambient surroundings. The off-gas exits the hood and passes through an off-gas jumper piping used to connect the four off-gas trains to the hood. The gas cooler follows and removes additional heat from the off-gas as it passes over cooling coils. Following the cooler, the off-gas enters the wet scrubbing system. This consists of a quencher, tandem nozzle venturi scrubber, and a mist eliminator. As the off-gas passes through the quencher, cool scrubbing water is injected into the off-gas. The injected water spray cools the gas and removes some of the suspended off-gas aerosols. The off-gas exits the quencher near saturation and enters the two stage nozzle scrubber. The first stage condenses vapors, removes larger acrosols, and initiates agglomeration of the smaller aerosols into larger ones so that they are more easily agglomerated in the second stage. The aerosols collide and agglomerate when mixed with the fine water droplets produced by spraying water into the subsonic nozzle. Mixing and agglomeration continue down the length of the mixing tube. The larger aerosols and water droplets are then removed by the mist eliminator and drained back into the scrub tank. The condenser follows and is a tube and shell heat exchanger that cools the off-gas. Condensed vapor will then be removed by the second mist eliminator. The off-gas is then heated above the dew point by the reheater to remove any remaining condensate. The final components of the off-gas system consist of a two-stage HEPA filter arrangement and an induced draft blower. The HEPA filters provide the final filtering of the off-gas. The induced draft blower draws the off-gas from the hood through the components. The blower outlet is connected to the exhaust stack through which the OGS process emissions are released to the environment.

\subsubsection{Component Design Descriptions}

The component design descriptions that follow are based upon the ISV LFT OGS preliminary design description. ${ }^{b}$

b. In Situ Vitrification Large Field Test Off-Gas System Preliminary System Design Description, Sections 1.4.3 and 2.2.3, attachment to letter KVB-06-91, from Ken V. Beard, EG\&G Idaho, Inc., Idaho Falls, Idaho, June 27, 1991. 


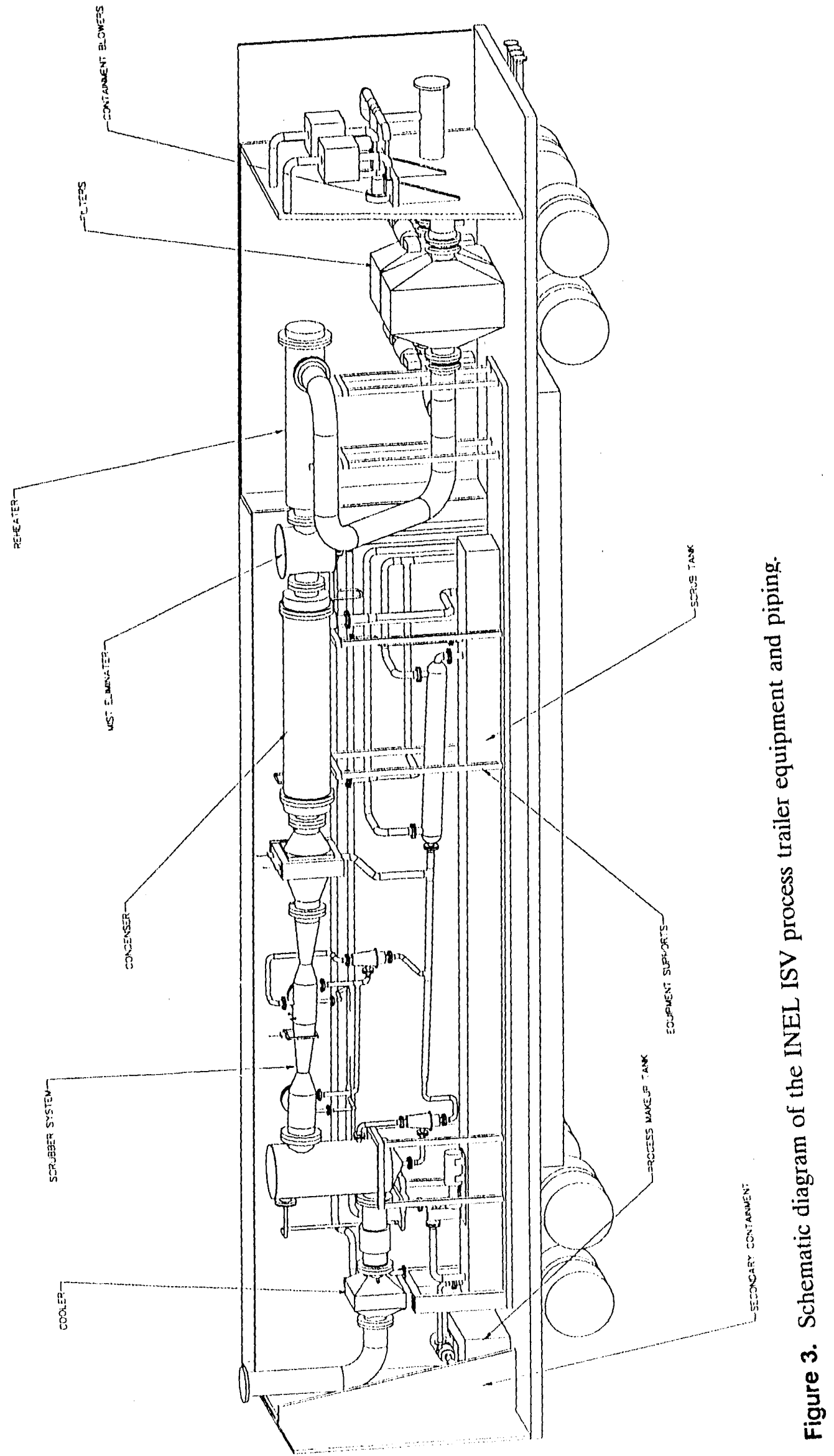




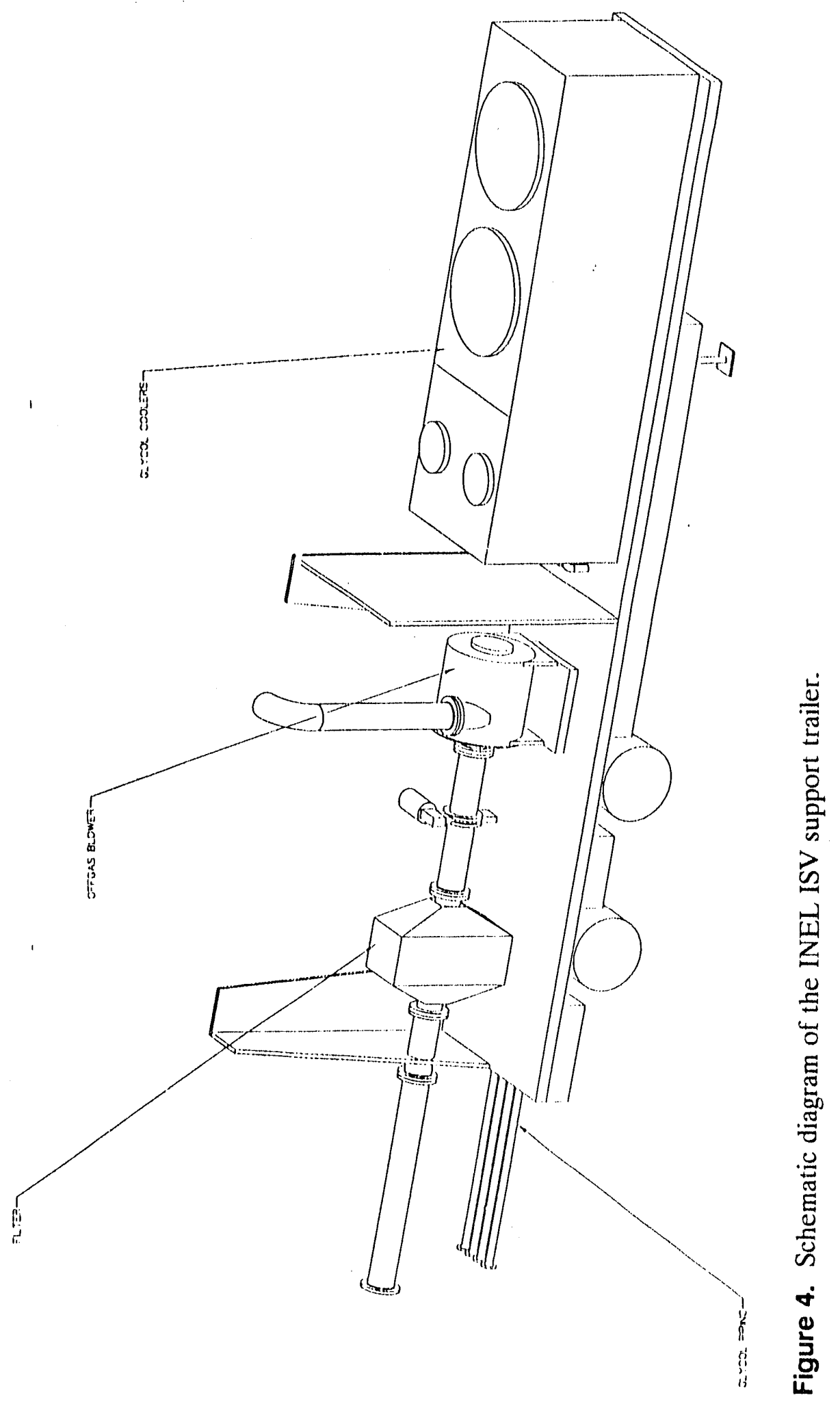




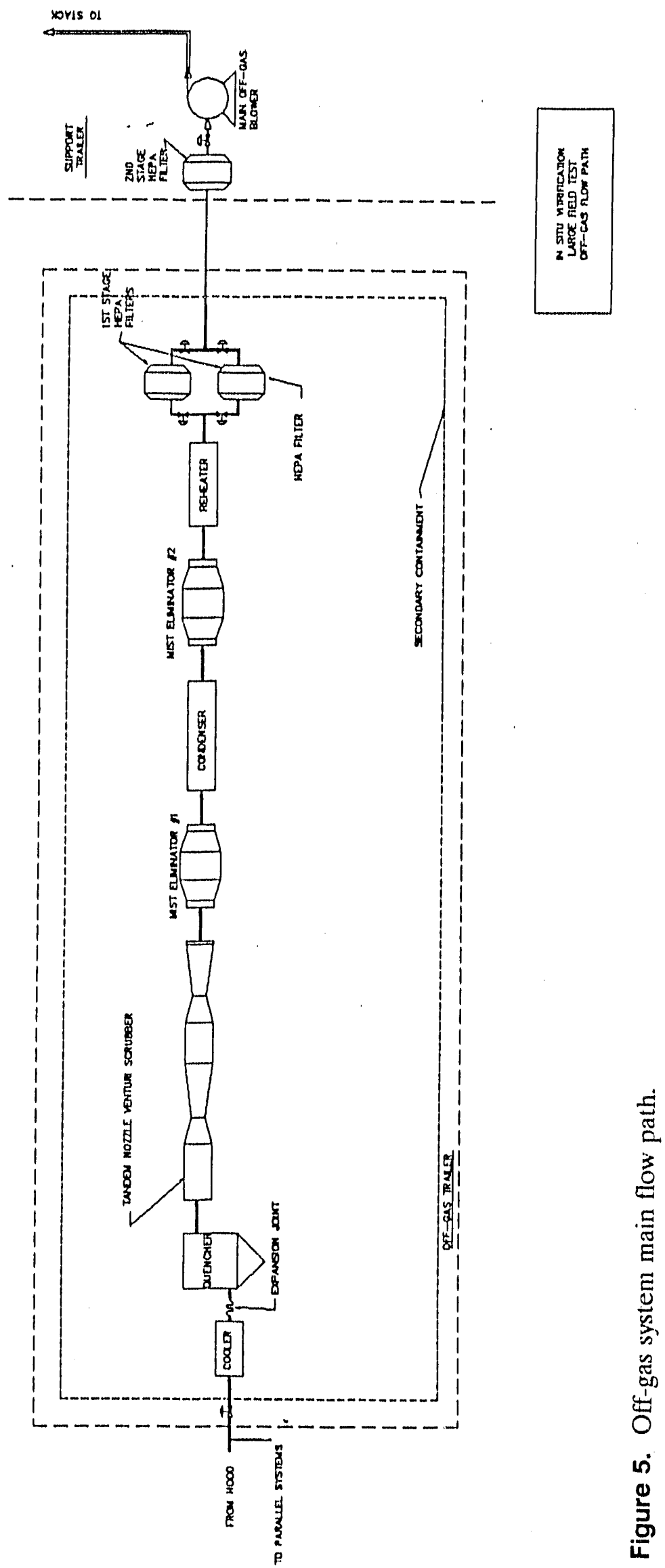


Gas Cooler. The preliminary design description specifies that the gas cooler will be a cooling coil capable of cooling the off-gas stream from 750 to $300^{\circ} \mathrm{C}\left(1,382\right.$ to $\left.572^{\circ} \mathrm{F}\right)$. The design calls for a nominal flow rate of 8385 ACFM (1520 SCFM dry air and $315 \mathrm{SCFM}$ water vapor) at $750^{\circ} \mathrm{C}$ and -5 in. w.g. at assembly inlet. The cooler will be designed for a range of flow of 1000 SCFM to 2000 SCFM (including moisture) and a particulate loading in the off-gas stream of $3,600 \mathrm{mg} / \mathrm{std} \mathrm{m}^{3}$ with a mean aerosol size of $1 \mu \mathrm{m}$. The cooler will be constructed of $3(04-\mathrm{L}$ stainless steel.

Wet Scrubber System. This system will consist of a quencher, tandem nozzle venturi scrubber, and a mist eliminator. The wet scrubber system will be designed to operate under the following conditions:

- Conditions at inlet: approximately -10 in. w.g. at 300$)^{\circ} \mathrm{C}$

- Conditions at outlet: approximately -72 in. w.g. at $60^{\circ} \mathrm{C}$

- Maximum particle loading of gas: $3,600 \mathrm{mg} / \mathrm{m}^{3}$ at a mean aerosol size of $1 \mu \mathrm{m}$

- Quencher design temperature: $750^{\circ} \mathrm{C}$

- Venturi scrubber and mist eliminator design temperature: $300^{\circ} \mathrm{C}$

- Nominal flow rate: 4,770 ACFM (1,520 SCFM dry air and 315 SCFM water vapor) at $300^{\circ} \mathrm{C}$ and -10 in. w.g. at inlet

- Range of flow: 1,000 to 2,000 SCFM (including moisture of $17 \%$ by volume).

Quencher-The quencher is designed to provide additional cooling and limited decontamination of the off-gas stream. It is essentially a vertical cylinder. The off gas stream enters at the bottom of the cylinder and exits at the top. Cooling of the gas is achieved by direct contact with a spray of scrubbing water entering near the top of the chamber. Excess water is collected in a drain at the bottom of the cylinder. No off-gas cleaning requirements are specified.

Tandem Nozele Scrubber-The tandem nozzle scrubber consists of two almost identical nozzle scrubber systems in series. Each system consists of a subsonic nozzle located inside a chamber, followed by a straight section of pipe. Scrubbing water is injected into the nozzle chamber through a ring around the nozzle exit. The off-gas enters the nozzle chamber through the subsonic nozzle, which serves to increase the off-gas velocity. The increased velocity at the tip of the nozzle serves to break the injected water into a fine mist. This water aerosol, along with the aerosol present in the off-gas, then enters the straight mixing tube. In this mixing tube, the large number of water aerosols collide and agglomerate with the aerosols in the off-gas, yielding larger acrosols. Some of these aerosols are removed by gravity and turbulent deposition within the nozzle scrubber system. Others remain suspended in the off-gas flow. The design specifications require that the nozzle scrubber system remove more than $90 \%$ of aerosols over $0.5 \mu \mathrm{m}$ at nominal flow.

Mist Eliminator-A mist eliminator follows the second nozzle scrubber. The mist eliminator is an impingement separator. It is composed of many corrugated profile plates, mounted 
on a frame, and enclosed in a housing structure. Each profile plate has a number of phase separating chambers, which consist of a 90 -degree bend and a liquid film trap attached to the convex side of the bend.

The impingement separation works as follows. The profiles split the gas flow into several parallel channels. The corrugated profiles turn the gas streams, but heavier aerosols cannot turn as quickly as the lighter gas molecules. Therefore, inertia forces the aerosols against the wall where they form a liquid film. This film is pushed along until it reaches the traps where the film is drained by gravity in this area of low gas velocity.

In general, the separation efficiency depends upon the size and concentration of the aerosols to be removed and on the velocity and density of the gas. The design specifications require that the mist eliminator remove $100 \%$ of the aerosols over $12 \mu \mathrm{m}$ in diameter at the nominal flow and $100 \%$ of aerosols over $20 \mu \mathrm{m}$ at minimum flow.

Condenser. The condenser shall cool the off-gas stream and condense additional vapor in the off-gas stream. Depending upon the vapor present and the flow conditions, it is expected that the vapor will condense on the condenser surfaces and on any aerosols remaining in the off-gas stream. Some vapor may also nucleate and form small aerosols in the condenser.

The design specifications require a tube and shell single-pass, countercurrent condenser with off-gas flow on the tube side and the cooling liquid on the shell side. The maximum inlet and outlet temperatures of the off-gas are 60 and $52^{\circ} \mathrm{C}\left(140\right.$ and $\left.126^{\circ} \mathrm{F}\right)$, respectively.

Mist Eliminator. A second mist eliminator follows the condenser to remove additional acrosols from the off-gas. The design specifications for this mist eliminator are identical to those of the previous one.

Reheater. The reheater heats the off-gas to evaporate any droplets remaining so as to prevent condensate from entering the HEPA filters that follow. The heater will be able to provide a controlled temperature rise of 7 to $\left.32^{\circ} \mathrm{C}(45 \text { to } 9)^{\circ} \mathrm{F}\right)$. The minimum and maximum inlet temperatures are 0 and $52^{\circ} \mathrm{C}\left(32\right.$ and $\left.126^{\circ} \mathrm{F}\right)$, respectively.

HEPA Filters. HEPA filters provide the final filtering of the off-gas stream. Three HEPA filters and housings will be provided in two stages. The first stage will consist of two filters connected in parallel. The second stage will consist of one filter connected in series with the first stage and will be located in the support trailer.

During operation, one filter of the first stage is used and the other remains as a backup in case the other becomes loaded. The first stage filter can be changed out during operation, without process shutdown. The second stage filter acts as a backup particulate filter in case a first stage filter fails. The design specifications require that each filter be $99.97 \%$ efficient for aerosols $0.3 \mu \mathrm{m}$ and larger.

Blower. The off-gas will be drawn through the components in the off-gas system by an induced draft blower. The design specifications require an operating inlet vacuum of 0 to $100 \mathrm{in}$. W.g. The range of flow will be 28 to $56.6 \mathrm{SCMM}(1,000$ to 2,000 SCFM), including moisture. The inlet header 
of the blower will be equipped with a llow control valve, which can be used to adjust the flow rate through the OGS.

Stack. The exhaust stack is connected to the blower outlet and will extend approximately two meters (six feet) above the top of the support trailer.

Currently, the LFT ISV OGS is still in the conceptual stage and an actual system has not been constructed. The OGS model developed here is therefore conceptual and is based upon a combination of information sources, including the LFT OGS design specifications, geometric descriptions of the PNL large-scale OGS, and assumptions. 


\section{PULSE/MOD-ISV/VER 1.0.0 COMPUTER CODE}

This section presents an overview of the PULSE/MOD-ISV/VER 1.0.0 computer code. The PULSE/MOD-ISV code is a modilied version of the TRAPMELT/PULSE code (see Reference 4.) The TRAPMELT/PULSE code has been modified to model the species, component geometries, and phenomena encountered in the in situ vitrification (ISV) off-gas system (OGS). The TRAPMELT/PULSE code was originally developed for investigating the Power Burst Facility Severe Fuel Damage experiments, ${ }^{6}$ but has been extended for numerous more recent applications.

The structure of this section closely follows that of Reference 4. Section 2.1 presents an overview of the PULSE/MOD-ISV code. Section 2.2 provides a summary of the models used in the code. Section 2.3 describes the modifications made to the TRAPMELT/PULSE code. Section 2.4 describes the code input requirements and Section 2.5 summarizes the output information available from PULSE/MOD-ISV/VER 1.0.0.

\subsection{Code Description}

The PULSE/MOD-ISV/VER 1.0.0 computer code models transient vapor and aerosol transport and deposition through circular and rectangular channels. A complex flow system can be modeled by defining a number of discreet channels in series. The thermal boundary conditions of the channel surfaces can be specified as a function of time. The acrosol deposition and transport equations are formulated using a Lagrangian approach. That is, the calculation follows packets of effluent through the channels rather than attempting 10 work with the more generally used Eulerian approach based on control volumes and junctions. This approach was used because it is efficient for tubes with high length to diameter ratios. Like TRAP-MELT2, ${ }^{7}$ the code that inspired TRAPMELT/PULSE's development, the PULSE/MOD-ISV code considers the five states illustrated in Figure 6. Two of these states, the vapor and aerosol, are mobile. The other three states, condensed on surface, chemisorbed on surface, and aerosols deposited on surfaces, are fixed. Mass transport is modeled for up to 20 condensible species among the various states. The various models are listed in Table 1.

PULSE/MOD-ISV VER 1.0.0 is written in standard FORTRAN 77. All calculations are carried out in double precision. The code has been compiled and run successfully on several platforms including the DEC 2100 and DEC 5000 workstations and a 386-based IBM PS/2 model 70 . On the IBM PS/2, the code was compiled with the LAHEY 32 bit FORTRAN 77 compiler. ${ }^{8}$ The code requires about 2 megabytes of memory.

\subsection{PULSE/MOD-ISV Models}

PULSE/MOD-ISV treats the problem of vapor and aerosol transport from the perspective of a reference frame moving along with a non-condensible gas packet. The flow is divided into a number of gas packets dependent upon the specified problem time. As each packet travels downstream it encounters the different components of the system. PULSE/MOD-ISV models the flow through these components by dividing them into a number of channel segments in series. Each segment has its own geometry such as wall area, cross section, and length and its own thermal boundary condition such as wall temperature or heat flux. Furthermore, to refine the results, each 


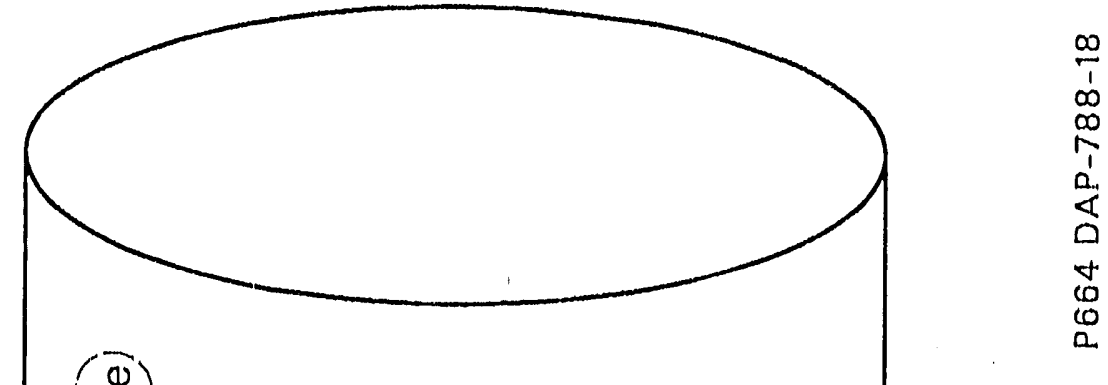

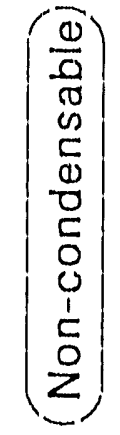

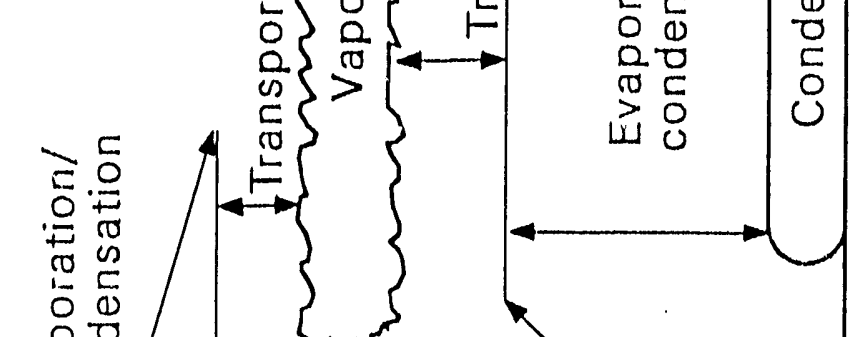

폴

$\frac{3}{0}$

형

亗

믐

\&

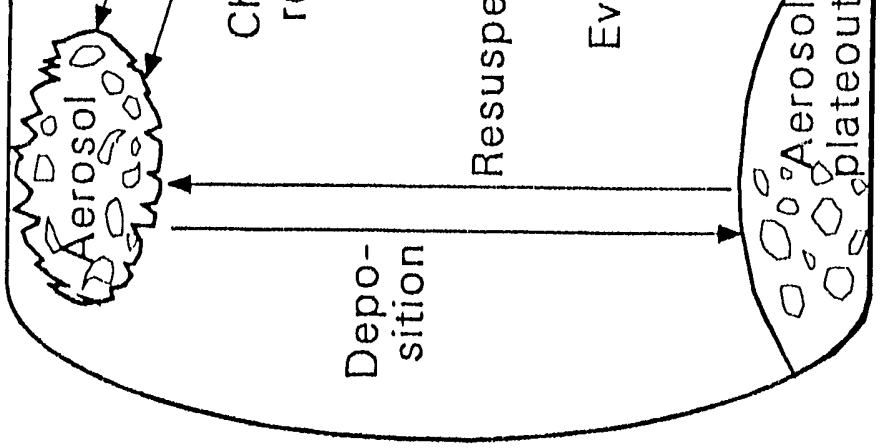

这

E

占 
Table 1. Models included in the PULSE/MOD-ISV/VER 1.0 .0 computer code.

$$
\text { Model }
$$

Relerence

Evaporation/condensation to walls

Bircl, Stewart, and Lightfoot ${ }^{9}$

Evaporation/condensation to aerosols

Bird, Stcwart, and Lightfoot ${ }^{9}$

Aerosol size change due to

evaporation/condensation of vapors

Hagrman ${ }^{4}$

Aerosol nucleation

Petti $i^{11}$

Aerosol agglomeration

Brownian motion

Jordan and Kuhlman, ${ }^{7}$ Hinds ${ }^{12}$

Differential gravitational settling

Saffmann and Turner ${ }^{13}$

Jordan and Kuhlman, ${ }^{7}$

Turbulence

Delichasios and Probstein ${ }^{14}$

Jordan and Kuhlman, ${ }^{7}$

Acrosol deposition

Diffusion from laminar llow

Gormley and Kennedy ${ }^{15}$

Diffusion from turbulent flow

Wood ${ }^{16}$

Gravitational settling

Hinds ${ }^{12}$ and Fuchs ${ }^{17}$

Centrifugal forces

Hagrman $^{4}$

Thermophoresis

Brock $^{18}$

Vapor to surface chemisorbtion

Hagrman $^{4}$

Gas bulk temperature

Hagrman $^{4}$

Materials properties

MATPRO $^{20}$ 
channel segment can be subdivided into smaller subsegments. The defined subsegments share the same boundary condition and geometry ol the parent segment.

Each condensible species in the gas packet is described by five different states - vapor, aerosol, condensate, chemisorbed mass, and deposited aerosol. Of these five states, only vapor and acrosol are considered mobile and are assumed to travel at the speed of the gas packet. Several mechanisms couple these different states. Vapor-to-wall condensation couples the vapor in the packet with the surface condensate. Similarly, chemisorbtion couples vapor with the mass chemisorbed by the wall surface. Condensation/evaporation and nucleation couple the vapor mass with the acrosol masses. Agglomeration provides a coupling between the various acrosol sizes. Acrosol deposition couples the suspended aerosol masses and the deposited acrosol mass. In addition to these coupling mechanisms, PULSE/MOD.ISV also uses heat transfer correlations to calculate the bulk gas temperature. The models used to represent these coupling mechanisms are discussed in the TRAPMELT/PULSE users' manual (see Reference 4). A brief' summary of the main features of the models is presented in this section.

\subsubsection{Vapor To Wall Condensation/Evaporation} as: ${ }^{9}$

The rate of condensation on the wall from the vapor present in the gas packet is calculated

$$
\frac{d m_{c}}{d t}=A k_{m}\left(C-C_{e w}\right)
$$

where

$$
\begin{aligned}
& \mathrm{m}_{\mathrm{c}}=\text { mass condensed on wall surface }(\mathrm{kg}) \\
& \mathrm{A}=\text { surface area of the packet }\left(\mathrm{m}^{2}\right) \\
& \mathrm{k}_{\mathrm{m}}=\text { mass transfer cocfficient }(\mathrm{m} / \mathrm{s}) \\
& \mathrm{C}=\text { species vapor concentration in packet }\left(\mathrm{kg} / \mathrm{m}^{3}\right) \\
& \mathrm{C}_{\mathrm{ew}}=\text { equilibrium concentration at wall temperature }\left(\mathrm{kg} / \mathrm{m}^{3}\right)
\end{aligned}
$$

Note that the above equation is valid for both evaporation and condensation, depending on whether the rate is negative or positive. Furthermore, this rate of condensation must be accompanied by a rate of change for the vapor mass given by

$$
\frac{d m_{v}}{d t}=-A k_{t m}\left(C-C_{e w}\right)
$$

where

$$
m_{v}=\text { mass in vapor phase }(\mathrm{kg}) \text {. }
$$

The mass transfer coefficient $k_{\mathrm{m}}$ in Equations (1) and (2) is calculated in PULSE/MOD-ISV by 
$k_{m}=N u_{m} D_{m} / D_{n}$

where
$\mathrm{Nu}_{\mathrm{m}}=$ mass transfor Nussclt number
$D_{m}=$ mass diffusivity of the species
$D_{h}=$ hydraulic diameter of the channel.

The wall surface mass transfer Nusselt number is given by ${ }^{10}$

$N u_{m}=\left[\begin{array}{cl}3.66 & \begin{array}{c}\text { laminar, circular pipe } \\ 7.54\end{array} \\ \frac{\operatorname{Re~Sc~} c_{\mathrm{f}} / 2}{1+12.7\left(\mathrm{Sc}^{2 / 3}-1\right) \sqrt{c_{\mathrm{f}} / 2}} & \begin{array}{l}\text { infinte aspect ratio } \\ \text { turbulent }\end{array}\end{array}\right]$

where

$\mathrm{Re}=$ Reynolds number

Sc $=$ Schmidt number

and $c_{f}$ is the friction coefficient given as

$$
\frac{c_{f}}{2}=\frac{3.86 \times 10^{-2}}{\left\{\log _{10}\left[\left(\epsilon / D_{h}\right)^{1.11}+(6.9 / R c)\right]\right\}^{2}}
$$

where

$$
\epsilon=\text { surface roughness. }
$$

Equations (4) and (5) are known as Petukhov's correlation and have been used for the turbulent Nusselt number to yield better results at higher Reynolds and Schmidt numbers and to account for the surface roughness $\epsilon$.

\subsubsection{Vapor to Aerosol Condensation/Evaporation}

Condensation f'rom vapor onto acrosols is calculated as (see Reference 9)

$$
\frac{d m_{l}}{d t}=n_{k} \cdot 4 \pi \cdot r_{k}^{2} \cdot k_{p} \cdot\left(C-C_{c g}\right)
$$


where

$$
\begin{aligned}
& n_{k}=\text { number of acrosols in bin size } k \\
& r_{k}=\text { radius of a acrosol in bin size } k(\mathrm{~m}) \\
& k_{\mathrm{p}}=\text { aerosol mass transfer coefficient }(\mathrm{m} / \mathrm{s}) \\
& \mathrm{c}_{\mathrm{eg}}=\text { equilibrium concentration at gas temperature }\left(\mathrm{kg} / \mathrm{m}^{3}\right)
\end{aligned}
$$

The aerosol mass transfer coefficient can be obtained by using a mass transfer Nusselt number of 2 for spheres yielding

$$
\mathrm{k}_{\mathrm{p}}=\frac{D_{m}}{\mathrm{r}_{\mathrm{k}}}
$$

Again, this rate of change is negative for evaporation. Furthermore, it is accompanied by an equivalent reduction in the vapor mass for condensation (and an increase for evaporation).

\subsubsection{Aerosol Size Change Due to Condensation/Evaporation}

Condensation/evaporation of vapor to or from an aerosol results in a change in the size of the aerosol. It does not, however, change the number of acrosols. After a time step, the aerosols in any particular bin size will either grow or shrink and must be shifted out of that bin. The final size, however, does not usually match another bin size exactly. PULSE/MOD-ISV handles this by splitting the aerosols between two adjacent bins such that the total number of aerosols and total mass are conserved. This split fraction is given by

$$
S_{k}=\frac{V_{k+1}-V_{f}}{V_{k+1}-V_{k}} \cdot \frac{V_{k}}{V_{f}} \quad ; \quad S_{k+1}=\frac{V_{f}-V_{k}}{V_{k+1}-V_{k}} \cdot \frac{V_{k+1}}{V_{f}}
$$

where

$$
\begin{aligned}
& \mathrm{S}_{\mathrm{k}}=\text { mass fraction into bin } \mathrm{k} \\
& \mathrm{V}_{\mathrm{k}}=\text { aerosol volume in bin } \mathrm{k} \\
& \mathrm{V}_{\mathrm{f}}=\text { final aerosol volume after condensation/evaporation. }
\end{aligned}
$$

\subsubsection{Aerosol Nucleation}

Nucleation in the presence of supersaturated vapors is incorporated in PULSE/MOD-ISV using correlations for critical supersaturation. The model is essentially that proposed by Petti ${ }^{11}$ and includes both homogeneous and heterogeneous nucleation. 


\subsubsection{Aerosol Agglomeration}

The aerosol agglomeration model in PULSE/MOD-ISV considers three mechanisms (Brownian motion, ${ }^{12}$ gravitational setlling, ${ }^{1.3}$ and turbulence ${ }^{14}$ ) that produce relative motion and, hence, collisions between acrosols of different sizes. All three effects are added together to yield the following rate of change for the number of aerosols in a bin size $k$ (see Reference 7):

$\frac{d n_{k}}{d t}=\sum_{m=1}^{k} A_{m, k} n_{m} n_{k}$

where

$n_{k}=$ number of aerosols in bin size $k$

$A_{m, k}=$ agglomeration kernel which is determined by all three mechanisms $\left(s^{-1}\right)$.

The above equation includes all collisions between bin $k$ and other bins. To simplify matters, PULSE/MOD-ISV breaks up the summation and considers one pair of collisions at a time. For each collision between bins $k$ and $m$, each bin will loose $n_{f}=A_{m, k} n_{k} n_{m}$ aerosols. However, this will produce $n_{f}$ aerosols whose individual volumes are the sum of the volumes in bins $m$ and $k$. These larger aerosols then must be split between two adjacent bins in a manner similar to that described earlier for condensation/evaporation of acrosols.

\subsubsection{Aerosol Deposition}

There are several mechanisms-laminar or turbulent diffusion, gravitational force, centrifugal force through bends, and thermophoresis-by which aerosols are deposited on the walls of the components. Each mechanism will be discussed separately in this section.

Laminar Diffusion. Laminar diffusion is modeled based upon the solution obtained by Gormley and Kennedy ${ }^{15}$ for pipes

$$
\frac{\mathrm{N}}{\mathrm{N}_{\mathrm{o}}}=\left\{\begin{array}{cc}
0.8191 \mathrm{e}^{-7.314 \mathrm{H}}+0.0975 \mathrm{e}^{-44.611}+0.0325 \mathrm{e}^{-114 H} & \mathrm{H} \geq 0.0156 \\
1-4.07 \mathrm{H}^{2 / 3}+2.4 \mathrm{H}+0.446 \mathrm{H}^{4 / 3} & \mathrm{H}<0.0156
\end{array}\right\}
$$

where

$$
\begin{aligned}
& \mathrm{N}=\text { number of aerosols exiting the pipe } \\
& \mathrm{N}_{0}=\text { number of acrosols entering the pipe }
\end{aligned}
$$

and $\mathrm{H}$ is a dimensionless parameter defined as 
$H=2 \frac{L \cdot D_{p}}{V_{g} \cdot D_{h}^{2}}$

where

$\mathrm{L}=$ channol segment length $(\mathrm{m})$

$\mathrm{D}_{\mathrm{p}}=$ particle diffusivity $\left(\mathrm{m}^{2} / \mathrm{s}\right)$

$\mathrm{V}_{\mathrm{g}}=$ velocity of the gas $(\mathrm{m} / \mathrm{s})$

$D_{h}=$ hydraulic diameter of the channel $(m)$.

Turbulent Deposition. Turbulent deposition is based on the integration of aerosol and eddy diffusivity performed by Wood. ${ }^{16}$ The turbulent deposition speed for the aerosols is described by

$$
\frac{V_{d}}{U^{*}}=\left\{\begin{array}{cc}
0.20 / 1 \mathrm{n}\left(\frac{25.2}{y^{+}-4.8}\right) & y^{+}>5 \\
\frac{1}{\left(I_{s}+24.2\right)} & y^{+} \leq 5
\end{array}\right\}
$$

where

$$
\begin{aligned}
& \mathrm{V}_{\mathrm{d}}=\text { aerosol deposition velocity }(\mathrm{m} / \mathrm{s}) \\
& \mathrm{U}^{*}=\text { friction velocity }(\mathrm{m} / \mathrm{s})
\end{aligned}
$$

and $\mathrm{y}^{+}$is defined as

$y^{+}=0.45 \frac{\epsilon U^{*}}{v}+0.15 \frac{\rho_{p}}{\rho_{\mathrm{g}}}\left(\frac{r_{k} U^{*}}{v}\right)^{2}$

where

$$
\begin{aligned}
& \rho_{\mathrm{p}}=\text { density of the aerosol particle }\left(\mathrm{kg} / \mathrm{m}^{3}\right) \\
& \rho_{\mathrm{g}}=\text { density of the gas packet }\left(\mathrm{kg} / \mathrm{m}^{3}\right) \\
& v=\text { kinematic viscosity of the gas packet }\left(\mathrm{m}^{2} / \mathrm{s}\right)
\end{aligned}
$$

and $I_{s}$ is an integral whose value is given by

$$
\begin{aligned}
& I_{s}=\frac{14.5\left[f\left(\phi_{2}\right)-f\left(\phi_{1}\right)\right]}{\left(D_{p} / v\right)^{2 / 3}} \\
& \phi_{1}=\frac{y^{+}}{14.5\left(D_{p} / v\right)^{1 / 3}} ; \quad \phi_{2}=\frac{5}{14.5\left(D_{p} / v\right)^{1 / 3}}
\end{aligned}
$$


and the function $\mathrm{f}$ is given as

$$
f(\phi)=\frac{1}{6} \ln \left[\frac{(1+\phi)^{2}}{1-\phi+\phi^{2}}\right]+\frac{1}{\sqrt{3}} \tan ^{-1}\left(\frac{2 \phi-1}{\sqrt{3}}\right) \text {. }
$$

Gravitational Settling. The settling velocity of an aerosol of bin size $\mathrm{k}$ is given by ${ }^{17}$ (see Reference 12)

$$
V_{g s}=\frac{4 \pi}{3} r_{k}^{3}\left(\rho_{p}-\rho_{g}\right) g B_{k}
$$

where

$$
\begin{aligned}
& \mathrm{V}_{\mathrm{gs}}=\text { settling velocity of the gas }(\mathrm{m} / \mathrm{s}) \\
& \mathrm{B}_{\mathrm{k}}=\text { aerosol mobility including Cunningham slip and Fuch's correction for Stokes' law } \\
& \mathrm{g}=\text { gravity }\left(\mathrm{m} / \mathrm{s}^{2}\right)
\end{aligned}
$$

Centrifugal Force. The aerosols experience centrifugal force as they travel through bends. This force tends to drive the heavier aerosols toward the outside wall where deposition occurs. PULSE/MOD-ISV models this by calculating the aerosol displacement caused by the centrifugal force and using this displacement to calculate the rate of deposition. For either circular or rectangular channels, the aerosol displacement is given as (see Reference 4)

$s=\frac{4 \pi}{3} \cdot r_{k}^{3}\left(\rho_{p}-\rho_{g}\right) B_{k} V_{g} \theta$

where

$\mathrm{s}=$ aerosol displacement distance $(\mathrm{m})$

$\theta=$ angle through which the effluent turns (radian).

Those aerosols that are displaced more than the distance to the wall are assumed to be deposited on the wall. For circular channels, the number fraction of acrosols that are not removed by this mechanism is given as (see Reference 4)

$$
\frac{N}{N_{o}}=\frac{2}{\pi}\left[\cos ^{-1}\left(\frac{s}{D_{h}}\right)-\frac{s}{D_{h}} \sqrt{1-\left(\frac{s}{D_{h}}\right)^{2}}\right]
$$


For rectangular channels with infinite aspect ratio, the number fraction of aerosols that remain is equal to the displacement distance over the plate spacing:

$$
\frac{\mathrm{N}}{\mathrm{N}_{\mathrm{o}}}=\frac{\mathrm{s}}{\mathrm{D}_{\mathrm{h}} / 2}
$$

For rectangular channels with an aspect ratio less than infinity, Equation (19) is only an approximation.

Thermophoresis. When there is a temperature gradient near the wall, the deposition speed caused by thermophoresis is given by combining Brock's expression ${ }^{18}$ with the aerosol mobility

$$
V_{d}=-\frac{1.5}{3+K n} \cdot \frac{k_{r}+2.5 K n}{1+2 k_{r}+5 K n} \cdot \frac{9 \pi \mu^{2} B_{k} R_{k}}{\rho_{p} T} \cdot\left(\frac{d T}{d r}\right)_{\text {wall }}
$$

where

$$
\begin{aligned}
& \mathrm{Kn}=\text { Knudsen number } \\
& \mathrm{k}_{\mathrm{r}}=\text { thermal conductivity ratio }-\mathbf{k}_{\mathrm{g}} / \mathbf{k}_{\mathrm{p}} \\
& \mathrm{T}=\text { gas temperature }
\end{aligned}
$$

\subsubsection{Chemisorbtion}

For the PULSE/MOD-ISV code, only the chemisorbtion of cesium hydroxide by stainless steel is modeled. Chemisorbtion of the other condensible species is assumed not to occur. In general, the rate of change for the chemisorbed mass of a species is modeled as (see Reference 4)

$\frac{\mathrm{dm}}{\mathrm{dt}}=\mathrm{A} \mathrm{k}_{\mathrm{r}} \mathrm{C}$

where

$$
\mathrm{k}_{\mathrm{r}} \quad=\quad \text { deposition speed }(\mathrm{m} / \mathrm{s})
$$

This rate is again accompanied by an equal and opposite change in the vapor mass. The vapor deposition speed for cesium hydroxide on to stainless steel is a function of the system temperature and is modeled using the following correlation: ${ }^{19}$

$k_{r}($ cesium hydroxide $)=\exp \left(-2.4563778-\frac{7284.8555}{T}\right)(\mathrm{m} / \mathrm{s})$. 


\subsubsection{Temperature Calculation}

The TRAPMELT/PULSE code calculates the temperature only once during the transit time over a sub-segment. This calculation involves only heat transfer with the wall of the sub-segment and neglects the thermal mass of the aerosol species and the latent heat released by condensation. This simplification is sufficient if the rate of condensation is slow and the aerosol thermal mass is negligible compared to that of the gas. For the ISV OGS, however, the thermal mass of the injected aerosol species can be substantial compared to that of the gas, especially in the quencher and scrubber. Moreover, the rate of condensation/evaporation can also affect the gas temperature significantly. Consequently, the temperature calculation has been modified in PULSE/MOD-ISV to include both the thermal mass of aerosol species and the latent heat due to condensation. Additionally, the calculation is carried out at every time step instead of only at the end of the sub-segment as is done in TRAPMELT/PULSE. The effect of latent heat on temperature is included by treating the heat released by condensation as a volumetric heat source. For a constant wall temperature, the change in temperature of the packet over a time step $8 \mathrm{t}$, is given by

$T_{t+\Delta t}-T_{t}=\left(T_{w}-T_{t}+\frac{Q}{A_{w} h}\right)\left(1-\exp \frac{-\frac{A_{w} h}{\rho_{g} c_{p} \nabla} \cdot 8 t}{)}\right.$

where

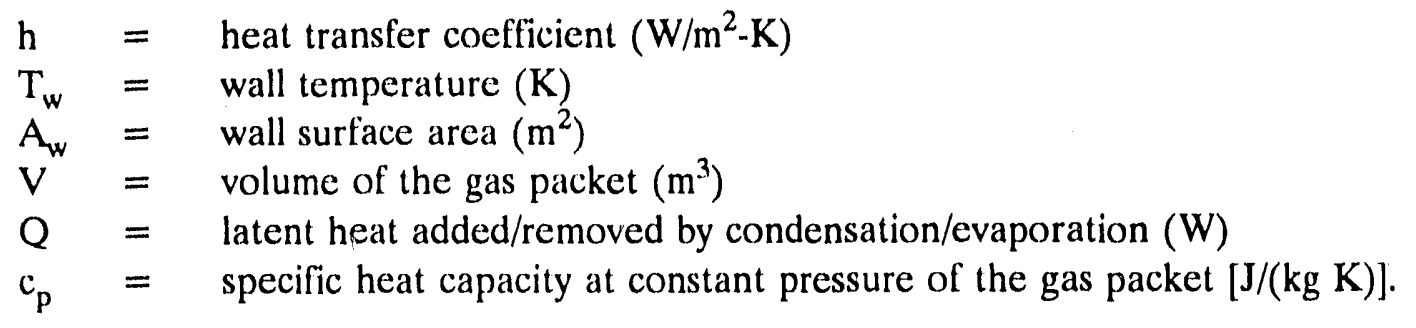

For a specified wall heat flux, the gas packet temperature change is calculated as

$T_{t+\delta t}-T_{t}=\frac{\left(Q+Q_{w} A_{w}\right)}{\rho_{g} c_{p} V} \cdot \delta t$

where

$\mathrm{Q}_{\mathrm{w}}=$ specified wall heat flux $\left(\mathrm{W} / \mathrm{m}^{2}\right)$.

The derivation of Equations (23) and (24) is presented in Appendix A. 


\subsubsection{Materlals Property Models}

A list of the condensible and non-condensible species that can be modeled with the PULSE/MOD-ISV/VER 1.0.0 code is given in Table 2. The condensible species have been modified from those modeled by the TRAPMELT/PULSE code. The revised species are those that might be encountered in the ISV process. The non-condensible gases have not been modified from those used in the TRAPMELT/PULSE code. A total of 15 material properties are required by the PULSE/MOD-ISV code. Six of these are non-condensible gas properties and the remaining eight are condensible species properties. In the code, each property is provided for by a function or data statement. In this section, the material property models and data are summarized. A detailed discussion of the material property models and data is presented in Appendix B.

Non-condensible Gas Properties. For the non-condensible gases, the properties used in the code are:

- gas thermal conductivity

- $\quad$ gas specific heat capacity at constant pressure

- gas density

- gas molecule mean free path

- $\quad$ gas effective emissivity

- gas viscosity.

All of the properties are modeled with functions identical to those in the TRAPMELT/PULSE code and all are described in detail in the MATPRO materials properties package documentation. ${ }^{20} \mathrm{~A}$ brief description of the property models follows.

Gas Thermal Conductivity-The thermal conductivity of the non-condensible gas mixture is required to calculate the temperature of the gas packet proceeding down a channel with wall temperatures different from gas. The thermal conductivity is calculated for a mixture of the 10 non-condensible gases.

Gas Specific Heat Capacity at Constant Pressure-As with the gas thermal conductivity, the specific heat capacity of the non-condensible gas mixture at constant pressure is required to calculate the temperature of the gas packet. The specific heat capacity at constant pressure is calculated for a mixture of the 10 non-condensible gases and is a function of the mole fractions of each component and the gas temperature. It is determined by dividing the molar heat capacity of the mixture by the molecular weight of the mixture.

Gas Density-The density of the non-condensible gas mixture is required to calculate the temperature and velocity of the gas packet. The density is calculated for a mixture of the 10 gases and is determined from van der Waals' equation of state for a gas mixture (see Reference 20). It is a function of the mole fractions of each component, the gas temperature, and the pressure.

Gas Viscosity-The viscosity of the gas mixture is used in many relations used to describe the flow conditions. The viscosity is calculated for a mixture of the ten gases and is a function of the mole fractions, viscosities of each component, and the gas temperature. 
Table 2. Condensible and non-condensible species modeled in the PULSE/MOD.ISV VER 1.0.0 code.

\begin{tabular}{|c|c|c|}
\hline & Condensible & Non-condensible \\
\hline 1. & Beryllium & 1. Helium \\
\hline 2. & Mercury & 2. Argon \\
\hline 3. & Cesium hydroxide & 3. Krypton \\
\hline 4. & Potassium & 4. Xenon \\
\hline 5. & Potassium chloride & 5. Hydrogen \\
\hline 6. & Potassium hydroxide & 6. Nitrogen \\
\hline 7. & Sodium & 7. Oxygen \\
\hline 8. & Sodium chloride & 8. Carbon monoxide \\
\hline 9. & Sodium hydroxide & 9. Carbon dioxide \\
\hline 10. & Lead & 10. Water vapor \\
\hline 11. & Plutonium dioxide & \\
\hline 12. & Uranium dioxide & \\
\hline 13. & Water & \\
\hline 14. & Carbon tetrachloride & \\
\hline 15. & Trichloroethane $\left(\mathrm{C}_{2} \mathrm{H}_{3} \mathrm{Cl}_{3}\right)_{1,1,2}$ & \\
\hline 16. & Regal oil $\left(\mathrm{C}_{20} \mathrm{H}_{42}\right)$ & \\
\hline 17. & Silicon Dioxide & \\
\hline 18. & $\operatorname{PCB}\left(\mathrm{C}_{12} \mathrm{H}_{9} \mathrm{Cl}\right)$ & \\
\hline 19. & Undefined & \\
\hline 20. & Undefined & \\
\hline
\end{tabular}

Gas Molecule Mean Free Path-The mean free path of the gas mixture is required to calculate the deposition rate due to thermophoresis. The mean free path of the mixture is approximated using the single component ideal gas relation for viscosity. The mean free path is a function of the mole fractions of each component, the gas temperature, density, and viscosity of the mixture.

Gas Effective Emissivity-The effective emissivity of the non-condensible gas mixture is used to approximate the radiative heat transfer between the gas packet and the channel surface. Use of the effective emissivity assumes the gas packet to be an opaque source. This simplification avoids solving the detailed differential equations for energy transport in a nontransparent media (see Reference 9).

The effective emissivity correlation assumes that water vapor is the only nontransparent species present and that the packet is cylindrical. The emissivity is a function of the mole fraction of water vapor, the gas temperature and pressure, and the effective diameter of the packet. The simplification 
that the gas mixture is transparent to all of the gases except water vapor is not accurate for all problems. First, the nonsymmetrical molecules like $\mathrm{CO}_{2}$ and $\mathrm{CO}$ also absorb infrared irradiation. When more than trace amounts of these components are present, the correlation gives incorrect results. Second, radiation from the suspended aerosols is neglected. For the relatively low temperatures expected to occur in the ISV OGS, these simplifications are reasonable. However, for high temperature applications, this gas emissivity model may require modifications.

Condensible Species. For the condensible species, the properties required are:

- $\quad$ species equilibrium vapor concentration (EVC)

- vapor deposition speed due to chemisorbtion

- aerosol thermal conductivity

- aerosol density

- $\quad$ surface tension of condensed species

- $\quad$ vapor specific heat capacity at constant pressure

- aerosol specific heat capacity at constant pressure

- latent heat of condensation/evaporation

- molecular weight

- molar volume.

The first five models of these properties were obtained from the TRAPMELT/PULSE code. Modification of the property values were made to model the condensible species listed in Table 2. The remaining models were developed as part of this project. A brief description of these models follows.

Equilibrium Vapor Concentration-The EVC is used to calculate the rate of condensation or evaporation onto wall surfaces or mobile aerosols. Also, it is used in modeling the nucleation of acrosols from vapor.

The EVC is a function of the system temperature and pressure and the equilibrium vapor pressures of the species. It is related to the equilibrium vapor pressure using an approximation based upon van der Waals' equation of state for a gas (see Reference 20).

A set of plots of the species' EVCs as a function of temperature is presented in Figure 7. These plots were obtained using Equation (B-25) with a system pressure of one atmosphere $\left(1.013 \times 10^{5} \mathrm{~Pa}\right)$. The plots on the left hand side of this figure have relatively high EVCs and those on the right hand side have low vapor concentrations.

Vapor Deposition Speed Due to Chemisorbtion-The vapor deposition speed is used to calculate the rate of chemisorbtion onto fixed wall surfaces. Of the species listed in Table 2, only the chemisorbtion of cesium hydroxide by stainless steel surfaces is modeled. The vapor deposition speed is a parameter in Equation (21). The vapor deposition speed for cesium hydroxide on to stainless steel is a function of the system temperature and is given by Equation (22).

Aerosol Thermal Conductivity-The thermal conductivity of suspended aerosols is used in calculating the deposition rate of acrosols due to thermophoresis. When more than one species 


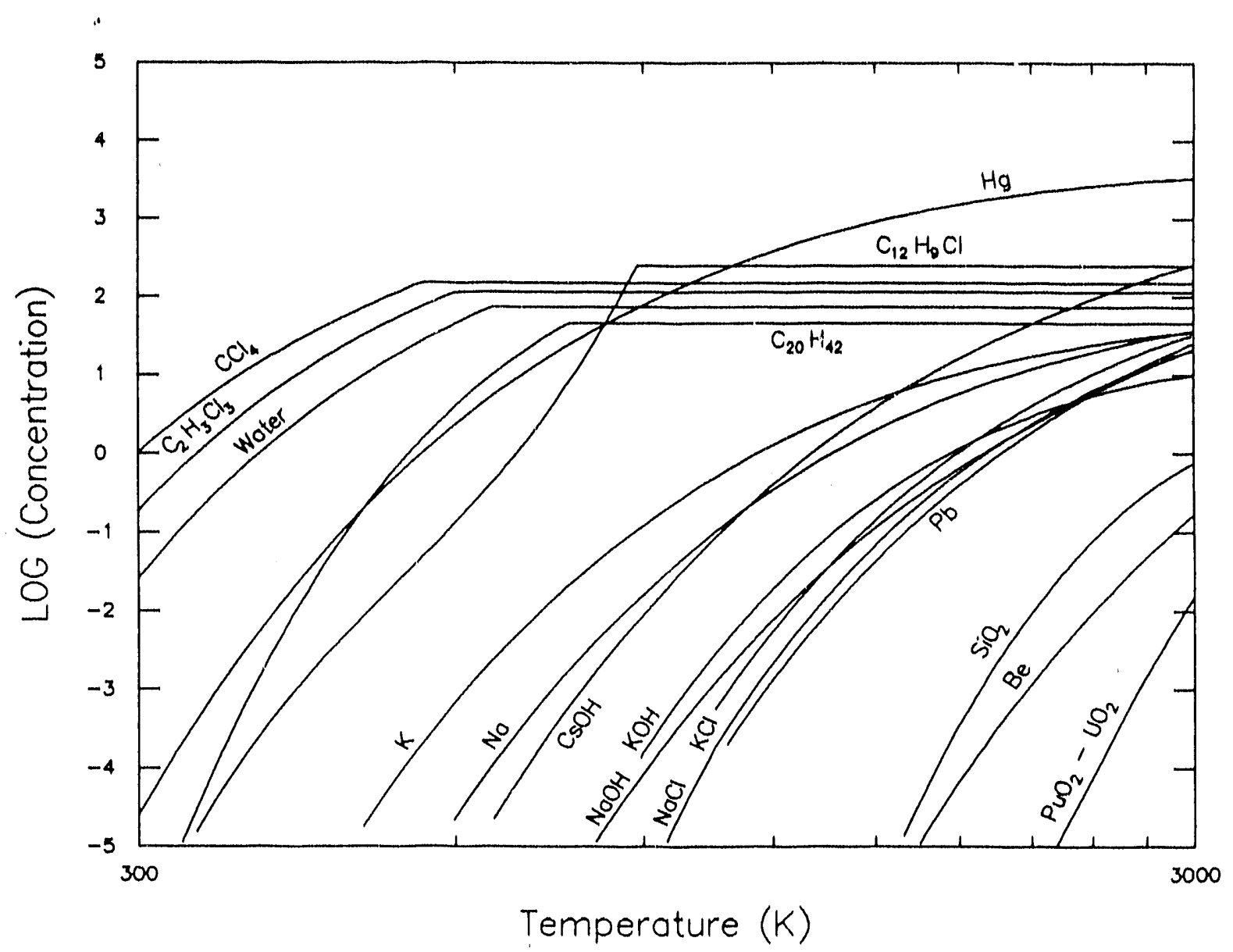

Figure 7. Equilibrium concentrations versus temperature for the 18 condensible species modeled in the PULSE/MOD-ISV/VER 1.0.0 code.

is present, an effective conductivity of the mixture is defined by combining the conductivities for each specie as though the species are slabs conducting in parallel.

Aerosol Density-The density of the condensed phase of the species is used in many of the aerosol deposition models, to calculate the van der Waals' coefficients used in other material property models, and to determine the volume fraction of each species. The densities are approximated as constant values.

Surface Tension of Condensed Species-The surface tension of the condensed species is used in modeling the nucleation of aerosols from vapor and is a function of temperature.

Condensible Vapor Specific Heats at Constant Pressure-The specific heat at constant pressure for the condensible species in the vapor phase is used in determining the total thermal mass in the gas packet. This information is then used in calculating the temperature of the ga i packet. For this model, the condensible species are assumed to behave as ideal gases when in the vapor phase. Therefore, the vapor specific heats are approximated as constants. This approximation is valid for small concentrations of the species. 
Condensed Phase Specific Heats at Constant Pressure-Similar to the vapor specilic heats, the specific heats for the condensed phase are used to calculate the temperature of the gas packet and is a function of temperature.

Latent Heats-The latent heat of evaporation/condensation for the condensible species is used in calculating the temperature of the gas packet. The latent heats are approximated as constant values.

Molecular Weights and Molar Volumes-The molecular weights and molar volumes for the condensible species are used in many of the property correlations described above.

\subsection{Code Modifications}

The PULSE/MOD-ISV code is a modified version of the TRAPMELT/PULSE code. Modifications of the TRAPMELT/PULSE code were necessary in order to adequately model the species, component geometries, and phenomena encountered in the ISV OGS. A summary of these modifications are described in this section. ${ }^{\mathrm{c}}$

\subsubsection{Rectangular Channels}

The TRAPMELT/PULSE code only considers flow through circular channels. However, in the ISV OGS, other geometries are encountered. For example, in the hood, gas cooler, and mist eliminator components, the flow passes through rectangular channels. Therefore, the TRAPMELT/PULSE code was extended to model flow through rectangular channels. To accomplish this extension, two modifications were necessary.

Hydraulic Diameter. The first modification alters how the diameter of the channel is calculated. For rectangular channels, the appropriate expression is the hydraulic diameter defined as

$\mathrm{D}_{\mathrm{h}}=4 \cdot \frac{\text { Channel cross sectional area }}{\text { Wetted perimeter }}$.

This expression is also valid for circular channels.

In establishing this modification, the location where the channel diameter is calculated is changed. The diameter is now calculated at the beginning of each segment. In the TRAPMELT/PULSE code, the diameter is calculated after entering a segment. This results in the

c. Unpublished calculation work sheet titled "Code Modifications for PULSE/MOD-ISV/VER 1.(0.0)," by V. X. Tung, EG\&G Idaho, Inc., Idaho Falls, Idaho, October 23, 1991. 
use of the previous segment diameter for part of the new segment calculations. For problems with large differences in the diameters of adjacent segments, the unmodilfed scheme will predict incorrect results.

Laminar Nusselt Number. The second modilication extended the laminar Nusselt number correlation to include rectangular channel geometries. The Nusselt number is used in calculating the heat and mass transfer coefficients. The Nusselt number for laminar flows in a circular channel is 3.66. This value is used in TRAPMELT/PULSE. For rectangular channels, the Nusselt number is a function of the channel aspect ratio. For large aspect ratios, the Nusselt number approaches a value of 7.54. For simplicity, this valuc is used in PULSE/MOD-ISV for laminar flow in rectangular channels regardless of the aspect ratio. While this value is appropriate only for large aspect ratios, significant errors are not likely to occur in modeling the ISV OGS. For those rectangular channels with small aspect ratios, such as in the hood, the flow is turbulent and the laminar Nusselt number is not used.

\subsubsection{Turbulent Nusselt Number}

The turbulent Nusselt number was calculated using the Dittus-Boelter equation. However, this correlation has been known to over-predict at higher Reynolds numbers and it does not account for surface roughness. ${ }^{21}$. For better results, Petukhov's correlation (see Reference 10) has replaced the Dittus-Boelter equation. A plot of the Nusselt number versus Reynolds number for a Prandlt number of 0.7 predicted by the two correlations is shown in Figure 8 .

\subsubsection{Agglomeration Split Fraction}

When two aerosols agglomerate, the resulting aerosol size usually does not match the discrete bin sizes exactly. TRAPMELT/PULSE handles this by splitting these aerosols between two neighboring bin sizes such that only the total number of aerosols is conserved. However, both the number of aerosols and the mass of aerosols must be conserved. Therefore, the split fractions have been modified to conserve both.

\subsubsection{Flow Sub-Division}

The TRAPMELT/PULSE code considers only a single flow path. However, in the ISV OGS model, splitting of the flow may be required. For example, if more than one OGS train is operating, the flow is split through the manifold piping to the number of trains operating. Similarly, accident sequences may involve secnarios in which part of the flow bypasses the OGS through a leak. Therefore, the TRAPMELT/PULSE code was extended to allow the flow to be split at any segment along the llow path. The flow split can be specified as any value greater than or equal to one. Values can also be specified between zero and one and will increase the llow by a factor equal to the inverse of the number specified. This is useful in recombining the flow after it is split between parallel systems.

Although this modification allows the flow to be split between any number of flow paths, only one flow path can be analyzed at a time. To analyze more than one flow path, each path must be computed separately. 


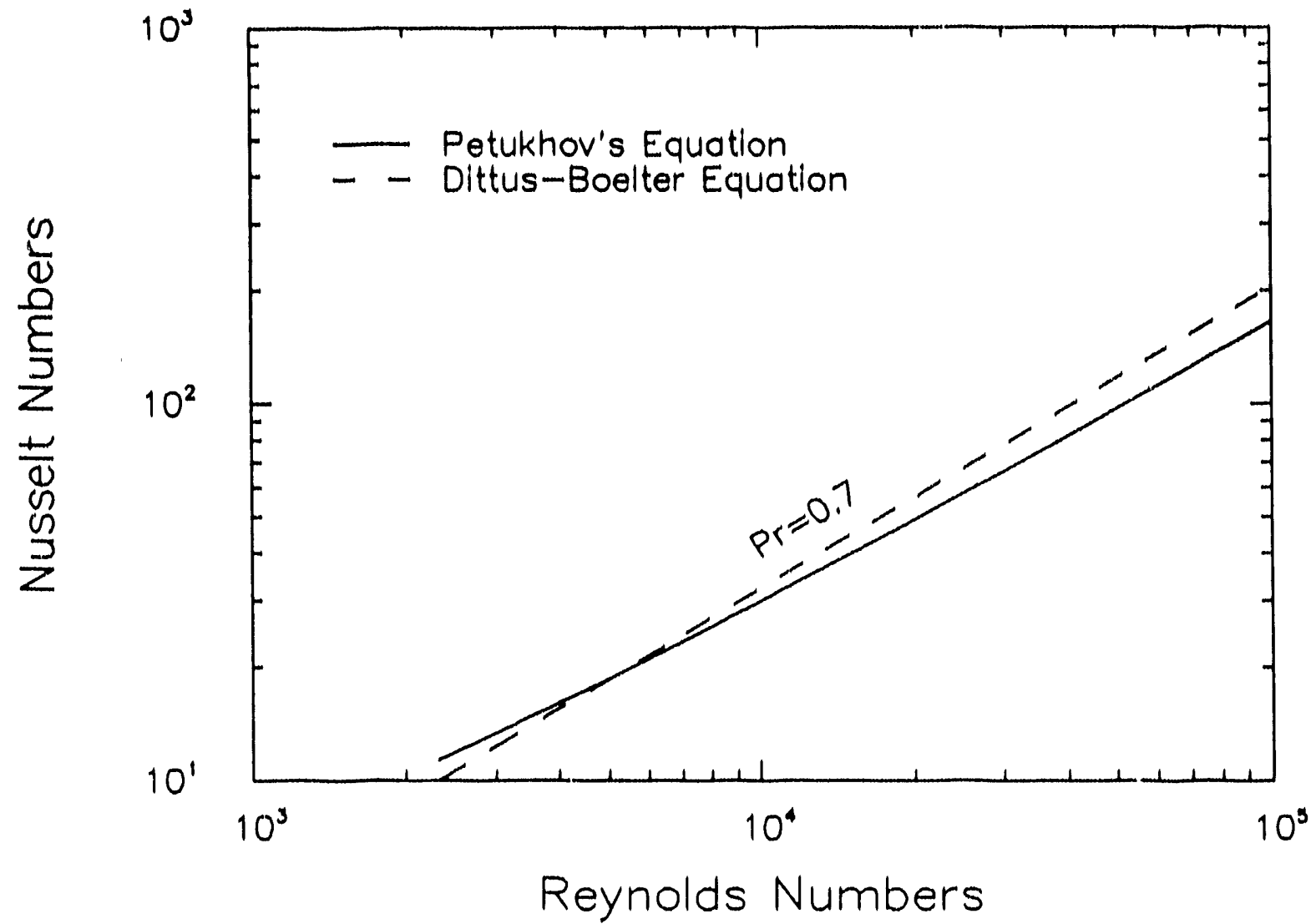

Figure 8. Comparison of the Petukhov and Dittus-Boclter correlations predictions of the turbulent convective transfer Nusselt number.

\subsubsection{Temperature Calculation}

Two modifications have been made in calculating the packet gas temperature. First, the TRAPMELT/PULSE code neglects the thermal mass of the acrosol species (except water) in calculating the packet gas temperature. Also, it neglects the latent heat due to condensation or evaporation. Modifications have been made to include the thermal mass of all species and the latent heat due to condensation/evaporation in the temperature calculation.

Second, with the TRAPMELT/CODE, the temperature calculations are performed only once for each sub-volume. However, because of the inclusion of latent heat effect, the temperature now is calculated at every time step taken during the transit time.

\subsubsection{Differential Equation Solver}

The differential equation solver in TRAPMELT/PULSE uses an absolute mass iteration convergence criterion. Although, there is nothing fundamentally wrong with this criterion, it was unaceptable for the ISV OGS modeling because the absolute masses for the various species vary 
over several orders of magnitude. Furthermors, some of the more hazardous spectes are found in trace amounts. With the absolute mass criterion, to aceurately calculate these trace amounts, the mass fraction tolerance would have to be set to a fraction equal to a tolerance desired of the smallest mass of interest. This would result in excessive iterations beciase the majority species were held to this same demanding mass tolerance. This convergenec crliction has been modilied to a relative mass tolerance. Essentially, the convergence criterion now recpulres that the difference between two iterations be less than the smaller of either a specified fraction of the previous iteration value or the specilied l'raction of the cotal mass of the species.

\subsubsection{ISV Specles}

Modifications were made to the condensible species property data in the TRAPMELT/PULSE code so as to represent those specles encountered in the ISV process. The non-condensible gases modeled were not modified. A brief description of the property models is given in Section 2.2.9. A detalled deseription of the models and data is presented in Appendix B.

\subsubsection{Multiple Source Inputs}

TRAPMELT/PULSE assumes that each species can be injected into the system only once. This restriction is too severe for the ISV OGS. In the OGS, water is injected once at the quencher and twice more at the tandem nozzle scrubber. Modifications have been made to allow up to ten points of injection for each species. 'To better model these injected sources, the point of injection was moved to the beginning of a sub-segment instead of the middle as was modeled in TRAPMELT/PULSE. This allows for a more precise handling of discontinuities in flow velocity and temperature.

\subsubsection{Source Addition}

The TRAPMELT/PULSE code assumes that the injected species are at the temperature of the gas packet at the injection location. However, for the OGS quencher and scrubber components, the injected scrubbing lluid can be several hundred of degrees cooler than the off-gas. Therefore, the TRAPMELT/PULSE code was modified to allow the species to be injected at a different temperature than the gas packet. The resulting gas packet temperature, assuming homogeneous mixing with the injected species, is accounted for using a modified temperature calculation. This modification accounts for the added energy and thermal mass of the injected source.

As part of the injected sourec modilications, the calculation of the gas packet transit time also had to be modified. In TRAPMELT/PULSE, the transit time is calculated at the beginning of a subsegment. However, this is no longer appropriate because it does not account for the volume and temperature changes due to the injected species. The packet transit time is now calculated after changes due to souree addition have been included in the packet density and velocity calculations. 


\subsubsection{Gas Packet Information}

TRAPMEITT/PULSE recalculates the gas packet inl'ormation such as packet mass, gas density, velocily, and concentrations at the end of a sub-segment. Even though this is sufficient for the TRAPMELT/PULSE code, the PULSE/MOD-ISV code requires that such information be recalculated whenever a change in temperature or pressure is incurred. Modilications have been made to recalculate the packet information at the beginning of each sub-segment to account for temperature changes due to nucleation and source addition.

\subsubsection{Maximum Number of Segments and Subsegments}

TRAPMELT/PULSE allows a maximum of 23 segments and 60 sub-segments. However, in modeling the ISV OGS, 60) segments and 105 subsegments are used. Furthormore, when testing convergence of the results, the number of segments and subsegments required can be four times the base case values. Therefore, the code was modified to increase the capacity of the code to 30() segments and 1,000 sub-segments.

\subsubsection{Decay Heat}

TRAPMELT/PULSE accounts for the decay heat of radioactive species. This decay heat is handled as a volumetric heat souree in solving for the gas temperature. Such decay heat, however, is negligible in the ISV process. As a consequence, this model was removed from PULSE/MOD-ISV.

\subsubsection{Thermal Boundary Condition}

The thermal boundary condition in the TRAPMELT/PULSE code is limited to specified wall temperatures. This boundary condition is not alway: appropriate for the ISV OGS. For example, the reheater and other components are more easily modeled by specilying a wall heat flux rather than a wall temperature. Therefore, the code was modified so that either a wall temperature or wall heat flux thermal boundary condition can be specified.

\subsubsection{Restart Capability}

The TRAPMELT/PULSE code allows restart only after one packet of gas has passed through the system. For an established code this capability is sufficient. However, a developmental code such as PUISE requires more flexibility for debugging purposes and in analyzing the results. Modifications have been made to the current version to allow a temporary termination of the program at any point in time and at any subsegment.

\subsubsection{Multiple Filter Segments}

The TRAPMELT/PULSE code models only a single filter. However, for the ISV OGS, two HEPA filters require modeling. Therefore, modifications were made to increase the maximum number of filter segments modeled to ten. 


\subsection{Code Inputs}

The PULSE/MOD-ISV/VER 1.0.0 code requires input data that describes the components and the flow conditions to be modeled. This section describes the inputs in general terms. It is not intended to be a users' manual since the code and detailed input data format instructions are not provided here. As a developmental code, a users' manual has not been prepared. The TRAPMELT/PUISE code does have a users' manual (see Reference 4), but the many modifications made in developing the PULSE/MOD-ISV version have made the input data format instructions presented there obsolete. Because of budget limitations there are no plans for preparing a users' manual for the PULSE/MOD-ISV/VER 1.0.0 code.

The input information required by the code consists of 10 general categories. For these 10 categories, there are a total of 19 distinct input items (some input categories are made up of several input items.) Similarly, most input items consist of several input data elements. The 10 categories are listed below:

- Descriptive title

- Geometric data

- Thermal boundary conditions

- Iilter efficiency data

- Inlet species and initial flow conditions

- Problem start and stop times

- Convergence tolerances and parameter value limits

- Output switches

- Restart switches

- Ion concentration.

\subsubsection{Input Deck Title}

The first input deck item is a single line, descriptive title for the input deck.

\subsubsection{Geometric Input Data}

The geometric information category consists of three input items, which are the second, third, and fourth input deck items. The first of these items contains two pieces of input information: the total number of segments and the number of subsegments for each segment.

The third input deck item and the second geometrical item is a collection of eight pieces of data which includes the segment length, the llow channel cross sectional area, the channel wall surface area, the settling surface area, the number by which the total mass flow rate through the segment is split, a flow channel cross section shape indicator, a wall composition indicator, and the wall surface roughness.

The fourth item of the inpul deck and the final geometric item specifies, for each subsegment of each segment, two pieces of information. This information consists of the angle through which the flow turns through each subsegment and the cosine of the angle between the average 
upward-facing surface normal (i.e., the surface normal area weighted over that part of the surface with a local normal that forms an angle with the acceleration of gravity that has a negative cosine).

\subsubsection{Thermal Boundary Conditions}

The thermal boundary condition information consists of two input items, which are the thirteenth and fifteenth input deck items. The first of these items specifies, for each segment, either the surface temperature or the surface heat flux as a function of time.

The second specifies the boundary and initial condition time constant as a function of time. This time constant data is used to determine the length of the effluent packet that is considered in the calculations. Time dependent input data is averaged over time spans equal to this time constant. The time constant should be obtained as a function of time by examination of all the time dependent input data, including the surface boundary conditions, the gas flow rates, the source rates, and the pressure. It should be chosen as the shortest length of time required for any of these input data to change by an amount that is more than the user is willing to average. For a steady state problem for which the boundary and initial conditions do not change, the time constant can be set equal to the duration of the problem.

\subsubsection{Filter Efficiencies}

The filter efficiency characteristics of a component are specified by the sixteenth input deck item. This input item is a multiple line input item. The first line lists the total number of filter segments. The second line specifies the segment number of the first filter. The third line begins a listing of the filter efficiency data. For each species considered (item six of the input deck), the mass fraction is specified that passes through the filter for each of the nineteen aerosol size classes. For more than one filter segment, the filter segment number and filter efficiency information is specified for each.

\subsubsection{Inlet Species and Flow Conditions}

The material flowing through the channel segments consists of condensible and non-condensible species. Six input items are required to describe the composition and condition of the species to be considered. Input deck items six, seven, and ten are used in describing the condensible species and items eleven, twelve, and fourteen describe the non-condensible species.

In describing the condensible species, item six is a single line of binary switches that indicates which species are to be considered. Item seven consists of two lines of information. On the first line, the number of discrete aerosol size classes is specified. On the second line, the smallest and largest acrosol size class average diameters are specified. In PULSE/MOD-ISV/VER 1.0.0, the number of acrosol size classes is fixed internally at 19 and an exira bin is added as the overflow bin. Aerosols larger than the largest bin size are placed in this overflow bin and are assumed to be deposited. Therefore, the total number of bin sizes is 20 . In choosing the minimum and maximum aerosol bin size diameters, the ratio of the maximum to minimum diameters must be at least 64 . 
Item ten is a multiple line input that specifies the source rates and temperature at inlet for each of the condensible species specified in item six. The sources rates can be specified as a function of time and can be specified as input at any of the segments. The physical form of the species can be specified as vapor, aerosol, or a combination of the two. Three different ways of describing the aerosol source rate are allowed:

1. Provide the aerosol geometric mean volume geometric mean standard deviation based on volume (three times the geometric mean standard deviation for diameter), and the total mass rate

2. Provide the mass rate for each of the 20 aerosol bin sizes

3. Indicate the lack of an acrosol of the species by specifying only the vapor mass rate and setting a switch for no aerosol.

For the non-condensible species, item eleven is a multiple line input which specifies the non-condensible gas source rates inlet at the first segment. The source rate information can be specified as a function of time and includes the total gas mass flow rate and the molar fractions for each gas component. Item twelve provides the temperature of the entering non-condensible gas as a function of time and item fourteen specifies the inlet pressure as a function of time.

\subsubsection{Problem Start and Stop Times}

The start and stop times for the problem are listed in input deck item five.

\subsubsection{Convergence Tolerances and Parameter Value Limits}

The differential equation solver convergence tolerances and parameter value limits are listed in items eight and eighteen of the input deck. Item eight consists of ten elements. The first specifies a relative mass tolerance for which the difference between the total mass in the packet and the mass in question is compared. The second is another relative mass tolerance for which the relative difference between two consecutive iterations is compared. The third specifies a tolerance which is used to check the aerosol number density for a given bin size. For aerosol number densities less than the specified tolerance, convergence testing is suspended for the bin size in question. The fourth specifies the maximum magnitude for an argument of the FORTRAN expenential function. The fifth specifies the truncation value for which all real numbers less than this value are set to zero. The sixth specifies the minimum mass fraction for the first step-back without invoking the dryout switch. The seventh specifies the fractional error allowed in checking the first part of a step-back. The eighth specifies the ratio of time constant for condensation onto aerosol to time step size for which tampiner is invoked. The ninth specifies the minimum mass to be considered in the relative mass convergence tests. For any mass less than this minimum mass, the convergence testing is suspended for the size class in question. Finally, the tenth specifies the absolute maximum temperature change allowed. In the differential equation solver, the time step is chosen such that the temperature change due to latent heat effects is less than this parameter. This parameter should be chosen sufficiently small to avoid temperature oscillations in the results. 
The second item, number eighteen, lists two elements. The first is the maximum number of iterations used by the differential equation solver. The second is the minimum number of time steps at each iteration.

\subsubsection{Output Switches}

The amount and frequency of the output information printed is specified by item nine. This input item has 36 switches. The first seven specify the frequency of the output. The remaining 29 are binary switches and are used to indicate what information is to be printed. A list of these print switches follow.

1. INDEX FOR PACKET NUMBER, SEGMENT NUMBER, SUBSEGMENT NUMBER, AND TIMES

2. INDEX FOR VOLUME AND WALL HEAT SOURCE

3. INDEX FOR EFFECTIVE WALL TEMP AND VOLUME HEAT ADDED

4. INDEX FOR EFFECTIVE GAS EMISSIVITY

5. INDEX FOR TIME CONSTANT AND CHARACTERISTIC LENGTH FOR GAS TEMPERATURE

6. INDEX FOR NOTICE WHEN METAL ZIRCALOY THICKNESS IS ZERO

7. INDEX FOR PACKET VOLUME, SURFACE AREA, AND LENGTH

8. INDEX FOR SPECIES AND MASS NUCLEATED, CONCENTRATION, EQUILIBRIUM CONCENTRATION, AND SIZE CLASS NUCLEATED

9. INDEX FOR TIN RELEASE AND TOTAL SUBSEGMENT RELEASE

10. INDEX FOR SPECIES EQUILIBRIUM CONCENTRATIONS

11. INDEX FOR SPECIES TIME CONSTANTS FOR CHEMISORBTION

12. INDEX FOR TIME CONSTANT FOR VAPOR EVAPORATION/CONDENSATION TO WALL

13. INDEX FOR LEVITATION DATA

14. INDEX FOR SPECIES BY SPECIES LEVITATION DATA

15. INDEX FOR DIFFERENTIAL EQUATION SOLVER INFORMATION

16. INDEX FOR PARTICLE DEPOSITION AND BIN SHIFT TIME CONSTANTS

17. INDEX FOR TIME CONSTANTS FOR AGGLOMERATION OUT OF SIZE CLASSES

18. INDEX FOR GAS AND WALL TEMPERATURES

19. INDEX FOR GAS PRESSURE

20. INDEX FOR GAS SPEED AND REYNOLDS NUMBER

21. INDEX FOR DEPTH OF AEROSOL DEPOSITION

22. INDEX FOR SPECIES VAPOR CONCENTRATION AND AMOUNT IN VAPOR

23. INDEX FOR SPECIES AEROSOL DENSITY AND AMOUNT IN AEROSOL

24. INDEX FOR SPECIES DISTRIBUTION AMONG AEROSOL SIZE CLASSES

25. INDEX FOR SPECIES CONDENSED, CHEMISORBED, AND DEPOSITED AS AEROSOL ON SUBSEGMENT WALLS

26. INDEX FOR MOBILE AEROSOL INFORMATION

27. INDEX FOR TIME CONSTANT FOR VAPOR TO AEROSOL CONDENSATION

28. INDEX FOR SUBSEGMENT DEPOSITION INFORMATION AFTER PACKET EXITS 


\section{INDEX FOR MASS IN \& MASS ACCOUNTED FOR AFTER PACKET EXITS}

\subsubsection{Restart Switches}

The nineteenth and last input item specifies two sets of indicators used for restarting the code calculations. The first set indicates the starting packet and ubsegment for restarting the code. The second set indicates the packet and subsegment at which to op the calculation. If all four indicators are set at zero, then no restart is selected and the calculation proceeds through the entire specified problem.

\subsubsection{Ion Concentration}

The ion concentration is specified in item number seventeen. This is a single line item for which the ion concentration at two segments is specified. However, for the ISV OGS modeling, the ion concentration is assumed to be negligible and the ion concentration is specified as zero.

\subsection{Code Outputs}

The output information produced by the PULSE/MOD-ISV/VER 1.0.0 code includes an echo of the input data, results generated for each defined segment and sub-segment, and a final summary of the results.

The amount and frequency of output results is specified by input item nine described above. The results that can be printed out for each subsegment include information on the gas packet, the mobile aerosol and vapor species, and the deposited material. The gas packet information includes the packet entrance and exit times, the packet transit time, the gas temperature at subsegment entrance and exit, the gas pressure, the density, the velocity, and the Reynolds number.

Information on the mobile aerosol species include for each species the aerosol density, the mass of aerosol in the packet, the aerosol distribution in the 20 aerosol bin sizes, and the amount and size of material nucleated, if any. Also, the total aerosol number, aerosol mass density, and the time constants for each deposition mechanism at the subsegment exit are specified. Information on the mobile vapor species include for each species the vapor equilibrium concentrations at the wall and gas temperature, the vapor concentration, the mass of vapor in the packet, and time constants for vapor to wall chemisorbtion and condensation/evaporation. The over-all time constant for vapor to aerosol condensation is also specified.

Information on the deposited aerosol species includes for each species the amount condensed, chemisorbed, and deposited on the wall. Also, the total depth of the deposited material is given.

The summary information includes, for each subsegment and for each species, the total amount of material condensed, chemisorbed, and deposited on the wall surface. Also, the net mass accounted for is provided. For each gas packet and for each species, the net mass input and output is provided. Also, the vapor concentration and mass at output are specified. The net mass chemisorbed, condensed, and deposited, and net mass accounted for in each gas packet is given. 
For each species, final time summary information is provided. This information includes the net mass input and output; the vapor concentration and mass at output; the net mass chemisorbed, condensed, and deposited; and net mass accounted for. Also, the deposited mass and mass per unit area for each subsegment is specified. The mass of aerosols in each of the 20 bin sizes at output is also given.

Finally, the total amount of all species chemisorbed, condensed, and deposited on each subsegment is provided. 


\section{OFF-GAS SYSTEM MODELS}

This section presents the off-gas system (OGS) component conceptual geometric model descriptions, thermal boundary conditions, and off-gas flow descriptions. While all of the significant modeling assumptions, simplifications, and limitations are described, detailed calculations of the geometry and boundary conditions are not presented here but can be found in the calculational work sheets footnoted in the text.

\subsection{Companent Models}

The PULSE/MOD-ISV/VER 1.0.0 code requires, as input data, geometrical and thermal boundary condition descriptions of the components to be modeled. The code models the flow of vapor and aerosols through circular and rectangular channel geometries. Therefore, the OGS component geometries must be described in terms of specific channel characteristics. The required channel characteristics include the channel length, the channel cross-sectional area, the channel wall surface area, the settling surface area, the number by which the total mass flow rate through the channel is subdivided, a flow channel cross-section shape indicator, the wall surface roughness, and the angle through which the flow turns through the channel.

The thermal boundary conditions specify as a function of time the surface temperature or heat flux of the channel surface. For the OGS model developed here, all boundary conditions are constant with time. However, the spatial variation of the surface boundary condition is modeled by dividing the components into a series of segments. For each segment, unique boundary conditions are specified.

Following is a description of the models and assumptions used in developing the geometrical information and boundary conditions for the ISV OGS components. ${ }^{d}$

\subsubsection{Off-Gas Hood}

Modeling of the hood is required to determine the vapor and aerosol flow rates that exit the hood and enter the OGS. The off-gas hood is designed to contain airborne and splattered matter evolved from the ISV process. Also, it facilitates the control of combustion of evolved gases within the hood by controlling the admission of airborne oxygen. The evolved gases exit the confinement of the hood and pass through the off-gas jumper pipe to the OGS. Vapor condensation and acrosol deposition within the hood is expected to be relatively small compared to other OGS components such as the tandem nozzle scrubber or the mist eliminator. However, depending upon the flow and boundary conditions, aerosol agglomeration and condensation of vapor onto aerosols may occur. These phenomena will increase the size of aerosols leaving the hood.

d. Unpublished calculational work sheet entitled "Boundary Conditions for Off-Gas Treatment System," by V. X. Tung, EG\&G Idaho, Inc., Idaho Falls, Idaho, May 8, 1991. 
A conceptual drawing of the hood is presented in Figure 2. The preliminary design description for the hood ${ }^{\mathrm{e}}$ specities that the hood will be a free standing enclosure, lacking a floor, which will rest upon the ground circumscribing the intended melt zone. The hood surface is composed of heavily dimpled sheet metal panels welded together. This dimpled skin is designed to allow thermal expansion at low stress levels. The hood design provides for miscellaneous penctrations, access ports, and sampling ports, complete with sealing mechanisms. Also, suspended from the hood eciling is a conical heat shield. The evolved gases pass through an orifice in this shield and exit the hood.

Geometry Inputs. A summary follows of the important assumptions used in obtaining the geometric inputs for the hood model. ${ }^{f}$ The geometric data for the hood is based upon the preliminary drawings and the design specifications noted above. The flow through the hood is simplified as flow through a vertical square channel $11.9 \mathrm{~m}(39 \mathrm{ft})$ on a side and $1.83 \mathrm{~m}(6.0 \mathrm{ft})$ in length. The surface penetrations and heat shield are neglected in this geometric model. The hood channel is modeled with a single segment. This segment is divided into five subsegments to properly calculate the vapor and aerosol dynamics. In determining the wall surface area, the floor and ceiling surfaces are neglected because the PULSE/MOD-ISV/VER 1.0.0 code assumes the segments to be a channel (either circular or rectangular) without end surfaces. Based upon this modeling assumption, the code determines the segment hydraulic diameter using a relationship between the cross-sectional area, the wall surface area, and the wetted perimeter. By neglecting the end surfaces, the hood hydraulic diameter is calculated correctly by the code, but the wall surface area is underestimated. This approximation is conservative with respect to the surface area available for vapor and aerosol deposition. Because the ground surface has been neglected, the settling surface area was specified as zero.

The total flow is assumed to pass through the hood; the number by which the flow was split was therefore set to 1.0. The flow channel cross-section shape indicator is specified as 1 to indicate a rectangular cross section. The PULSE/MOD-ISV/VER 1.0.0 code assumes that rectangular channels have an infinite aspect ratio (the aspect ratio is the ratio of the sides of the rectangle). This information is used in determining the surface convective heat and mass transfer coefficients for laminar flow conditions. For the hood, the aspect ratio is 1.0. However, it is anticipated that the flow in the hood is turbulent $(\mathrm{Re}>2300$ ) and the heat and mass transfer coefficients are independent of the cross-sectional shape.

Boundary Condition Inputs. The hood surface was modeled with a constant temperature boundary condition for the single hood segment. The hood interior surface temperature was determined using an energy balance on the hood surface. The inside hood surface receives a heat flux $q_{i}$ from the heat exchange inside the hood and the outside surface looses heat to the ambient at a rate $q_{0^{*}}$. The heat exchange inside the hood consists of radiation exchange between the gas, the

e. "Large Field Test In Situ Vitrification System Conceptual System Design Description of Hood, Electrode Feed Support Structure, and Emergency Ofl-Gas," Sections 1, 2, and 5, attachment to letter PBW-02-91, from P. B. West, EG\&G Idaho, Inc., Idaho Falls, Idaho, January 30, 1991.

l. Unpublished calculational work sheet entitled "INEL ISV OGS Hood Geometry Inputs for PULSE/MOD-ISV/VER 1.0.0," by Daniel Pafford, EG\&G Idaho, Inc., Idaho Falls, Idaho, September 30, 1991. 
hood surfaces, the top of the melt, and the ground surface inside the hood. Convective transfer within the hood was negligible compured to the radiative heat transler and is neglected in the calculations. On the outside surface of the hood, radiation and natural convection transfers the heat received by the hood surface to the ambient air. A list of the simplifications and assumptions used are:

- Steady state condition

- The ambient temperature is $27^{\circ} \mathrm{C}\left(81^{\circ} \mathrm{F}\right)$

- The average temperature of the off-gas entering the hood after combustion is $854^{\circ} \mathrm{C}$ $\left(1569^{\circ} \mathrm{F}\right)$

- $\quad$ The melt surface temperature is $727^{\circ} \mathrm{C}\left(1341^{\circ} \mathrm{F}\right)$

- Convection within the hood is negligible compared to radiation

- All of the hood surfaces are diffuse gray surfaces.

The heat transfer between the off-gas and the interior surface of the hood are modeled in a manner similar to that utilized by the PULSE/MOD-ISV/VER 1.0.0 code. The heat transfer between the off-gas and a surface of the enclosure was determined as

$q=\epsilon_{g} \sigma\left(T_{g}^{4}-T_{s}^{4}\right)$

where

$\mathrm{q}=$ the heat transler between the off-gas and a surface

$\boldsymbol{\epsilon}_{\mathrm{g}}=$ the effective emissivity gas to surface emissivity

$\sigma^{\prime} \quad=$ the Stefan-Boltzmann constant, $5.669 \times 10^{-8} \mathrm{~J} / \mathrm{K}$

$\mathrm{T}_{\mathrm{g}}=$ the average gas temperature in the enclosure

$\mathrm{T}_{\mathrm{s}}=$ the average surface temperature.

The detailed calculations yield a surface temperature of $347^{\circ} \mathrm{C}\left(657^{\circ} \mathrm{F}\right)$ for the hood surface and an exit temperature of $448^{\circ} \mathrm{C}\left(838^{\circ} \mathrm{F}\right)$ for the off-gas.

\subsubsection{Off-Gas Jumper and Manifold Piping}

The off-gas stream exits the hood and enters the ofl-gas jumper and manifold piping which leads to the four OGS trains. Because of the length and surface temperature of this piping, the off-gas temperature drop along this piping is expected to be significant. Vapor condensation and aerosol deposition within this piping is expected to be relatively small compared to other OGS components, such as the tandem nozzle scrubber or the mist eliminator. However, condensation of some species will occur as the ofl-gas stream drops in temperature. Also, deposition of the larger 
aerosols and droplets will occur, especially at the elbow pipe bends and tee junctions. For completeness, this piping has been included in the OGS vapor and acrosol transport model.

A conceptual drawing of the olf-gas jumper and manifold piping is presented in Figure 2. The preliminary design description (see footnote a) specifies that the ofl-gas jumper will consist of approximately 50 feet of 16 -in. Schedule $10304-\mathrm{L}$ stainless steel pipe. Piping, tees, and elbows will be used to form a manifold to connect the four trains to this 16 -in. pipe. All piping used to construct the manifold will be 12 in. Schedule 10S 304-L stainless steel pipe.

Geometry Inputs. A summary follows of the important assumptions used in obtaining the geometric inputs for this model.g The geometric data for the piping is based upon the design specifications noted above and the piping layout as shown in Figure 2. However, neither information source provides the lengths of the pipe sections nor the radii of curvature of the pipe bends. Therefore, this information was assumed in modeling the geometry.

Modeling of the flow through each branch of the tec junctions was simplified as that through a small radius 90 -degree elbow bend. The radius of curvature for the llow through these tee junctions was assumed to be one-half pipe outside diameter. For the 90 -degree pipe bends, the radius of curvature was assumed to be one and a half pipe outside diameters. The radius of curvature for the tee junctions is smaller than that of the pipe bends because of much sharper turns for these junctions.

The assumed lengths of the various piping sections are as follows. The off-gas jumper piping up to the second set of tee connectors is modeled as $16 \mathrm{in}$. Schedule $10304-\mathrm{L}$ stainless steel pipe. This section of piping starts with a straight vertical $1.829 \mathrm{~m}(6 \mathrm{ft})$ section exiting the hood. This is followed by a vertical 90 -degree bend. The length of the bend is $0.958 \mathrm{~m}(3.1 \mathrm{ft})$. This is followed by a horizontal straight section assumed to be $15.24 \mathrm{~m}(50 \mathrm{ft})$ in length. Following this is a horizontal tee. Whether or not the flow is split through this tee, only one llow path requires modeling as the two flow paths are identical. Therefore, the flow turns 90 degrees through the tee connector. The flow length through this tee connector is $0.32 \mathrm{~m}(1 \mathrm{ft})$. This tee is followed by a horizontal section assumed to be $3.048 \mathrm{~m}(10 \mathrm{ft})$ in length. This section connects to the second tec. Again, only one flow path through the tee requires modeling as the split flow paths are identical. Also, the geometry of this tee is identical to the previous one. This tee is followed by a short $16 \mathrm{in}$. to $12 \mathrm{in}$. reducer and then a straight horizontal section assumed to be $3.048 \mathrm{~m}(10 \mathrm{ft}$ ) in length. For simplicity, the reducer is not included in this model. However, following the reducer, the manifold piping is modeled as 12 in. diameter. The first section of this manifold piping is a vertical 9 -degree bend. The length of this bend is $0.763 \mathrm{~m}(2.5 \mathrm{ft})$. This is followed by a straight vertical section assumed to be three feet in length. Finally, a vertical concave up 90-degree bend connects the piping to the cooler component. The length of this bend is $0.763 \mathrm{~m}(2.5 \mathrm{ft})$.

g. Unpublished calculational work sheet entilled "ISV OGS Off-Gas Jumper and Manifold Piping Geometry Inputs for PULSE/MOD-ISV/VER 1.0.(0," by Daniel Palford, EG\&G Idaho, Inc., Idaho Falls, Idaho, September 30, 1991. 
The flow split through this piping is dependent upon how many off-gas system trains are operating and how the flow is split hetween the trains. If only one train is operating, then the flow split is equal to 1.0 for all of the jumper and manifold segments. If the l'ow is equally split at one of the tee junctions, then the llow split would be 2.0 for all of the segments (including the OGS component segments) following the split. For the input data described here, the flow split is set to 1.0 for all of the jumper and manlfold piping. Following this piping, the tlow is then split equally between two OGS trains. This flow split is reflected in all of the OGS component segments that follow.

Boundary Condition Inputs. The inside surface temperature variation along the length of piping was modeled as a series of constant temperature segments. The surface temperature of each segment was approximated as being constant along the length of each segment, but the temperature was allowed to vary from one segment to another. A priori, the wall temperature distribution was unknown, but was related to the mixed mean off-gas stream temperature and the ambient temperature using the steady flow energy relation. This relation states that the heat transferred to the wall must equal the decrease in lluid enthalpy. Likewise, the heat transferred across the wall must equal the heat lost to the ambient.

Using this steady flow energy relation, the inside wall temperature for cach of these segments was calculated as follows. The heat transfer from the offegas stream to the inside pipe wall was modeled as a combination of forced convection and gray diffuse radiative transfer. The heat transfer coefficient modeled fully developed turbulent tube flow plus a linearized radiative term. The heat transfer across the pipe wall, was modeled as one-dimensional steady heat conduction across a hollow cylinder. Finally, the heat transfer from the outside pipe wall to the ambient modeled a combination of natural convection and gray diffuse radiative heat transfer. The heat transfer coefficient was specified as that for natural convection from a horizontal cylinder plus a linearized radiative term.

The surface temperatures of these pipe sections were obtained with the following assumptions:

- Steady state

- Ambient was at $27^{\circ} \mathrm{C}\left(81^{\circ} \mathrm{F}\right)$.

Also, the geometry used in the calculations assumed the off-gas jumper was approximately $26 \mathrm{~m}$ (86 ft) of 16 -in. Schedule 40 piping. This geometry was based upon preliminary conceptual drawings of the LFT ISV OGS. A revised design description and four train site plan layout presented an alternative off-gas jumper and manifold arrangement (see footnote a). This latest piping geometry was described. The total length for the revised jumper piping was approximately $27 \mathrm{~m}(89 \mathrm{ft})$. The surface temperature calculations were not updated because of schedule and budget limitations. However, differences in the pipe surface temperature and off-gas stream temperature drop along the piping for the revised geometry are not expected to be significant because the piping lengths for the two arrangements are so similar. Table 3 is a summary of the calculated pipe surface temperatures and the off-gas temperature at the segment inlets and exits. 
Table 3. Calculated offegas jumper pipe surfice temperatures.

\begin{tabular}{|c|c|c|c|}
\hline Pipe Segment & $\mathrm{T}_{w}{ }^{\circ} \mathrm{C}$ & $\mathrm{T}_{(1,1)}{ }^{\circ} \mathrm{C}$ & $\mathrm{T}_{\text {')(III) }}{ }^{\circ} \mathrm{C}$ \\
\hline $1.9 \mathrm{~m}$ Vertical & 315 & 448 & 442 \\
\hline Ist Bend & 310 & 442 & 4.32 \\
\hline $15.2 \mathrm{~m}$ Horizontal & 294 & 4.32 & 387 \\
\hline 2nd Bend & 278 & 387 & 379 \\
\hline 3rd Bend & 273 & 379 & 371 \\
\hline
\end{tabular}

\subsubsection{Cooler}

The gas cooler modeled here is designed to cool the olf'-gas streum entering the oll'-gas system. Vapor condensation and aerosol deposition within this cooler is expected to occur, but the magnilude of the deposition will be dependent upon the operating conditions and the purticular ofl'-gets species.

The gas cooler for the INEL ISV LFT OGS has not yet been procured and the actual geometry of the component is not avallable. However, the INEL gas cooler design specilications are similar to those of the gas cooler currently used in the PNL large-scale ISV OGS for which geometry information is available." The notable difference between the two designs is that the PNL cooler is designed for a flow rate of 14,260 ACFM (304() SCFM air dry plus 6.30) SCFM water vapor) at 75()$^{\circ} \mathrm{C}$ inlet temperature. This flow rate capacity is nearly twice that of the INEL design. The difference in llow rate capacities is due to the INEL design splitting the ofl-gas stream to more than one OGS prior to entering the cooler. The PNL system splits the off'-gas stream alter the cooler. In any case, for lack of better intormation, the gas cooler was modeled using the geometry information of the PNL gas cooler.

The PNL gas cooler is a Marlo Coil brand stainless steel cooling eoil with an airtight housing, manufactured by Nuclear Coollng, Inc., High Ridge, Missouri, model number 8W22-36-5608F-1.05. ${ }^{22}$ The cooling coil features plate type lins and staggered tube arrangements. Each tube is supported across its entire length by the lins. The coil has 8 rows of eoils, with 22 tubes per row, and a tube length of $0.9144 \mathrm{~m}(36 \mathrm{in}$.$) . The height of the cooler is 0.9144 \mathrm{~m}(36 \mathrm{in}$.) and the linned width is $0.8477 \mathrm{~m}(33.375 \mathrm{in}$.$) . There are 8$ fin plates per inch width of the eooler and each fin is $2.032 \times 10^{-4}$ $\mathrm{m}(0.008 \mathrm{in}$.) thick. The height and length of the fin plates are 0.9144 and $0.3556 \mathrm{~m}$ (36 and $14 \mathrm{in}$.), respectively. The total number of fin plates is 267 . The cooling coil and fin plate structure is located in an airtight housing $4911 / 16 \mathrm{in}$. long and $44 \mathrm{in}$, high.

h. Private communication dated February 4, 1991, from James M. Scaly, Batlelle Pacilic Northwest Laboratories, Richland, Washington, lo Rudy W. Bonnenberg, EG\&G Idaho, Inc., Idaho Falls, Idaho. 
Geometry Inputs. A summary follows of the important assumplions used in obluining the

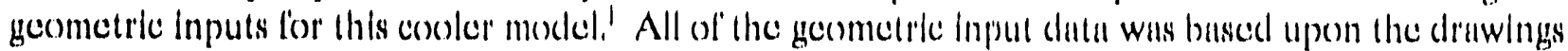
relerred to above, the OCS design specilications noted above, and the geometrie partumeders specilled in the Marlo Coil catalog (sec Reforence 22.) The vapere and neresel transport and depesilton in the cooler was modeled by slmplifylng the problem to the liow botween the parallel lin plates. Neglectling edge effects, this llow approximates through rectungular channels of very large aspect ration. The multiple channels were redued 10 a single channel by specliying the geometrie data for all of the channels eombined. The ecolling lubes Intersecting and porpendicular to the fin plates were neglected. This simplification was made oul of necesslly since the PULSE/MOD.ISV/VER 1,().() code is not capable of modelling the deposition phenomenu associated with such eomplex geometries. However, this simplification is expected to be insignilicent since the lotal surface aren of the lubes is approximately $8 \mathrm{~m}^{2}$ compared $10170 \mathrm{~m}^{2}$ for the lin plates. This simplification is conservative with respect to the total surface area modeled. But, it is unknown at this time whether or not neglecting the phenomenon due to the eomplex lube geometry is a conservative moxleling assumption.

Another assumption in modeling the cooler was to neglect the housing surface. This simplification is justified because the housing surlice is insignificant compared to the fin plate surfaces in cooling the ofl'-gas and in surface area. 'The surface area of the housing is less than $7 \mathrm{~m}^{2}$ compared to uppreximately $170 \mathrm{~m}^{2}$ for the fin plates, By neglecting the housing surfince, the estimate of the total surface urea available for coposition is conservative.

The fin plates were divided into eight segments ulong the length of the plates. All of the segments were modeled with a single subsegment. 'This segmentation was chosen because of the large temperature drop expected along the length of the fin plates. The segmenting of the plates followed the physical layout of the eight ecoling tubes and allowed the fin plate surface temperature distribution to be determined.

Boundary Condition Inputs. The surface temperatures for the cooler were obtained in a manner similar to that for the pipe. By becaking the ecoler into a number of smaller segments, the rapid change in temperature along the lin surfaces of the ecoler eould be calculated to any degree of accuracy. The cooler fins were modeled as standard radial lins with a constant base lemperature. In obtaining these temperatures, the following assumptions were made:

- Uniform llow, steady statc

- $\quad 5() \%$ glyeol solution on the lube side, enters al $91^{\circ} \mathrm{C}\left(196^{\circ} \mathrm{F}\right)$.

As described above, the cooler was divided into eight segments in the direction of llow. The culculated surface temperatures of these segments are tabulated in Table 4.

i. Unpublished calculational work sheet entitled "Munters TS-5/4 Mist Eliminator Geometry Inputs for PUISE/MOD-ISV/VER 1.01,0," hy Daniel Palford, EG\&G Idaho, Inc., Idaho Falls, Iduho, August 27, 1\%)1. 
Table 4. Calculated gas coroler fin plate surfince temperalures.

\begin{tabular}{cccc}
\hline Segment Number & $\mathrm{T}_{\mathrm{w},}{ }^{\circ} \mathrm{C}$ & $\mathrm{T}_{\ln 1}{ }^{\circ} \mathrm{C}$ & $\mathrm{T}^{1}{ }^{\circ}{ }^{\circ}{ }^{\circ} \mathrm{C}$ \\
\hline 1 & 276 & 371 & $3(1) 8$ \\
2 & 23.5 & $30) 8$ & 260 \\
3 & $2(12$ & 260 & 222 \\
4 & 177 & 222 & 192 \\
5 & 158 & 192 & 169 \\
6 & 142 & 169 & 151 \\
7 & 130 & 1.51 & 1.37 \\
8 & 121 & 1.37 & 127 \\
\hline
\end{tabular}

\subsubsection{Quencher}

The preliminary design specifies the quencher as part of the wet serubber system, which eonsists of the quencher, tandem nozzle venturf scrubber, and a mist eliminator. Modeling of the ofl-gas transport through the quencher is required to determine the flow eonditions at the inlet to the tandem nozale scrubber. The vapor and aerosol transport and deposition through the quencher will depend upon the operating conditions and the llow conditions. If the water vapor in the olf'-gas enters the quencher saturated, condensation may occur and the injected scrubbing water droplets may grow larger. If the flow condition is subsaturated, then the injected droplets may evaporate before leaving the quencher.

The guencher for the INEL ISV LFT OGS has not yet been procured and the actual geometry of the component is not available. However, the INEL quencher design specifications are similar to those of the quencher currently used in the PNL large-scale ISV OGS. Geometry information is available for the PNL component. Therefore, for lack of better information, the quencher was modeled with the geometry information of the PNL component.

The PNL quencher is part of the Hydrosonic System Model-150) TN-VS Type wet serubber system manulactured by Hydro-Sonic Systems, Inc., Lone Star, Texas. The quencher is a vertical circular chamber with liguld water sprayed and mixed with the ofl'-gas flow at the top of the chamber. The ofl'-gas enters horizontally at the bottom, turns upward $\mathscr{N}$ () degrees, flows vertically through the body of the chamber, and then makes another $9($ )-degree turn 10 exit horizontally at the lop of the chamber. Most of the injected water droplets lall by gravity and collect in a drain at the bottom of the quencher. Some of the injected droplets may evaporate or be small enough to stay aloft and leave the quencher along with the off'-gas. Cooling of the off-gas is achieved by direct contact with the water spray. The height of the guencher, including the conical bottom and drain, is $1.83 \mathrm{~m}$ (72 in.) and the outside diameter is $0.71 \mathrm{~m}(28 \mathrm{in}$.) The height of the quencher body without the conical bollom and drain is $1.55 \mathrm{~m}$ (61 in.) 
Geometry Inputs. A summary follows of the important assumptions used in obtaining the geometric inputs for this quencher model. All of the geometric input data is based upon the drawing referred to above. The vapor and acresol transport and deposition in the quencher is modeled by simplifying the problem to the llow through a vertical circular shannel with a horizontal inlet at the bottom and a horizontal exit at the lop.

In modeling the quencher, the complex counter-current liow and entrance and exit geometrics were simplified as follows. The counter-current flow of the injected water spray and the off-gas was simplified by injecting the spray at the bottom of the chamber instead of the top. This simplification was valid because homogeneous mixing with the off-gas stream oceurs allowing the cooling effect to be determined. Furthermore, the change in water droplet sizes due to the mixing and condensation/evaporation processes is accounted for and those small enough to remain suspended are carried away with the offegas. The remaining larger droplets fall to the bottom surface by gravitational deposition.

The entrance and exit regions geometries consist of a horizontal circular piping intersecting the vertical circular chamber. To approximate the depesition due to the average tlow turning 90 degrees in these regions, the llow through the entrance and exit segments were simplified as that passing through a 90 degree elbow bend.

Three segments were utilized in modeling the quencher geometry. The segmenting was based solely on geometry considerations and consisted of the entrance in which the flow turns 90 degrees, the straight vertical chamber body, and the exit in which the llow makes another 9 ()-degree turn. 'The entrance and exit segments were not subsegmented. The main body of the (quencher was divided into five subsegments to allow the code 10 adequately calculate the phenomenon associated with the mixing of the off-gas and injected scrubbing liquid. The scrubbing liquid is injected in the first subsegment of the quencher body.

Boundary Condition Inputs. For simplicity the inside surface temperature of the quencher was not determined. Rather, an adiabatic boundary condition is used and the heat loss from the quencher to the ambient is neglected. This simplification is valid for the typical conditions described below.

Based upon the design specifications, the off ngas stream temperature at inlet to the quencher is approximately 30()$^{\circ} \mathrm{C}\left(572^{\circ} \mathrm{F}\right)$. The of 'l-gas temperature at the exit of the quencher is not stated, but the temperature at the outlet of the mist eliminator following the tandem nozzle scrubber is approximately 6()$\left.^{\circ} \mathrm{C}(14)^{\circ} \mathrm{F}\right)$. Sinec the off degrees in the landem nozzle scrubber and mist eliminator, the mist eliminator outlet temperature is approximately the quencher outlet temperature. Therefore, the ofl'-gas stream temperature is expected to decrease approximately $241^{\circ} \mathrm{C}\left(432^{\circ} \mathrm{F}\right)$ in the quencher. This drop in the gas temperature is due to approximately $240 \mathrm{~kW}$ of energy being transferred from the gas to the injected water. Assuming the water vapor enters the quencher at subsaturated conditions, most of the heat exchange

j. Unpublished ealculational work sheet entitled "ISV OGS Quencher Geometry Inputs for PULSE/MOD-ISV/VER 1.(1.(1," by Vu Tung, EG\&G Idaho, Inc, Idaho Falls, Idaho, August 26, 1991. 
is due to the latent heat of evaporation of the injected water. For example, a water evaporation rate of only $0.1 \mathrm{~kg} / \mathrm{s}$ would require $240 \mathrm{~kW}$.

Since most of the energy luss from the off-gas was assumed to be transfierred to the injected water, the heat transfer from the off-gas through the quencher housing to the ambient environment of the OGS trailer was expected to be small. To confirm this assumption, the off-gas temperature drop due to heat transfer to the ambient was calcuiated.

Neglecting the injected water spray, the off-gas flow through the quencher was modeled as that through a vertical pipe, the temperature drop through the quencher was determined in a manner similar to that done for the off-gas jumper piping described above. For these conditions, an off-gas temperature drop of approximately $4^{\circ} \mathrm{C}\left(8^{\circ} \mathrm{F}\right)$ was calculated assuming the cylinder length is $1.8 \mathrm{~m}$ $(6 \mathrm{ft})$, is made from $28 \mathrm{in}$. Schedule 10 stainless steel piping, the off gas enters at $300^{\circ} \mathrm{C}\left(572^{\circ} \mathrm{F}\right)$, the ambient temperature in the trailer is $27^{\circ} \mathrm{C}\left(80^{\circ} \mathrm{F}\right)$, and a mass flow rate of $1 \mathrm{~kg} / \mathrm{s}$ of air flows through the quencher. This off-gas temperature drop corresponds to a heat loss of less than $5 \mathrm{~kW}$ from the off-gas stream to the ambient air. This estimated temperature drop and heat loss to the ambient is small compared with the approximately $240^{\circ} \mathrm{C}\left(432^{\circ} \mathrm{F}\right)$ drop in off-gas temperature and approximately $240 \mathrm{~kW}$ of heat transferred from the off-gas to the water spray by latent heat transfer. Therefore, the adiabatic boundary condition for the quencher housing is a good approximation.

Injected Water Initial Conditions. The injected liquid water enters the quencher in the first subsegment of the quencher body and was assumed to be homogeneously mixed with the off-gas. The water enters at a flow rate of $0.93 \mathrm{~kg} / \mathrm{s}(14.7 \mathrm{gpm})$. An inlet aerosol size of $200 \mu \mathrm{m}$ was assumed for lack of better information. The temperature of the injected water was specified as $52^{\circ} \mathrm{C}\left(126^{\circ} \mathrm{F}\right)$.

\subsubsection{Tandem Nozzle Scrubber}

The venturi scrubber is part of the wet scrubber system. Modeling of the off-gas transport through the venturi scrubber is important beca use of the significant amount of aerosol agglomeration and deposition expected to occur. Similar to the quencher, the vapor and aerosol transport and deposition through the venturi scrubber depends upon the operating conditions and the flow conditions. If the water vapor in the off-gas enters the venturi scrubber saturated, the injected water droplets will grow larger due to condensation and agglomeration. If the water vapor is subsaturated, then the injected droplets may evaporate before agglomerating with other aerosols in the off-gas stream. It is expected that the water vapor entering the venturi scrubber will be saturated; other species with high vapor pressures, such as miercury, may be subsaturated.

The tandem nozzle scrubber for the INEL ISV LFT OGS has not yet been procured and the actual geometry of the component is not available. However, the INEL tandem nozzle scrubber design specifications are similar to those of the component currently used in the PNL large-scale ISV OGS. Geometry information is available for the PNL component. Therefore, for lack of better information, the tandem nozzle scrubber modeled here was based upon the geometry information of the PNL component.

The PNL tandem nozzle scrubber is part of the Hydrosonic System Model-150) TN-VS Type wet scrubber system manufactured by Hydro-Sonic Systems, Inc., Lone Star, Texas. The tandem 
nozzle scrubber consists of two identical sub-systems connected in series by a diffuser section. Each sub-system consists of a nozzle located inside a chamber followed by a straight section of pipe. Liquid water is injected into the nozzle chamber through a ring around the nozzle exit. The off-gas enters the nozzle chamber through the subsonic nozzle which serves to increase the gas velocity. This gas flow, in turn, breaks up the injected water into a fine mist which agglomerates with existing aerosols in the off-gas flow. Agglomeration takes place in the straight mixing tube following the nozzle chamber yielding larger aerosols. The larger aerosols are then removed by the various deposition mechanisms. The length of the tandem nozzle scrubber is $3.68 \mathrm{~m}$ (144.75 in.). The outside diameter of the nozzle chambers and mixing tubes are $0.41 \mathrm{~m}(16 \mathrm{in}$.$) and 0.20 \mathrm{~m}(8 \mathrm{in}$.$) , respectively.$

Geometry Inputs. A summary follows of the important assumptions used in obtaining the geometric inputs for this model. ${ }^{k}$ All of the geometric input data were based upon the drawing referred to above. The vapor and acrosol transport and deposition in the venturi scrubber was modeled by simplifying the problem to the flow through a series of horizontal straight circular channels with liquid water injected as droplets at the entrance of the two nozzle chambers.

A total of nine segments were utilized in modeling the tandem nozzle scrubber geometry. The segmenting was based solely on geometry considerations. The geometry and segmenting of the two sub-systems were identical. Each sub-system consisted of three segments: the nozzle chamber, the reducer joining the chamber and the agglomeration tube, and the mixing tube. The diffuser section which joins the two nozzle sub-systems was modeled with three segments. The nozzle geometry within the nozzle chamber was not modeled since the agglomeration is assumed to occur predominantly in the mixing tube. As stated above, the purpose of the nozzle is simply to increase the off-gas velocity so as to break the injected liquid into a fine mist. The mechanisms by which the off-gas flow breaks up the injected liquid into a fine mist are not modeled by the PULSE/MOD-ISV/VER 1.0.0 code. In modeling the injected water, the droplet size after break up must be input to the code as part of the injected water flow conditions. The injected water flow conditions are described later in this section.

The nozzle chamber and mixing tube segments were subsegmented into 5 and 10 subsegments, respectively. This subsegmenting was done because of the phenomenon expected to occur upon mixing the off-gas with the injected water. This water is injected in the first subsegment in each of the two nozzle chambers.

Boundary Condition Inputs. Like the quencher described above, the inside surface temperatures of the tandem nozzle scrubber segments were not determined. The off-gas temperature is not expected to drop more than a few degrees in the tandem nozzle scrubber. Therefore, an adiabatic boundary condition is used and the heat loss from the scrubber to the ambient is neglected under typical conditions.

Injected Water Initial Conditions. The injected liquid water enters the tandem nozzle scrubber in the first subsegment in each of the two nozzle chambers and is assumed to be homogeneously

k. Unpublished calculational work sheet entitled "ISV OGS Scrubber Geometry Inputs for PULSE/MOD-ISV/VER 1.0.0," by Vu Tung, EG\&G Idaho, Inc., Idaho Falls, Idaho, August 26, 1991. 
mixed with the off-gas. The water enters at a flow rate of $0.9 \mathrm{~kg} / \mathrm{s}(14.3 \mathrm{gpm})$ in each of the nozzle chambers. An inlet acrosol size of $20 \mu \mathrm{m}$ was assumed for lack of beller information. The temperature of the injected water was specified as $52^{\circ} \mathrm{C}\left(126^{\circ} \mathrm{F}\right)$.

\subsubsection{First Mist Eliminator}

The OGS design specifies that there will be two mist eliminators. One is part of the wet scrubber system and is located after the tandem nozzle venturi scrubber. The second is located after the condenser. The design specifications for the two mist eliminators are identical. Modeling of the off-gas transport through the mist eliminators is important because of the significant amount of deposition expected to occur. Similar to the quencher and venturi scrubber, the vapor and aerosol transport and deposition through the mist eliminator depends upon the operating conditions and the flow conditions. The most important flow parameters affecting the mist eliminator performance are the aerosol diameter and the off-gas flow velocity.

The mist eliminator for the INEL ISV LFT OGS has not yet been procured and the actual geometry of the component is not available. However, the INEL mist eliminator design specifications are similar to those of the mist eliminator currently used in the PNL large-scale system for which geometry information is available. A notable difference between the two designs is that the PNL system uses two different sized mist eliminators. The first mist eliminator of the PNL system is designed for a nominal gas flow rate of 1520 SCFM dry air dry plus 315 SCFM water vapor at $300^{\circ} \mathrm{C}$ $\left(572^{\circ} \mathrm{F}\right)$ inlet temperature. The second mist eliminator in designed for a nominal gas flow rate twice that of the first. In the INEL system, the flow rate capacity of the two mist eliminators is the same and equal to that of the first mist eliminator of the PNL system. The geometry information currently available is for the second PNL mist eliminator and is, therefore, oversized in modeling the INEL OGS mist eliminators. The use of this geometrical model with the nominal flow rate specified in the INEL design specifications will predict removal rates that are less than the specified removal requirements. The larger flow capacity of this geometry results in a reduced velocity between the separator plate surfaces, and the aerosol removal rate is approximately proportional to the flow velocity. In any case, for lack of better information, the mist eliminator modeled here will be based upon the geometry information of the second PNL mist eliminator.

The mist eliminator modeled here is a Munters TS-5/4 mist eliminator manufactured by the Munters Corporation, Fort Myers, Florida, 33911. This mist eliminator is an impingement separator. ${ }^{23}$ It is composed of corrugated profiles plates, mounted on a frame, and enclosed in a housing structure. Each profile plate has four phase separating chambers, which are simply a 90-degree bend with a liquid film trap attached to the convex side of the bend.

The impingement separation works as follows. The profiles split the gas flow into several parallel streams. The corrugated profiles turn the gas streams, but the heavier aerosols cannot turn as quickly as the lighter gas. Therefore, inertia forces the acrosols against the wall where the drops are transformed into a liquid film. This film is pushed along until reaching the traps, where the film is drained by gravity in this area of low gas velocity. In general, the separation efficiency depends upon the size and concentration of the drops to be removed and on the velocity and density of the gas. 
Geometry Inputs. A summary follows of the important assumptions used in obtaining the geometric inputs for this model. The vapor and aerosol transport and deposition in the mist eliminator was modeled by simplifying the problem to horizontal flow through a series of straight rectangular channels alternating with 90-degree curved rectangular channels. The multiple channels were modeled by specifying the total flow passes through one channel with geometric data equivalent to all the channels combined.

The geometric data for the vane mist eliminator was based upon the schematic diagram referred to above. The vane plates' height, profile length, offset distance, spacing, and thickness are specified as $0.521 \mathrm{~m}, 0.254 \mathrm{~m}, 12.8 \mathrm{~mm}, 20 \mathrm{~mm}$, and $1.4 \mathrm{~mm}$ (20.5 in., 10.0 in., 0.5 in., $0.787 \mathrm{in}$., and $0.054 \mathrm{in}$.), respectively. However, not all of the geometric specifications are available from the drawing because some are proprietary. For example, the lengths of the straight segments and curved segments of the vane plates were unspecified. Therefore, the leading and trailing edge were assumed to be of equal lengths, $0.0328 \mathrm{~m}(1.29 \mathrm{in}$.). The interior straight section lengths was assumed to be $0.0477 \mathrm{~m}$ (1.88 in.) and the length of the curved sections was assumed to be $0.0295 \mathrm{~m}$ (1.16 in.). Although these lengths are assumed values, the centrifugal deposition model for bends in PULSE/MOD-ISV does not depend upon the length or curvature radius of the bend sections but rather on the total angle through which the bend curves. Therefore, the assumed values will not affect the absolute mass of material deposited on the bend surfaces, but will affect the deposited mass per unit area for these surfaces.

In modeling the mist eliminator, the number of segments chosen was nine. The nine segments consist of a leading straight section, four curved sections, three straight sections, and a trailing or exit straight section. The four curved segments alternate with the five straight segments. The straight and curved sections of the vane surfaces were segmented separately to allow for simple and accurate geometric specifications. The effective cross-sectional area of the curved segments was not specified the same as for the straight segments because the film trap located on the convex side of the curve effectively reduces the channel width in the curved segment. One effect of this reduced channel width is to increase the off-gas flow velocity through the bend segments which increases the amount of aerosols removed by the bends. The radial displaceme : of aerosols in the off-gas flow is directly proportional to the gas velocity. Increased gas velocity increases the radial displacement of aerosols which increases the amount of aerosols removed by the bend. The distance that the film trap protrudes into the flow channel is not specified in the drawings. Therefore, an assumed value of half the channel width or $6.4 \mathrm{~mm}$ was used.

Finally, in modeling this component, the housing surface was neglected and only the vane separator plate surfaces were modeled. Although the surface areas are comparable (approximately $2 \mathrm{~m}^{2}$ for the housing and $6 \mathrm{~m}^{2}$ for the total surface area of the separator plates), the simplification is justified on the basis that the amount of deposition on the housing surfaces is expected to be significantly less than on the vane separator plates because of the highly effective design of the plates at removing suspended aerosols from the off-gas stream.

1. Unpublished calculational work sheet entitled "Munters TS-5/4 Mist Eliminator Geometry Inputs for PULSE/MOD-ISV/VER 1.0.0," by Daniel J. Pafford, EG\&G Idaho, Inc., Idaho Falls, Idaho, August 27, 1991. 
Boundary Condition Inputs. As presented in the geometry input description above, the housing surfaces were neglected and only the interior vane separator plates were considered. The heat transfer to or from these interior plates is expected to be negligible because they are isolated from the ambient conditions and are only in contact with the off-gas stream. The off-gas temperature remains constant through the mist eliminator. Therefore, the appropriate thermal boundary condition for these plates is an adiabatic boundary condition.

\subsubsection{Condenser}

The condenser component was not modeled because sufficient geometric information was not obtained on either the conceptual INEL system component or the PNL large-scale system component. The INEL conceptual design description states that the condenser will be a tube and shell single pass, counter current llow condenser with the off-gas flow on the tube side, and the cooling liquid on the shell side. Based upon this description, geometrical modeling and determination of the internal surface temperatures or heat flux of the condenser should be straight forward once the specific internal geometry is available.

\subsubsection{Second Mist Eliminator}

The mist eliminator following the condenser has the same design specifications as the first mist eliminator and is modeled identically here. Note again that this model is based upon the PNL system mist eliminator which has nearly twice the flow capacity of the INEL mist eliminator. Use of this geometrical model with nominal flow rate specified in the INEL design specifications will predict removal rates that are less than the specified removal requirements.

\subsubsection{Reheater}

The reheater component of the OGS is designed to heat the off-gas to prevent moisture condensation in the HEPA filters that follow. Vapor condensation and aerosol deposition within the reheater is expected to be relatively small compared to other OGS components such as the tandem nozzle scrubber or the mist eliminator. However, depending upon the off-gas temperature and the species considered, some deposition will occur. Furthermore, modeling of the reheater is required to determine the vapor and aerosol flow rates that exit the reheater and enter the HEPA filters.

The geometry information for the INEL ISV LFT OGS reheater is not available. However, the INEL reheater design specifications are similar to those of the reheater currently used in the PNL large-scale ISV OGS for which limited geometry information is available. Therefore, the reheater geometric specifications were based upon information obtained for the PNL large-scale system component. It should be noted that the scale of the PNL component is larger than the INEL's. The PNL design specifies a maximum flow rate of 3,670 SCFM including moisture; the INEL LFT OGS design specifies a maximum flow rate of 2,000 SCFM including moisture. Because the scale of the PNL and INEL OGS are different, the reheater specifications differ slightly between the two designs. For example, the PNL reheater design specifies that the heater be rated at $170 \mathrm{~kW}$ and be able to provide a controlled temperature rise of 25 to $50^{\circ} \mathrm{C}\left(77\right.$ to $\left.122^{\circ} \mathrm{F}\right)$. The INEL design specifies that the heater will be rated at $100 \mathrm{~kW}$, and be able 10 provide a controlled temperature 
rise of 7 to $32^{\circ} \mathrm{C}\left(45\right.$ to $\left.90^{\circ} \mathrm{F}\right)$ under specified flow conditions. However, for lack of better information, the geometric specilications for the PNL component will be used here.

The reheater modeled was an air circulation heater, model number HP35-3071-()), manufactured by Heatcon Inc., 2733 Fourth Avenue South, Seattle, Washington 98134. It is expected that the heater internal consists of a large number of heating elements (the drawing specilies 108.) However, the shape and dimensions of the elements are not specified. Furthermore, because of time limitations and the inability to contact Heatcon, Inc., this information was not pursued further. Therefore, the reheater internals were neglected in modeling the geometry. This simplification was made because of lack of information. The significance of this simplification depends upon the importance of aerosol deposition onto the reheater internal surfaces. Assuming the deposition within the reheater is very small compared to that occurring in other OGS components, then even large inaccuracies in the reheater deposition model will have a small effect on the overall model predictions.

Geometry Inputs. A summary follows of the important assumptions used in obtaining the geometric inputs for this model. ${ }^{\mathrm{m}}$ The geometric data for the reheater housing is based upon the schematic diagram referred to above. The reheater housing is made from $20 \mathrm{in}$., Schedule 40 stainless steel circular pipe. Ignoring the entrance and exit flanges, the reheater was modeled with two circular channel segments. The two segments consist of a straight horizontal entrance segment and an exit segment in which the flow turns horizontally 90 degrees. The total internal length of the component was approximately $2.245 \mathrm{~m}(883 / 8 \mathrm{in}$.).

Boundary Condition Inputs. The reheater was modeled with a constant wall heat flux condition. The reheater power input is yet to be specified in the ISV OGS design. However, the design specified $7^{\circ} \mathrm{C}\left(45^{\circ} \mathrm{F}\right)$ temperature rise under the maximum flow rate requires a power input of approximately $35 \mathrm{~kW}$. The surface heat flux from the heater to the gas packet is simply the ratio of this power input to the heater element surface area. However, as the geometry of the heating elements has not been specified, as an approximation, the surface area of the housing was used instead. Even though this will overestimate the housing surface temperature, the increase in gas temperature depends only on the total power input and will be predicted correctly.

\subsubsection{Piping Connecting the Reheater with the HEPA Filters}

The piping which connects the reheater and the HEPA filters is contained within the OGS trailer. This piping was included in this OGS model because the three bends in this section of piping may act as acrosol traps. However, compared with other OGS components such as the tandem nozzle scrubber or the mist eliminator, the vapor condensation and aerosol deposition within this piping is expected to be relatively small. The layout of this piping is shown in Figure 3.

m. Unpublished calculational work sheet entitled "ISV OGS Reheater Geometry Inputs for PULSE/MOD-ISV/VER 1.0.(0)" by Danicl J. Pafford, EG\&G Idaho, Inc., Idaho Falls, Idaho, September 27, 1991. 
Geometry Inputs. A summary follows of the important assumptions used in obtaining the geometric inputs for this piping model." The geometric data for the piping was based upon the design specifications and the configuration depicted in Figure 3. However, neither source of information provides the lengths of the pipe sections nor the angle of tilt of the piping depicted in the diagram. Therefore, this information was assumed. As more information becomes available, this piping model can be updated as needed.

The piping connecting the reheater with the first stage HEPA filter was modeled as 12 -in. Schedule 10S 304-L stainless steel pipe. Seven segments were chosen. The first segment of piping consisted of a one-foot straight horizontal section exiting the rehcater. This was followed by a 90-degree elbow bend, a horizontal four-foot straight section, another 9)-degree elbow bend, a vertical four-foot straight section, a 90 -degree elbow bend, and finally, a horizontal six-foot straight section that entered the first stage HEPA filter. In determining the lengths of the elbow bends, a bend radius of $0.5 \mathrm{~m}$ at the pipe center line was assumed. This bend radius was chosen for lack of better information. The total length of this piping has an assumed length of approximately $6.9 \mathrm{~m}$ $(22.7 \mathrm{ft})$.

Boundary Condition Inputs. As stated above in the geometry input description, this pipe section was divided into seven segments for geometrical modeling considerations. However, in determining the boundary conditions for this section of pipe, the inside surface temperature is expected to be nearly constant and the temperature drop of the off-gas through this piping is expected to be negligible. For example, an off-gas temperature drop of approximately $2.5^{\circ} \mathrm{C}\left(4.6^{\circ} \mathrm{F}\right)$ occurs assuming the piping is horizontal, that the gas is air and enters the piping at a mass flow rate of $1 \mathrm{~kg} / \mathrm{s}$ and a temperature of $77^{\circ} \mathrm{C}\left(170^{\circ} \mathrm{F}\right)$, and the ambient air temperature is $27^{\circ} \mathrm{C}\left(80^{\circ} \mathrm{F}\right)$. Since the surface temperature of this pipe remains nearly constant, all of the pipe segments were modeled with a constant surface temperature of $65^{\circ} \mathrm{C}\left(149^{\circ} \mathrm{F}\right)$.

\subsubsection{HEPA Filters}

The HEPA filter components of the OGS are designed to provide the final filtering of the off-gas stream. Significant aerosol deposition within the filters is expected. Vapor condensation is expected to be small. However, depending upon the off-gas temperature and the species considered, some condensation within the filters can occur. This section presents both the geometry inputs for the HEPA filter housings and the filter efficiency characteristic inputs. The PULSE/MOD-ISV/VER 1.0.0 code does not determine the filtering capabilities of the HEPA filters by first principles. Rather, the filtering capability was modeled by simply specifying the design efficiency.

The preliminary INEL design description specifies that two first-stage HEPA filters are connected in parallel and located in the ISV process trailer. The second stage filter will be connected in series with the two first-stage filters and are located in the support trailer. Piping used to connect

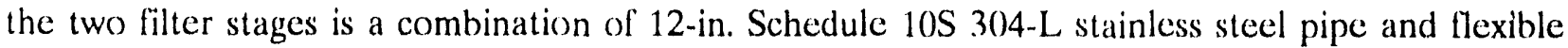

n. Unpublished calculational work sheet entitled "ISV OGS Piping Geometry Inputs for PULSE/MOD-ISV/VER 1.0.0," by Daniel J. Pafford, EG\&G Idaho, Inc., Idaho Falls, Idaho, October 1, 1991. 
stainless steel jumpers. The filter housings contain two 24 in. $x 24$ in. $x 12$ in. filters. Each filter is 99.97\% efficient for aerosols $0.3 \mu \mathrm{m}$ and larger.

Goometry Inputs. A summary follows of the important assumptions used in obtaining the geometric inputs for this HEPA filter model. ${ }^{\circ}$ Conceptual drawings of the first- and second-stage filter housings are presented in Figure 3 and Figure 4. However, these drawings do not give the geometrical specifications. Therefore, the housing geometry was based upon the specified filter sizes. The first- and second-stage filter housings are identical in design and were modeled as rectangular channels, 24 in. high, 48 in. wide, and 12 in. in length. The tapered inlet and exit were neglected. The pipe connecting the first and second stage filters was assumed to be $15 \mathrm{ft}$ in length, straight, and oriented horizontally.

In modeling the first stage filters, only one of the two parallel filters will be in operation at any one time. Therefore, only one of the two first stage filters was included in this model. The number of segments chosen for the first stage HEPA filter was one, the pipe connecting the two filter stages was segmented into a single segment, and the second stage filter was also modeled as a single segment.

The filter efficiency data was based upon the specified design. The first and second stage filters are identical in design and are each $99.97 \%$ efficient for aerosols 0.3 and larger. The filter efficiency model assumes that this efficiency remains constant with time and is independent of all other parameters including the filter loading, gas flow rate, and temperature.

Using the filter model, the HEPA filter efficiency was approximated such that the mass fraction that passes through the filter was 1.0 for all aerosol size classes less than $0.3 \mu \mathrm{m}$ and $3.0 \times 10^{-4}$ for all size classes greater or equal to $0.3 \mu \mathrm{m}$. For the conceptual model developed here, the aerosol bin size distribution ranges from $2.0 \times 10^{-3} \mu \mathrm{m}$ to $2.0 \times 10^{3} \mu \mathrm{m}$ and is listed below:

Aerosol bin

1

Acrosol diameter

\begin{tabular}{c}
$\mu \mathrm{m}$ \\
\hline $2.00 \times 10^{-3}$ \\
$4.31 \times 10^{-3}$ \\
$9.28 \times 10^{-3}$ \\
$2.00 \times 10^{-2}$ \\
$4.31 \times 10^{-2}$ \\
$9.28 \times 10^{-2}$ \\
$2.00 \times 10^{-1}$ \\
$4.31 \times 10^{-1}$ \\
$9.28 \times 10^{-1}$ \\
$2.00 \times 10^{0}$
\end{tabular}

o. Unpublished calculational work sheet entitled "ISV OGS First and Second Stage HEPA Filter Geometry and Characteristic Inputs for PULSE/MOD-ISV/VER 1.0.(), by Daniel J. Pafford, EG\&G Idaho, Inc., Idaho Falls, Idaho, September 30, 1991. 


$\begin{array}{ll}11 & 4.31 \times 10^{0} \\ 12 & 9.28 \times 10^{0} \\ 13 & 2.00 \times 10^{1} \\ 14 & 4.31 \times 10^{1} \\ 15 & 9.28 \times 10^{1} \\ 16 & 2.00 \times 10^{2} \\ 17 & 4.31 \times 10^{2} \\ 18 & 9.28 \times 10^{2} \\ 19 & 2.00 \times 10^{3}\end{array}$

Note that the $0.3 \mu \mathrm{m}$ aerosol size limit is between the seventh and eighth bin sizes. Therefore, for these discrete bin sizes, the mass fraction that passes through the filter was specified as 1.0 for bin sizes one through seven and was specified as $3.0 \times 10^{-4}$ for bin sizes eight through nineteen.

Boundary Condition Inputs. An adiabatic boundary condition was used for both the first and second stage HEPA filters since the off-gas temperature drop through the filters is expected to be negligible.

The piping connecting the first and second stage filters passes from the OGS trailer to the support trailer and is exposed to the ambient air over much of its length. For simplicity, the actual wall temperature was not calculated for this pipe section. Rather, an adiabatic boundary condition was used since the temperature drop along this section of pipe is expected to be negligible under typical conditions. For example, an off-gas temperature drop of approximately $1.7^{\circ} \mathrm{C}\left(3^{\circ} \mathrm{F}\right)$ occurs assuming the pipe length is $4.6 \mathrm{~m}(15 \mathrm{ft})$ and the temperature difference between the off-gas stream and the ambient air is approximately $50^{\circ} \mathrm{C}\left(120^{\circ} \mathrm{F}\right)$.

\subsubsection{Blower}

The driving force of the off-gas flow through the OGS is a blower. Vapor condensation and aerosol deposition within the blower is expected to be relatively small compared to other OGS components such as the tandem nozzle scrubber or the mist eliminator. However, depending upon the off-gas temperature and the species considered, some deposition will occur. Therefore, for completeness, the blower component was included in the OGS vapor and aerosol transport model.

The design specifications present an envelope drawing of the blower system. However, detailed geometric specifications of the blower are not currently available. Specifically, the geometry of the blower internal blades and surfaces are unknown. However, even if the blower internal geometrical information were available, it is not expected that the PULSE/MOD-ISV/VER 1.0.0 computer code would be able to model the vapor and aerosol transport for such complex geometry. Therefore, only the blower housing was modeled. 
Geometry Inputs. A summary follows of the important assumptions used in obtaining the geometric inputs for this model.p The geometric specifications for the housing were based upon the envelope drawing of the blower system. The vapor and aerosol transport and deposition in the blower housing was simplified as flow through a horizontal circular channel approximately $0.9144 \mathrm{~m}$ $(3 \mathrm{ft})$ in diameter and $0.6096 \mathrm{~m}(2 \mathrm{ft})$ in length. The entrance and exit flanges were neglected in this model. The housing was modeled with a single segment.

Boundary Condition Inputs. Heating of the off-gas stream by the blower may occur due to the high operating temperature of the electric motor. Additionally, heat transfer from the blower housing to the cooler ambient may occur. However, sufficient information concerning the heat load of the electric motor and the geometry of the blower is not currently available. Therefore, as a simplification, the blower housing was assumed to be an adiabatic surface.

\subsubsection{Stack}

The exhaust stack is designed to interface with the blower outlet and extend high enough in prevent interference with the HVAC systems of the OGS trailers. Vapor condensation and aerosol deposition within the stack is expected to be relatively small compared to other OGS components such as the tandem nozzle scrubber or the mist eliminator. However, for completeness, the exhaust stack has been included in the OGS vapor and aerosol transport model.

Geometry Inputs. The design description specifies that the exhaust stack extends approximately six feet above the top of the support trailer. A conceptual drawing of the support trailer including the blower and exhaust stack is presented in Figure 4. The geometric data for the exhaust was based upon the design specifications and the conceptual drawing. As shown in Figure 4 drawing, the exhaust stack has a 9() -degree bend at the exit. The length of the straight section of the stack was assumed to be $3.048 \mathrm{~m}(10 \mathrm{ft}) .{ }^{9}$ The 90 -degree bend at the stack exit was assumed to have a bend radius of $0.5 \mathrm{~m}$ (at the pipe center line). The total length of the stack is approximately 3.83 .3 $\mathrm{m}(12.6 \mathrm{ft})$.

Boundary Condition Inputs. The heat transfer from the stack to the environment depends on the ambient temperature within the trailer and with the ambient air outside. However, for simplicity, the surface temperature of the stack was not calculated. Rather, an adiabatic boundary condition was used since the temperature drop along the stack was expected to be negligible under typical conditions. For example, an off-gas temperature drop of approximately $2.4^{\circ} \mathrm{C}\left(4^{\circ} \mathrm{F}\right)$ occurs assuming the stack length is approximately $3.8 \mathrm{~m}(12.5 \mathrm{ft})$, the temperature difference between the off-gas stream and the ambient air is approximately $80^{\circ} \mathrm{C}\left(176^{\circ} \mathrm{F}\right)$, and a mass flow rate of $1 \mathrm{~kg} / \mathrm{s} \mathrm{of}$ air passes through the stack.

p. Unpublished calculational work sheet entitled "ISV OGS Blower Geometry Inputs for PULSE/MOD-ISV/VER 1.0.()," by Danicl J. Pafford, EG\&G Idaho, Inc., Idaho Falls, Idaho, September 27, 1991.

q. Unpublished calculational work sheet entitled "ISV OGS Exhaust Stack Geometry Inputs for PULSE/MOD-ISVNER 1.0.0," by Daniel J. Pafford, EG\&G Idaho, Inc., Idaho Falls, Idaho, September 27, 1991. 


\subsection{Off-Gas Inlet Flow Description}

This section presents a conceptual model of the flow conditions of the ofl'-gas entering the ISV OGS after mixing and reacting with the air inlet to the hood.

The off-gas stream entering the OGS is composed of a variety of compounds and species. The off-gas entering the hood originates from gases released from the melt elther by decomposition of materials, boiling of volatile compounds, or simple outgasing. Also, the ofli-gas will contain particulate matter carried by the evolved gases to the melt surface. These evolved gases and particulate matter collect above the melt zone within the confinement of the hood where they are mixed with fresh air inlet to the hood. Combustible gases mixed with the inlet air will burn within the combustion area of the hood. The off-gas that exits the hood and enters the OGS is composed of these evolved gases, the products of combustion, and aerosols.

The PULSE/MOD-ISV/VER 1.0.0 code can model up to 20 condensible species and 10) non-condensible species. For the conceptual model developed here, the off-gas consisted of 11 condensible species and three non-condensible species. Table 5 lists the species and mass flow rates used.' The temperature of the off-gas after mixing and reacting with the inlet air was calculated to be $854^{\circ} \mathrm{C}\left(1570^{\circ} \mathrm{F}\right) 8^{8}$ This temperature was used as the off-gas temperature at the entrance to the hood. The physical state of the condensible species at the hood entrance was based upon the equilibrium vapor concentration (EVC) at the inlet conditions. Three cases were possible: all vapor, a combination of vapor and aerosol, and all aerosol. For entering mass flow rates less than or equal to the rate necessary to maintain the EVC, then the species was input as all vapor. If the mass flow rate was greater than what was necessary to maintain the EVC, then the species was input as a combination of vapor and aerosol. For this latter case, the fraction entering as vapor was equal to that amount necessary to maintain the EVC and the balance was input as aerosol. For some of the species, the EVC was suffi iently small that all of the mass was entered as aerosol. For an inlet temperature of $854^{\circ} \mathrm{C}, \mathrm{Hg}, \mathrm{CsOH}$, and $\mathrm{H}_{2} \mathrm{O}$ were input as all vapor; $\mathrm{KCl}, \mathrm{KOH}, \mathrm{NaCl}, \mathrm{NaOH}$, and $\mathrm{Pb}$, were input as a combination of vapor and aerosol; and $\mathrm{Be}, \mathrm{PuO}_{2}$, and $\mathrm{UO}_{2}$ were input as all aerosols. Table 6 presents the entering vapor and aerosol mass fractions and flow rates for an inlet temperature of $854^{\circ} \mathrm{C}$. For those species input as aerosol, the aerosol size distribution at the inlet to the hood must be specified. However, this information was not available. Therefore, sensitivity calculations were made with three values of inlet aerosol diameters: $0.2,2.0$ and $9.3 \mu \mathrm{m}$.

r. Unpublished calculation work sheet entitled "Illustrative Vapor and Acrosol Source Rate Inputs for PULSE/MOD-ISV/VER 1.0.0," by Daniel J. Pafford, EG\&G Idaho, Inc., Idaho Falls, Idaho, October 5, 1991.

s. Unpublished calculation work sheet entitled "Boundary Conditions For Off-Gas Treatment System," by V. X. Tung, EG\&G Idaho, Inc., Idaho Falls, Idaho, May 8, 1991. 
Table 5. Conceptual mass flow rates of' ofl'-gits compounds entering the ISV OGS.

\begin{tabular}{|c|c|c|}
\hline $\begin{array}{l}\text { Condensible } \\
\text { spocies }\end{array}$ & $\begin{array}{c}\text { Muss Flow rute } \\
\text { culcring OCIS } \\
\mathrm{kg} / \mathrm{s}\end{array}$ & Muss llow \\
\hline $\mathrm{Bc}$ & $9.4 \times 10^{-4}$ & \\
\hline $\mathrm{CsOH}$ & $1.9 \times 10^{.11}$ & \\
\hline $\mathrm{H}_{2} \mathrm{O}$ & $8.7 \times 10^{.2}$ & \\
\hline $\mathrm{Hg}$ & $8.7 \times 10^{-4}$ & \\
\hline $\mathrm{KCl}$ & $6.9 \times 10^{-3}$ & \\
\hline $\mathrm{KOH}$ & $1.8 \times 10^{-3}$ & \\
\hline $\mathrm{NaCl}$ & $9.3 \times 10^{.3}$ & \\
\hline $\mathrm{NaOH}$ & $5.3 \times 10^{.3}$ & \\
\hline $\mathrm{Pb}$ & $1.2 \times 10^{-2}$ & \\
\hline $\mathrm{PuO}_{2}$ & $2.8 \times 10^{-7}$ & \\
\hline $\mathrm{UO}_{2}^{2}$ & $2.0 \times 10^{-4}$ & \\
\hline Total & $1.2 \times 10^{-1}$ & \\
\hline $\begin{array}{l}\text { Non-condensible } \\
\text { species }\end{array}$ & $\begin{array}{l}\text { Mass flow rate } \\
\text { entering OGS } \\
\mathrm{kg} / \mathrm{s} \\
\end{array}$ & $\begin{array}{l}\text { Molar percent } \\
\text { entering OGS }\end{array}$ \\
\hline $\mathrm{CO}_{2}$ & $1.4 \times 10^{-1}$ & 4.6 \\
\hline $\mathrm{N}_{2}$ & $1.5 \times 10^{0}$ & 78.9 \\
\hline $\mathrm{O}_{2}$ & $3.7 \times 10^{-1}$ & 16.5 \\
\hline Total & $2.0 \times 10^{0}$ & $1(k), 0$ \\
\hline
\end{tabular}


Table 6. Inlet vapor and acrosol mass fractions for an Inlet temperature of $854^{\circ} \mathrm{C}\left(1569^{\circ} \mathrm{F}\right)$,

\begin{tabular}{|c|c|c|c|c|}
\hline \multirow[b]{3}{*}{ Species } & & & \multicolumn{2}{|c|}{ Inlet mass flow rate } \\
\hline & \multicolumn{2}{|c|}{ Inlet mass fraction } & Vapor & Acrosiol \\
\hline & Vapor & osol & $\mathrm{kg} / \mathrm{s}$ & $\mathrm{kg} / \mathrm{s}$ \\
\hline $\mathrm{Bo}$ & $0.0000 \times 10^{0}$ & $1 .(0 \times 0) \times 10^{0}$ & $0 .(K)(K) \times 10^{0}$ & $9.411 \times 10^{.4}$ \\
\hline $\mathrm{Hg}$ & $1 .(K()) \times 10^{0}$ & $0.000 \times 10^{0}$ & $8.676 \times 10^{-4}$ & $0 .(00) \times 10^{0}$ \\
\hline $\mathrm{CsOH}$ & $1.0000 \times 10^{0}$ & $0.000 \times 10^{0}$ & $1.945 \times 10^{.11}$ & $0 .(000) \times 10^{0}$ \\
\hline $\mathrm{KCl}$ & $1 .(00) \times 10^{0}$ & $0.000 \times 10^{0}$ & $6.933 \times 10^{-3}$ & $0.00(0) \times 10^{0}$ \\
\hline $\mathrm{KOH}$ & $1.0 \times 0 \times \times 10^{0}$ & $0.000) \times 10^{0}$ & $1.767 \times 10^{-3}$ & $0.0(0) \times 10^{0}$ \\
\hline $\mathrm{NaCl}$ & $5.258 \times 10^{-1}$ & $4.742 \times 10^{-1}$ & $4.876 \times 10^{-3}$ & $4.397 \times 10^{-3}$ \\
\hline $\mathrm{NaOH}$ & $1.0(x) \times 10^{0}$ & $0.000 \times 10^{0}$ & $5.325 \times 10^{-3}$ & $0.000 \times 10^{0}$ \\
\hline $\mathrm{Pb}$ & $2.554 \times 10^{-1}$ & $7.446 \times 10^{-1}$ & $3.055 \times 10^{-3}$ & $3.905 \times 10^{-3}$ \\
\hline $\mathrm{PuO}_{2}$ & $0.000 \times 10^{0}$ & $1.0000 \times 10^{0}$ & $0.000 \times 10^{0}$ & $2.829 \times 10^{-7}$ \\
\hline $\mathrm{UO}_{2}$ & $0.0000 \times 10^{0}$ & $1.000 \times 10^{0}$ & $0.000) \times 10^{0}$ & $2.046 \times 10^{-4}$ \\
\hline $\mathrm{H}_{2} \mathrm{O}$ & $1.0(0) \times 10^{0}$ & $0.0(0) \times 10^{0}$ & $8.670 \times 10^{-2}$ & $0.000 \times 10^{0}$ \\
\hline
\end{tabular}




\section{PRELIMINARY MODEL ANALYSES}

'Three preliminary analyses of' the in situ vitrification (ISV) off-gas system (OGS) release model have been performed using the PULSE/MOD-ISV/VER 1.(0,() computer code. In Section 4.1, convergence test results for the hood component are presented, Section 4.2 presents a comparison of code predictions with periormance data for the mist eliminater component, and Section 4.3 describes a preliminary sensitivity study of the overall OGS model. Note that the PULSE/MOD-ISV/VER 1.0.0 code is develcpmental and a thorough verification and validation process has not been performed. Furthermore, the ISV OGS component models used in the calculations are conceptual and do not represent an actual operating system. Therefore, the results are preliminary and are only illustrative exercises of the code. The results should not be interpreted as predictions of the performance of the ISV OGS or its components.

\subsection{PULSE/MOD-ISV/VER 1.0.0 Convergence Test}

Convergence testing of the developmental PULSE/MOD-ISV/VER 1.0.0 computer code was performed. This testing was limited to examination of results for the hood component only. The results were examined for convergence in two ways. First, a sericss of three calculations were made in which the code's differential equation solver iteration tolerances were systematically reduced from $10^{-3}$ to $10^{-4}$ to $10^{-6}$. Second, another series of calculations were made in which the number of subsegments in the hood was increased from 5 to 10 to 20. In the first test, convergent results would be achieved if, as the tolerance values are decreased, the precision of the results increased. Likewise, in the second test, the precision of the results should increase, as the spatial segmenting is increased.

The convergence test calculations were made on a DEC 50(k) workstation. A total of live calculations were performed.' The hood geometry and thermal boundary conditions were based upon the information described in Section 3.1.1. The condensible species considered were: $\mathrm{Be}, \mathrm{Hg}, \mathrm{CsOH}$, $\mathrm{KCl}, \mathrm{KOH}, \mathrm{NaCl}, \mathrm{NaOH}, \mathrm{Pb}, \mathrm{PuO}_{2}, \mathrm{UO}_{2}$, and $\mathrm{H}_{2} \mathrm{O}$. The non-condensible species considered were $\mathrm{CO}_{2}, \mathrm{~N}_{2}$, and $\mathrm{O}_{2}$. The mass flow rates of these species were obtained from Table 5 . All boundary and flew conditions were constant with time and the problem time was 6) seconds.

\subsubsection{Iteration Tolerance Results}

A series of three calculations were made with the iteration toierances set to $10^{3}, 10^{-4}$, and $10^{-6}$. For these calculations the hood was divided into five subsegments. The results of these calculations are presented in Table 7. These results include, for each of the condensible species, the mass of vapor and aerosol at the hood exit and the total mass removed by condersation deposition. Examination of the results indicates that as the iteration tolerances are decreased, the predicted results for the mass of vapor and aerosol at the hood exit become increasingly precise. Likewise, the results for the mass removed become increasingly precise with the exception of those for $\mathrm{Be}, \mathrm{PuO}_{2}$ and $\mathrm{UO}_{2}$. The results for the mass removed for these three species are only precise to an order of magnitude because of the relatively small amounts of mass removed. For example, for a problemtime

t. Unpublished calculation work sheel titled "Convergence "Testing for PULSE/MOD-ISV/VER 1.(1.()" by V. X. Tung, EG\&G Idaho, Inc., Idaho Falls, Idaho, October $21, \mid(x) 1$. 
Table 7. Mass of vapor and aerosol at the hood exit and the mass removed in the hood as a function of the iteration tolerance.

\begin{tabular}{|c|c|c|c|}
\hline & \multirow[b]{2}{*}{$10^{3}$} & \multicolumn{2}{|c|}{ Iteration tolerance } \\
\hline & & $10^{-4}$ & $10^{-6}$ \\
\hline \multicolumn{4}{|c|}{ Vapor mass, kg } \\
\hline $\mathrm{Be}$ & $1.90 \times 10^{-14}$ & $2.29 \times 10^{-14}$ & $2.30 \times 10^{-14}$ \\
\hline $\mathrm{Hg}$ & $5.21 \times 10^{-2}$ & $5.21 \times 10^{-2}$ & $5.21 \times 10^{-2}$ \\
\hline $\mathrm{CsOH}$ & $1.17 \times 10^{-9}$ & $1.17 \times 10^{-9}$ & $1.17 \times 10^{-9}$ \\
\hline $\mathrm{KCl}$ & $3.44 \times 10^{-5}$ & $3.76 \times 10^{-5}$ & $3.76 \times 10^{-5}$ \\
\hline $\mathrm{KOH}$ & $1.66 \times 10^{-3}$ & $1.76 \times 10^{-3}$ & $1.76 \times 10^{-3}$ \\
\hline $\mathrm{NaCl}$ & $6.88 \times 10^{-6}$ & $7.58 \times 10^{-6}$ & $7.59 \times 10^{-6}$ \\
\hline $\mathrm{NaOH}$ & $1.28 \times 10^{-3}$ & $1.35 \times 10^{-3}$ & $1.35 \times 10^{-3}$ \\
\hline $\mathrm{Pb}$ & $2.18 \times 10^{-5}$ & $2.34 \times 10^{-5}$ & $2.34 \times 10^{-5}$ \\
\hline $\mathrm{PuO}_{2}$ & $7.54 \times 10^{-21}$ & $9.46 \times 10^{-21}$ & $9.47 \times 10^{-21}$ \\
\hline $\mathrm{UO}_{2}$ & $7.43 \times 10^{-21}$ & $9.32 \times 10^{-21}$ & $9.33 \times 10^{-21}$ \\
\hline $\mathrm{H}_{2} \mathrm{O}$ & $5.26 \times 10^{0}$ & $5.26 \times 10^{0}$ & $5.26 \times 10^{0}$ \\
\hline \multicolumn{4}{|c|}{ Acrosol mass, kg } \\
\hline $\mathrm{Be}$ & $3.11 \times 10^{-3}$ & $3.11 \times 10^{-3}$ & $3.11 \times 10^{-3}$ \\
\hline $\mathrm{Hg}$ & 0 & 0 & 0 \\
\hline $\mathrm{CsOH}$ & 0 & 0 & 0 \\
\hline $\mathrm{KCl}$ & $4.16 \times 10^{-1}$ & $4.16 \times 10^{-1}$ & $4.15 \times 10^{-1}$ \\
\hline $\mathrm{KOH}$ & $1.04 \times 10^{-1}$ & $1.04 \times 10^{-1}$ & $1.04 \times 10^{-1}$ \\
\hline $\mathrm{NaCl}$ & $5.57 \times 10^{-1}$ & $5.57 \times 10^{-1}$ & $5.57 \times 10^{-1}$ \\
\hline $\mathrm{NaOH}$ & $3.18 \times 10^{-1}$ & $3.18 \times 10^{-1}$ & $3.18 \times 10^{-1}$ \\
\hline $\mathrm{Pb}$ & $7.20 \times 10^{-1}$ & $7.20 \times 10^{-1}$ & $7.20 \times 10^{-1}$ \\
\hline $\mathrm{PuO}_{2}$ & $1.70 \times 10^{-5}$ & $1.70 \times 10^{-5}$ & $1.70 \times 10^{-5}$ \\
\hline $\mathrm{UO}_{2}{ }^{2}$ & $1.50 \times 10^{-2}$ & $1.50 \times 10^{-2}$ & $1.50 \times 10^{-2}$ \\
\hline $\mathrm{H}_{2} \mathrm{O}$ & 0 & 0 & 0 \\
\hline \multicolumn{4}{|c|}{ Mass removed, $\mathrm{kg}$} \\
\hline $\mathrm{Be}$ & $3.71 \times 10^{-9}$ & $1.41 \times 10^{-9}$ & $9.08 \times 10^{-9}$ \\
\hline $\mathrm{Hg}$ & 0 & 0 & 0 \\
\hline $\mathrm{CsOH}$ & $1.17 \times 10^{-14}$ & $1.17 \times 10^{-14}$ & $1.17 \times 10^{-14}$ \\
\hline $\mathrm{KCl}$ & $2.11 \times 10^{-4}$ & $1.91 \times 10^{-4}$ & $1.96 \times 10^{-4}$ \\
\hline $\mathrm{KOH}$ & $1.92 \times 10^{-4}$ & $1.89 \times 10^{-4}$ & $1.92 \times 10^{-4}$ \\
\hline $\mathrm{NaCl}$ & $8.47 \times 10^{-5}$ & $8.26 \times 10^{-5}$ & $8.53 \times 10^{-5}$ \\
\hline $\mathrm{NaOH}$ & $3.26 \times 10^{-4}$ & $3.07 \times 10^{-4}$ & $3.27 \times 10^{-4}$ \\
\hline $\mathrm{Pb}$ & $5.72 \times 10^{-5}$ & $5.55 \times 10^{-5}$ & $5.84 \times 10^{-5}$ \\
\hline $\mathrm{PuO}_{2}$ & $2.01 \times 10^{-11}$ & $7.56 \times 10^{-12}$ & $4.95 \times 10^{-11}$ \\
\hline $\mathrm{UO}_{2}$ & $1.78 \times 10^{-8}$ & $6.68 \times 10^{-9}$ & $4.37 \times 10^{-8}$ \\
\hline $\mathrm{H}_{2} \mathrm{O}$ & 0 & 0 & 0 \\
\hline
\end{tabular}


of 60 seconds, the mass of $\mathrm{Be}, \mathrm{PuO}_{2}$ and $\mathrm{UO}_{2}$ that enters the hood is $3.11 \mathrm{E}-03,1.70 \mathrm{E}-05$, and $1.50 \mathrm{E}-02 \mathrm{~kg}$, respectively. The ratio of the mass removed to the inlet mass for these species was on the order of $10^{-6}$. However, this is the same order as the smallest specified iteration tolerance so that the answers are within an order of magnitude of the convergent answer. In order to obtain more prrcise results for these relatively small mass quantities, tolerances less than $10^{-6}$ would have to be specified. However, for most problems of interest, such precise answers are not required.

\subsubsection{Subsegmenting Results}

Two additional calculations were made in which the number of hood subsegments was specified as 10 and 20. For both of these calculations the iteration tolerances were set to $10^{-4}$. The results of these calculations are presented in Table 8 and include the results from the previous series of calculations for which the number of hood segments was 5 and the tolerances $10^{-4}$. As for the previous results, the presented results include, for each of the condensible species, the mass of vapor and aerosol at the hood exit and the total mass removed by condensation and deposition. Examination of these results indicate that as the number of subsegments is increased the results become more precise.

\subsubsection{Convergence Test Summary}

Overall, $t_{1}$, results from these convergence tests indicate that with five subsegments and iteration tolerances of $10^{-4}$, the predicted vapor mass and mass removed are precise to at least one significant digit (with the exception of $\mathrm{Bc}, \mathrm{PuO}_{2}$, and $\mathrm{UO}_{2}$, which are within an order of magnitude of the converged answer) and the aerosol mass has at least three significant digits. Note that these convergence test results are valid only for the specified hood component and flow conditions. In general, other components and/or tlow conditions would yield different results.

\subsection{Mist Eliminator Performance Comparison}

The PULSE/MOD-ISV/VER 1.0.0 computer code was used to predict the efficiency of the Munters TS-5/4 mist eliminator with published performance data (see Reference 23.) This mist eliminator is typical of the component specified for the ISV OGS and was described previously in Section 3.1.6. The performance data provided includes the limit drop size and the fractional efficiency. The limit drop size is the smallest drop which is completely removed at a specified flow velocity. Droplets smaller than the limit drop size are not completely removed. The fractional efficiency specifies the mass fraction removed for droplets smaller than the limit drop size.

\subsubsection{Procedure}

The computer code calculations were obtained using the developmental PUISE/MOD-ISV/VER 1.0.0 computer code. These calculations were made on an IBM PS/2 Model 70386 personal computer and the code was compiled using the Lahey F77L-EM/32FORTRAN compiler (see Reference 8). A series of thirteen code calculations were 
Table 8. Mass of vapor and aerosol at the hood exit and the mass removed in the hood as a function of the number of hood subsegments.

\begin{tabular}{cccc}
\hline & 5 & 10 & $\begin{array}{c}\text { Number of subsegments } \\
20\end{array}$ \\
\hline Vapor mass, $\mathrm{kg}$ & & & \\
$\mathrm{Be}$ & $2.29 \times 10^{-14}$ & $2.24 \times 10^{-14}$ & $2.82 \times 10^{-14}$ \\
$\mathrm{Hg}$ & $5.21 \times 10^{-2}$ & $5.21 \times 10^{-2}$ & $5.21 \times 10^{-2}$ \\
$\mathrm{CsOH}$ & $1.17 \times 10^{-9}$ & $1.17 \times 10^{-9}$ & $1.17 \times 10^{-9}$ \\
$\mathrm{KCl}$ & $3.76 \times 10^{-5}$ & $3.67 \times 10^{-5}$ & $4.07 \times 10^{-5}$ \\
$\mathrm{KOH}$ & $1.76 \times 10^{-3}$ & $1.72 \times 10^{-3}$ & $1.82 \times 10^{-2}$ \\
$\mathrm{NaCl}$ & $7.58 \times 10^{-6}$ & $7.40 \times 10^{-6}$ & $8.31 \times 10^{-6}$ \\
$\mathrm{NaOH}$ & $1.35 \times 10^{-3}$ & $1.32 \times 10^{-3}$ & $1.38 \times 10^{-3}$ \\
$\mathrm{~Pb}$ & $2.34 \times 10^{-5}$ & $2.28 \times 10^{-5}$ & $2.48 \times 10^{-5}$ \\
$\mathrm{PuO}_{2}$ & $9.46 \times 10^{-21}$ & $9.22 \times 10^{-21}$ & $1.21 \times 10^{-20}$ \\
$\mathrm{UO}_{2}$ & $9.32 \times 10^{-21}$ & $9.09 \times 10^{-21}$ & $1.19 \times 10^{-20}$ \\
$\mathrm{H}_{2} \mathrm{O}$ & $5.26 \times 10^{0}$ & $5.26 \times 10^{0}$ & $5.26 \times 10^{0}$
\end{tabular}

Aerosol mass, $\mathrm{kg}$

$\begin{array}{cccc}\mathrm{Be} & 3.11 \times 10^{-3} & 3.11 \times 10^{-3} & 3.11 \times 10^{-3} \\ \mathrm{Hg} & 0 & 0 & 0 \\ \mathrm{CsOH} & 0 & 0 & 0 \\ \mathrm{KCl} & 4.16 \times 10^{-1} & 4.16 \times 10^{-1} & 4.16 \times 10^{-1} \\ \mathrm{KOH} & 1.04 \times 10^{-1} & 1.04 \times 10^{-1} & 1.04 \times 10^{-1} \\ \mathrm{NaCl} & 5.57 \times 10^{-1} & 5.57 \times 10^{-1} & 5.57 \times 10^{-1} \\ \mathrm{NaOH} & 3.18 \times 10^{-1} & 3.18 \times 10^{-1} & 3.17 \times 10^{-1} \\ \mathrm{~Pb} & 7.20 \times 10^{-1} & 7.20 \times 10^{-1} & 7.20 \times 10^{-1} \\ \mathrm{PuO}_{2} & 1.70 \times 10^{-5} & 1.70 \times 10^{-5} & 1.70 \times 10^{-5} \\ \mathrm{UO}_{2} & 1.50 \times 10^{-2} & 1.50 \times 10^{-2} & 1.50 \times 10^{-2} \\ \mathrm{H}_{2} \mathrm{O} & 0 & 0 & 0\end{array}$

Mass removed, $\mathrm{kg}$

$\begin{array}{cccc}\mathrm{Be} & 1.41 \times 10^{-9} & 1.45 \times 10^{-9} & 1.44 \times 10^{-9} \\ \mathrm{Hg} & 0 & 0 & 0 \\ \mathrm{CsOH} & 1.17 \times 10^{-14} & 1.20 \times 10^{-14} & 1.21 \times 10^{-14} \\ \mathrm{KCl} & 1.91 \times 10^{-4} & 2.13 \times 10^{-4} & 2.13 \times 10^{-4} \\ \mathrm{KOH} & 1.89 \times 10^{-4} & 1.98 \times 10^{-4} & 1.98 \times 10^{-4} \\ \mathrm{NaCl} & 8.26 \times 10^{-5} & 8.46 \times 10^{-5} & 8.47 \times 10^{-5} \\ \mathrm{NaOH} & 3.07 \times 10^{-4} & 3.35 \times 10^{-4} & 3.32 \times 10^{-4} \\ \mathrm{~Pb} & 5.55 \times 10^{-5} & 5.73 \times 10^{-5} & 5.73 \times 10^{-5} \\ \mathrm{PuO}_{2} & 7.56 \times 10^{-12} & 7.78 \times 10^{-12} & 7.71 \times 10^{-12} \\ \mathrm{UO}_{2} & 6.68 \times 10^{-9} & 6.87 \times 10^{-9} & 6.81 \times 10^{-9} \\ \mathrm{H}_{2} \mathrm{O} & 0 & 0 & 0\end{array}$


performed." The results of these calculations were then compared with supplied performance data. Three limit drop sizes and seven fractional efficiencies were analyzed. The limit drop sizes were analyzed by selecting a limit drop size and then performing a scries of calculations in which the gas mass flow rate (and thus the flow velocity) was increased. The minimum gas flow rate at which all of the droplets were removed was determined and compared with the performance data. The three limit drop sizes selected were $16.9,12.1$, and $8.7 \mu \mathrm{m}$. The fractional efficiency was determined for seven droplet sizes smaller than the $12.1 \mu \mathrm{m}$ limit drop size. These calculation were performed with droplet sizes of $10.3,8.7,7.37,5.28,3.21,1.95$ and $1.18 \mu \mathrm{m}$.

The code calculations were performed as follows. The injected droplets were modeled as water at saturated conditions of $20^{\circ} \mathrm{C}\left(68^{\circ} \mathrm{F}\right)$ and $1.0 \times 10^{5} \mathrm{~Pa}$. The mass flow rate of the injected water droplets was specified as a constant $0.01 \mathrm{~kg} / \mathrm{s}$ so that the total mass input over 100 seconds of problem time was $1 \mathrm{~kg}$. For each calculation, the total aerosol mass flow rate was initially placed into a single aerosol bin size. The aerosol bin sizes chosen for the limit drop size calculations were the $14^{\text {th }}, 16^{\text {th }}$, and $18^{\text {th }}$ size classes which correspond to average aerosol sizes of $8.70,12.1$, and $16.9 \mu \mathrm{m}$, respectively. For the seven fractional efficiency calculations, the $2^{\text {th }}, 5^{\text {th }}, 8^{\text {th }}, 11^{\text {th }}, 13^{\text {th }}, 14^{\text {th }}$, and $15^{\text {th }}$, aerosol bin sizes were specified. These aerosol bin sizes correspond to average aerosol sizes of 1.18, $1.95,3.21,5.28,7.37,8.70$, and $10.3 \mu \mathrm{m}$, respectively.

The non-condensible gas was specified as a mixture of air and water vapor. The supplied performance data is based upon an air/water system at standard conditions of $20^{\circ} \mathrm{C}$ and $1.0 \times 10^{5} \mathrm{~Pa}$. Assuming saturated conditions, the partial pressure of water vapor at $20^{\circ} \mathrm{C}$ is $2.377 \times 10^{3} \mathrm{~Pa}$ and the molar fraction of water vapor is 0.0238 . The corresponding molar fraction of air is 0.9762 . For each limit drop size prediction, a series of code calculations was performed. In each calculation, the gas mass flow rate was adjusted from the previous value until the minimum flow rate was found for which all of the water aerosols were removed.

\subsubsection{Results}

In Table 9, a summary is given of the limit drop size predictions. Table 10 presents the calculated mass balances for droplets smaller than the limit drop diameter of $12.1 \mu \mathrm{m}$ at a gas velocity of $4.22 \mathrm{~m} / \mathrm{s}$.

Figure 9 and Figure 10 present the supplied performance data for the Munters TS-5/4 horizontal flow mist eliminator. The predicted results are represented by points on these figures. As can be seen from these figures, the predicted results compare quite favorably with the performance data.

u. Unpublished calculational work sheet entitled "Comparison of PULSE/MOD-ISV/VER 1.0.() Predictions with MUNTERS TS-5/4 Mist Eliminator Performance Data," by Daniel J. Pafford, EG\&G Idaho, Inc., Idaho Falls, Idaho, September 27, 1991. 
Table 9. Summary of calculated velocities and mass balance statements for specified limit drop sizes.

\begin{tabular}{|c|c|c|c|c|c|}
\hline Run & $\begin{array}{l}\text { Limit drop } \\
\text { diameter } \\
\mu \mathrm{m}\end{array}$ & $\begin{array}{l}\text { Calculated } \\
\text { velocity } \\
\mathrm{m} / \mathrm{s}\end{array}$ & $\begin{array}{c}\text { Mass in } \\
\mathrm{kg}\end{array}$ & $\begin{array}{l}\text { Mass } \\
\text { removed } \\
\mathrm{kg}\end{array}$ & $\begin{array}{l}\text { Mass out } \\
\mathrm{kg}\end{array}$ \\
\hline 1 & 16.9 & 2.17 & 1.0 & $1.0 \times 10^{0}$ & $1.8 \times 10^{-18}$ \\
\hline 2 & 16.9 & 2.24 & 1.0 & $1.0 \times 10^{0}$ & $1.3 \times 10^{-98}$ \\
\hline 1 & 12.1 & 4.15 & 1.0 & $1.0 \times 10^{0}$ & $2.1 \times 10^{-11}$ \\
\hline 2 & 12.1 & 4.22 & 1.0 & $1.0 \times 10^{0}$ & $1.6 \times 10^{-98}$ \\
\hline 1 & 8.70 & 8.05 & 1.0 & $1.0 \times 10^{0}$ & $4.6 \times 10^{-13}$ \\
\hline 2 & 8.70 & 8.11 & 1.0 & $1.0 \times 10^{0}$ & $2.5 \times 10^{-98}$ \\
\hline
\end{tabular}

Table 10. Calculated mass balances for droplet sizes smaller than the limit drop diameter of 12.1 $\mu \mathrm{m}$ at a gas velocity of $4.22 \mathrm{~m} / \mathrm{s}$.

\begin{tabular}{ccccc}
\hline Run & $\begin{array}{c}\text { Drop } \\
\text { diameter } \\
\mu \mathrm{m}\end{array}$ & $\begin{array}{c}\text { Mass in } \\
\mathrm{kg}\end{array}$ & $\begin{array}{c}\text { Mass } \\
\text { removed } \\
\mathrm{kg}\end{array}$ & $\begin{array}{c}\text { Mass out } \\
\mathrm{kg}\end{array}$ \\
\hline 1 & 10.3 & 1.0 & $9.96 \times 10^{-1}$ & $4.510^{-3}$ \\
2 & 8.70 & 1.0 & $9.51 \times 10^{-1}$ & $4.9 \times 10^{-2}$ \\
3 & 7.37 & 1.0 & $8.47 \times 10^{-1}$ & $1.53 \times 10^{-1}$ \\
4 & 5.28 & 1.0 & $5.73 \times 10^{-1}$ & $4.27 \times 10^{-1}$ \\
5 & 3.21 & 1.0 & $2.58 \times 10^{-1}$ & $7.42 \times 10^{-1}$ \\
6 & 1.95 & 1.0 & $1.06 \times 10^{-1}$ & $8.94 \times 10^{-1}$ \\
7 & 1.18 & 1.0 & $4.3 \times 10^{-2}$ & $9.57 \times 10^{-1}$ \\
\hline
\end{tabular}




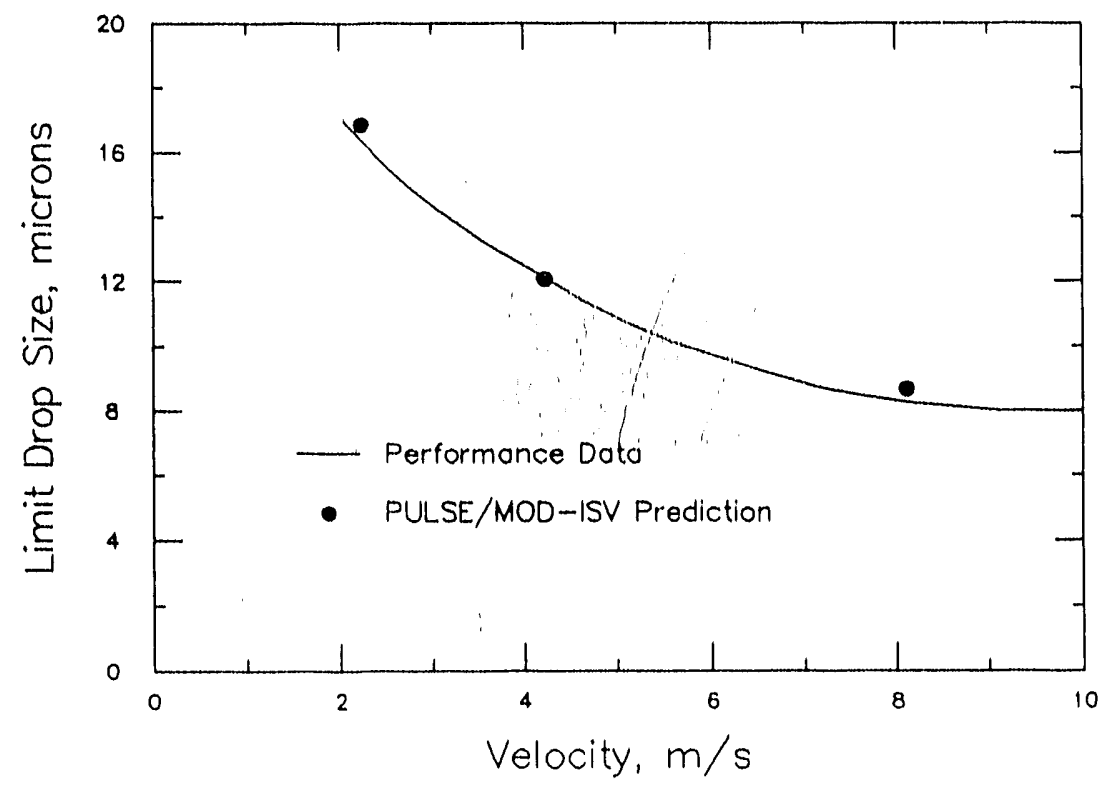

Figure 9. Limit drop size versus inlet velocity for the Munters TS-5/4 horizontal flow mist eliminator.

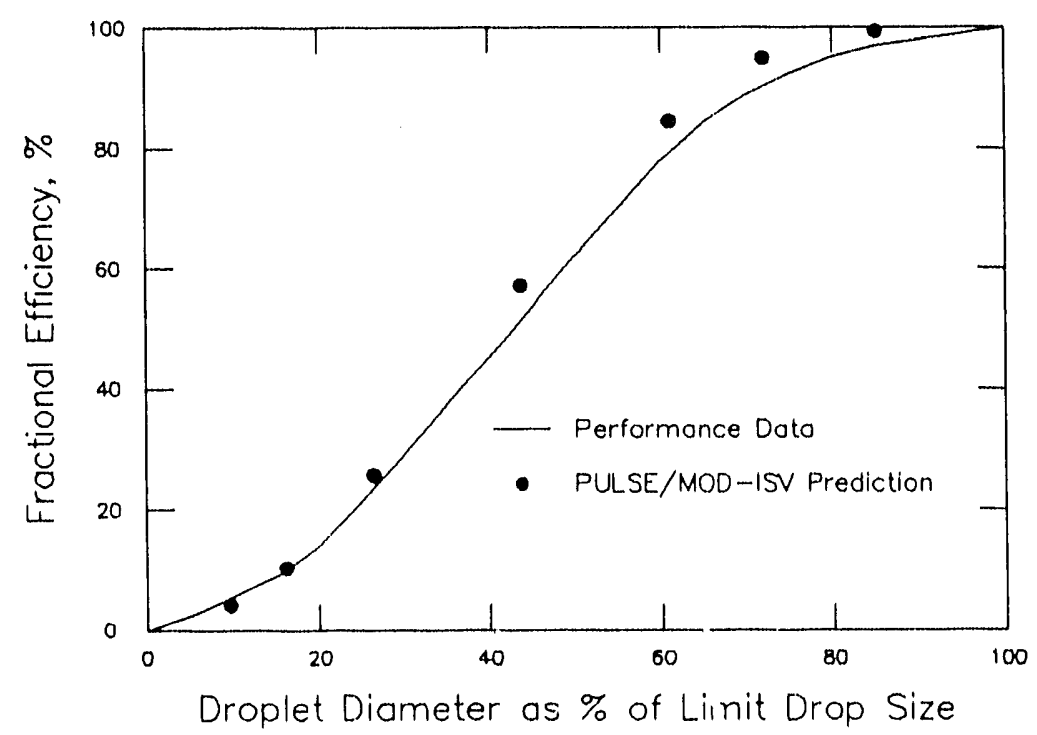

Figure 10. Fractional efficiency versus droplet sizes, as expressed as a percentage of the limit drop size for the Munters TS-5/4 horizontal flow mist eliminator. 


\subsection{Sensitivity Study}

A preliminary sensitivity study of the completed model was performed and the results are presented in this section. This study was limited to evaluating the effect of the inlet aerosol diameter on the transport and deposition of material in the OGS. The results of this study include the fraction of mass removed in each of the OGS components, the mass weighted average aerosol diameter at the component exits, the off-gas temperature at the component exits, the decontamination fraction (DF) for the overall ISV OGS, and the release fraction (RF) for the overall ISV OGS.

The mass fraction removed in each component was obtained as the ratio of the sum of mass removed by condensation, chemisorbtion, and deposition to the total mass input to the OGS. The mass weighted average aerosol diameter was defined as

$$
d_{i}=\frac{\sum_{k=1}^{20} m_{i, k} d_{k}}{\sum_{k=1}^{20} m_{i, k}}
$$

where

$$
\begin{array}{lll}
d_{i} & = & \text { mass weighted average aerosol diameter of species } \mathrm{i}(\mathrm{m}) \\
\mathrm{m}_{\mathrm{i}, \mathrm{k}} & = & \text { mass of species } \mathrm{i} \text { in aerosol bin size } \mathrm{k}(\mathrm{kg}) \\
\mathrm{d}_{\mathrm{k}} & = & \text { aerosol diamcter of bin size } \mathrm{k}(\mathrm{m})
\end{array}
$$

and the summations were performed over all 20 aerosol bin sizes. The DF was defined as the ratio of the total mass removed to the total mass input. The RF was defined as the ratio of the total mass released to the total mass input. For water, the total mass inlet to the OGS included the vapor entering the hood and the water spray injected in the quencher and scrubber components.

\subsubsection{Procedure}

Three separate calculations were made with aerosols entering the hood specified as $0.2,2.0$, and $9.3 \mu \mathrm{m}$ in diameter. ${ }^{\vee}$ These three calculations are referred to as Runs 1,2 , and 3 , respectively. All of the calculations were steady state; the inlet flow conditions and thermal boundary conditions were specified as constant in time. The problem time was 60 seconds. Although this is a relatively small time duration, for steady state calculations the results are independent of the problem time. The off-gas temperature at the entrance to the hood was specified as $854^{\circ} \mathrm{C}\left(1569^{\circ} \mathrm{F}\right)$. The condensible species considered were: $\mathrm{Be}, \mathrm{Hg}, \mathrm{CsOH}, \mathrm{KCl}, \mathrm{KOH}, \mathrm{NaCl}, \mathrm{NaOH}, \mathrm{Pb}, \mathrm{PuO}_{2}, \mathrm{UO}_{2}$, and $\mathrm{H}_{2} \mathrm{O}$. The non-condensible species considered were $\mathrm{CO}_{2}, \mathrm{~N}_{2}$, and $\mathrm{O}_{2}$. The mass flow rates of these species were obtained from Table 5. The fraction of inlet mass in the vapor and aerosol phases was

v. Unpublished calculational work sheet entitled "Sensitivity of the ISV OGS Model to Inlet Aerosol Size," by Daniel J. Pafford, EG\&G Idaho, Inc., Idaho Falls, Idaho, January 8, 1992. 
obtained from the equilibrium vapor concentration (EVC) at the inlet temperature as described in Section 3.2. The entering vapor and acrosol mass fractions are presented in Table 6. All three runs were made on a DEC 5000 workstation.

To simplify the presentation, the results for the eleven condensible species considered were binned into six groups. This grouping was based upon the EVC characteristics of the species as depicted in Figure 7. Species with similar vapor concentration characteristics were grouped together. It is assumed (and confirmed by the results) that the transport and removal characteristics of the species in each group are similar. The six groups arranged in order of increasing EVC are:

\begin{tabular}{ll} 
Group & Species \\
\cline { 2 - 2 } 1 & $\mathrm{Be}, \mathrm{UO}_{2}$, and $\mathrm{PuO}_{2}$ \\
2 & $\mathrm{KCl}, \mathrm{NaCl}$, and $\mathrm{Pb}$ \\
3 & $\mathrm{KOH}$ and $\mathrm{NaOH}$ \\
4 & $\mathrm{CsOH}$ \\
5 & $\mathrm{Hg}$ \\
6 & $\mathrm{H}_{2} \mathrm{O}$
\end{tabular}

The EVC characteristics for the six groups are as follows. The species in the first group have very low vapor concentrations at the OGS operating temperatures. For an inlet temperature of $854^{\circ} \mathrm{C}\left(1569^{\circ} \mathrm{F}\right)$, all of the species in this group were specified as aerosols. In Figure 7 , the concentration curves for these species are located near each other on the far right side.

Groups two and three consist of species with low EVCs at the inlet temperature stated above. The vapor concentration curves for the five species in these two groups can be found in the center of Figure 7. While the vapor concentration curves for these five species are all located near each other, the two hydroxides of group three have slightly higher vapor concentrations than the species in group two. At the inlet temperature of $354^{\circ} \mathrm{C}\left(1569^{\circ} \mathrm{F}\right)$, the species in group three were specified as vapor. At this same temperature, the species in group two were inlet as a mixture of vapor and aerosol (with the exception of the potassium chloride which was specified as all vapor.)

Cesium hydroxide, mercury, and water were placed in separate groups because the EVCs were widely different over the ISV OGS operating temperature range of interest (from approximately 50 to $900^{\circ} \mathrm{C}$.) The vapor concentration curves for these three species can be found on the left half of Figure 7 and all three have relatively high vapor concentrations. For the inlet temperature listed above, all three of these species were specified as vapor at inlet.

\subsubsection{Results}

The calculated ISV OGS overall DF and RF as a function of the inlet aerosol size and species groups are presented in Figure 11 and Figure 12, respectively.

For an inlet aerosol diameter of $0.2 \mu \mathrm{m}$, the calculated mass flow rates exiting the OGS, the DFs, and RFs for each specie are presented in Table 11. The mass fraction removed in each of the OGS components and the mass weighted average aerosol diameter at the component exits as a 


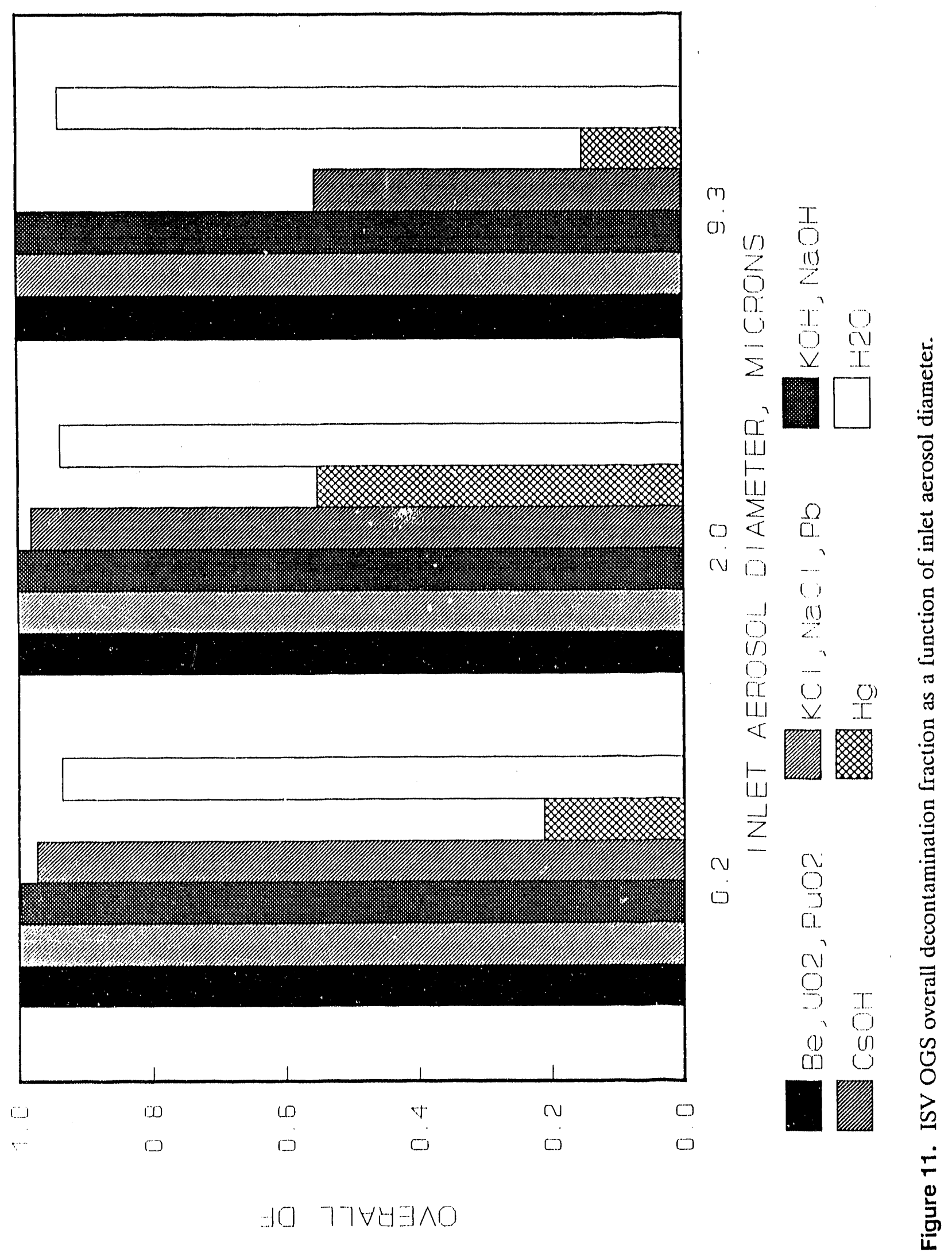




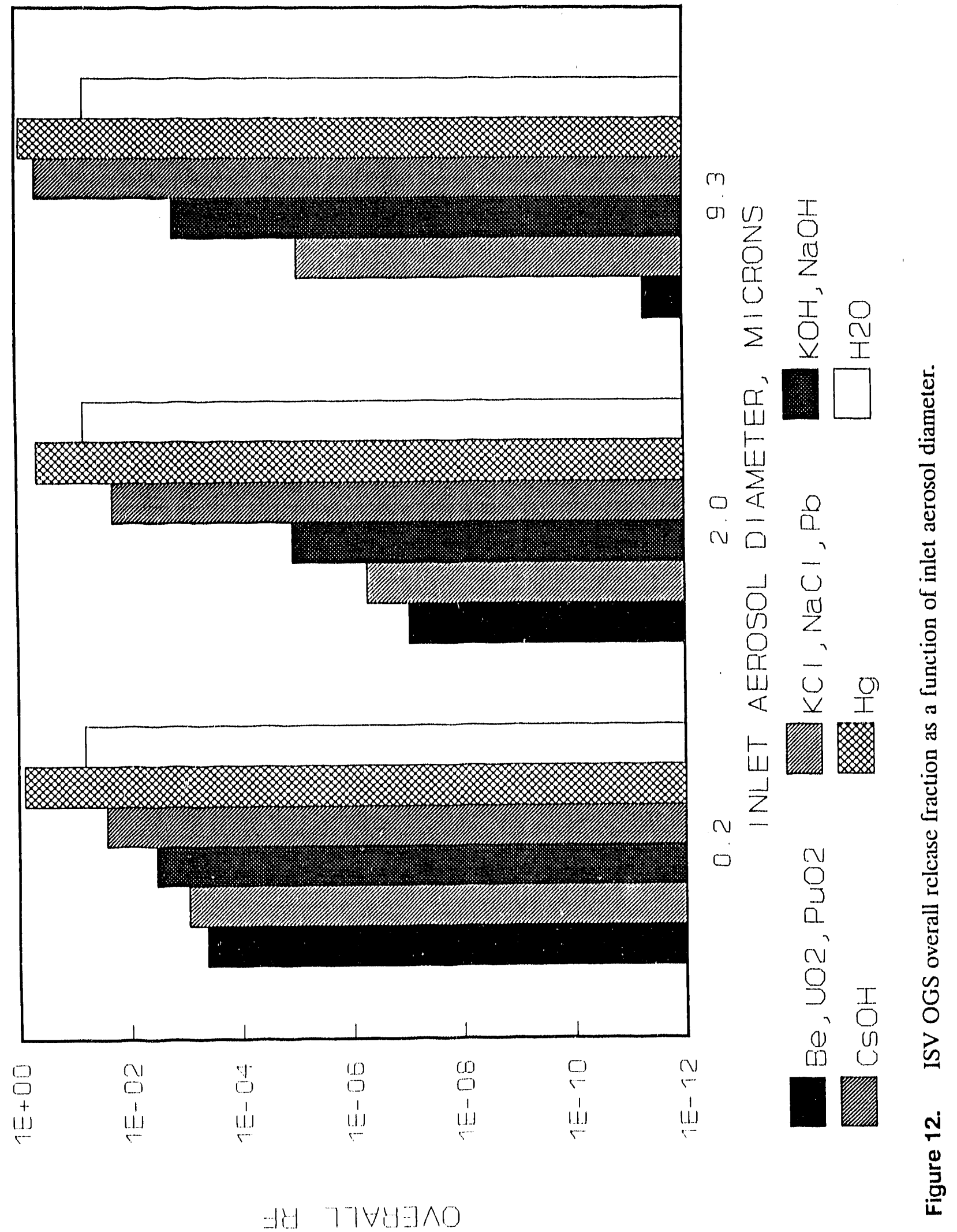


Table 11. Predicted OGS exit mass flow rates, decontamination fractions, and release fractions for an inlet aerosol diameter of $0.2 \mu \mathrm{m}$.

\begin{tabular}{lcccc}
\hline $\begin{array}{c}\text { Condensible } \\
\text { species }\end{array}$ & $\begin{array}{c}\text { Mass flow rate } \\
\text { entering OGS } \\
\mathrm{kg} / \mathrm{s}\end{array}$ & $\begin{array}{c}\text { Mass flow rate } \\
\text { exiting OGS } \\
\mathrm{kg} / \mathrm{s}\end{array}$ & $\begin{array}{c}\text { Decontamination } \\
\text { fraction }\end{array}$ & $\begin{array}{c}\text { Releasc } \\
\text { fraction }\end{array}$ \\
\hline $\mathrm{Be}$ & $9.4 \times 10^{-4}$ & $4.1 \times 10^{-7}$ & $9.9957 \times 10^{-1}$ & $4.2 \times 10^{-4}$ \\
$\mathrm{CsOH}$ & $1.9 \times 10^{-11}$ & $5.2 \times 10^{-13}$ & $9.7301 \times 10^{-1}$ & $2.7 \times 10^{-2}$ \\
$\mathrm{H}_{2} \mathrm{O}^{\mathrm{a}}$ & $2.8 \times 10^{0}$ & $1.8 \times 10^{-1}$ & $9.3484 \times 10^{-1}$ & $6.5 \times 10^{-2}$ \\
$\mathrm{Hg}$ & $8.7 \times 10^{-4}$ & $6.8 \times 10^{-4}$ & $2.1181 \times 10^{-1}$ & $7.9 \times 10^{-1}$ \\
$\mathrm{KCl}$ & $6.9 \times 10^{-3}$ & $1.1 \times 10^{-5}$ & $9.9845 \times 10^{-1}$ & $1.6 \times 10^{-3}$ \\
$\mathrm{KOH}$ & $1.8 \times 10^{-3}$ & $8.5 \times 10^{-6}$ & $9.9518 \times 10^{-1}$ & $4.8 \times 10^{-3}$ \\
$\mathrm{NaCl}$ & $9.3 \times 10^{-3}$ & $7.0 \times 10^{-6}$ & $9.9925 \times 10^{-1}$ & $7.5 \times 10^{-4}$ \\
$\mathrm{NaOH}$ & $5.3 \times 10^{-3}$ & $1.6 \times 10^{-5}$ & $9.9702 \times 10^{-1}$ & $3.0 \times 10^{-3}$ \\
$\mathrm{~Pb}$ & $1.2 \times 10^{-2}$ & $7.2 \times 10^{-6}$ & $9.9940 \times 10^{-1}$ & $6.0 \times 10^{-4}$ \\
$\mathrm{PuO}_{2}$ & $2.8 \times 10^{-7}$ & $1.2 \times 10^{-10}$ & $9.9957 \times 10^{-1}$ & $4.3 \times 10^{-4}$ \\
$\mathrm{UO}_{2}$ & $2.0 \times 10^{-4}$ & $8.9 \times 10^{-8}$ & $9.9957 \times 10^{-1}$ & $4.3 \times 10^{-4}$ \\
\end{tabular}

a. Entering mass flow rate composed of the vapor that enters the hood and the spray injected in the quencher and scrubber components. 
lunction of the species' groups are presented in Figure 13 and Figure 14, respectively. Finally, the off-gas temperature at the component exits is presented in Figure 15.

For an inlet aerosol diameter of $2.0 \mu \mathrm{m}$, the calculated mass flow rates exiting the OGS, the DFs, and RFs for each specie are presented in Table 12. The mass fraction removed in each of the OGS components and the mass weighted average aerosol diameter at the component exits as a function of the species' groups are presented in Figure 16 and Figure 17, respectively. Finally, the off-gas temperature at the component exits is presented in Figure 18.

For an inlet aerosol diameter of $9.3 \mu \mathrm{m}$, the calculated mass flow rates exiting the OGS, the DFs, and RFs for each specie are presented in T'able 13. The mass fraction removed in each of the OGS components and the mass weighted average aerosol diameter at the component exits as a function of the species' groups are presented in Figure 19 and Figure 20, respectively. Finally, the off-gas temperature at the component exits is presented in Figure 21.

\subsubsection{Discussion}

In this section, the results presented above will be discussed. First, a description of the results for each component will be presented. This will be followed by a summary of the overall effect of inlet aerosol size on the vapor and aerosol transport and deposition in the OGS.

Component Results. This section provides a sequential description of the vapor and aerosol transport through the OGS components. This description includes the results for all three inlet aerosol sizes. Significant differences that occur for the three runs are noted.

Hood-Upon entering the hood, the off-gas temperature was $854^{\circ} \mathrm{C}\left(1569^{\circ} \mathrm{F}\right)$. As the off-gas passed through the hood, heat was removed from the off-gas by heat transfer to the cooler hood surface. The off-gas temperature at the hood exit was $517^{\circ} \mathrm{C}\left(963^{\circ} \mathrm{F}\right)$. The drop in off-gas temperature resulted in some of the vapor, for species' groups two and three, condensing onto aerosols and, to a much lesser degree, the hood surface. The acrosols increased in size due to the vapor condensed on them, but mostly due to agglomeration with other aerosols. Very little mass was removed in the hood. The off-gas exited the hood and entered the off-gas jumper piping connecting the hood with the four off-gas trains.

Ofr-Gas Jumper and Manifold Piping-The off-gas temperature continued to decrease in this piping as heat was transferred to the cooler pipe wall. As the acrosol size increased due to agglomeration and condensation, the amount of mass removed increased. The removal mechanisms were dominated by deposition in the piping elbow bends, gravitational settling, and turbulent deposition. As a result of deposition of the larger acrosols, the mass averaged aerosol sizes decreased. At the piping exit, the off-gas temperature was 417,415 , and $410^{\circ} \mathrm{C}\left(78.3,779\right.$, and 77()$\left.^{\circ} \mathrm{F}\right)$, for inlet aerosol sizes of $0.2,2.0$, and $9.3 \mu \mathrm{m}$, respectively. This variation in the exit temperature was due to the thermal mass of the off-gas decreasing as more mass was removed for the larger inlet acrosol size cases. As the thermal mass was decreased, the temperature drop through the pipe was increased. 


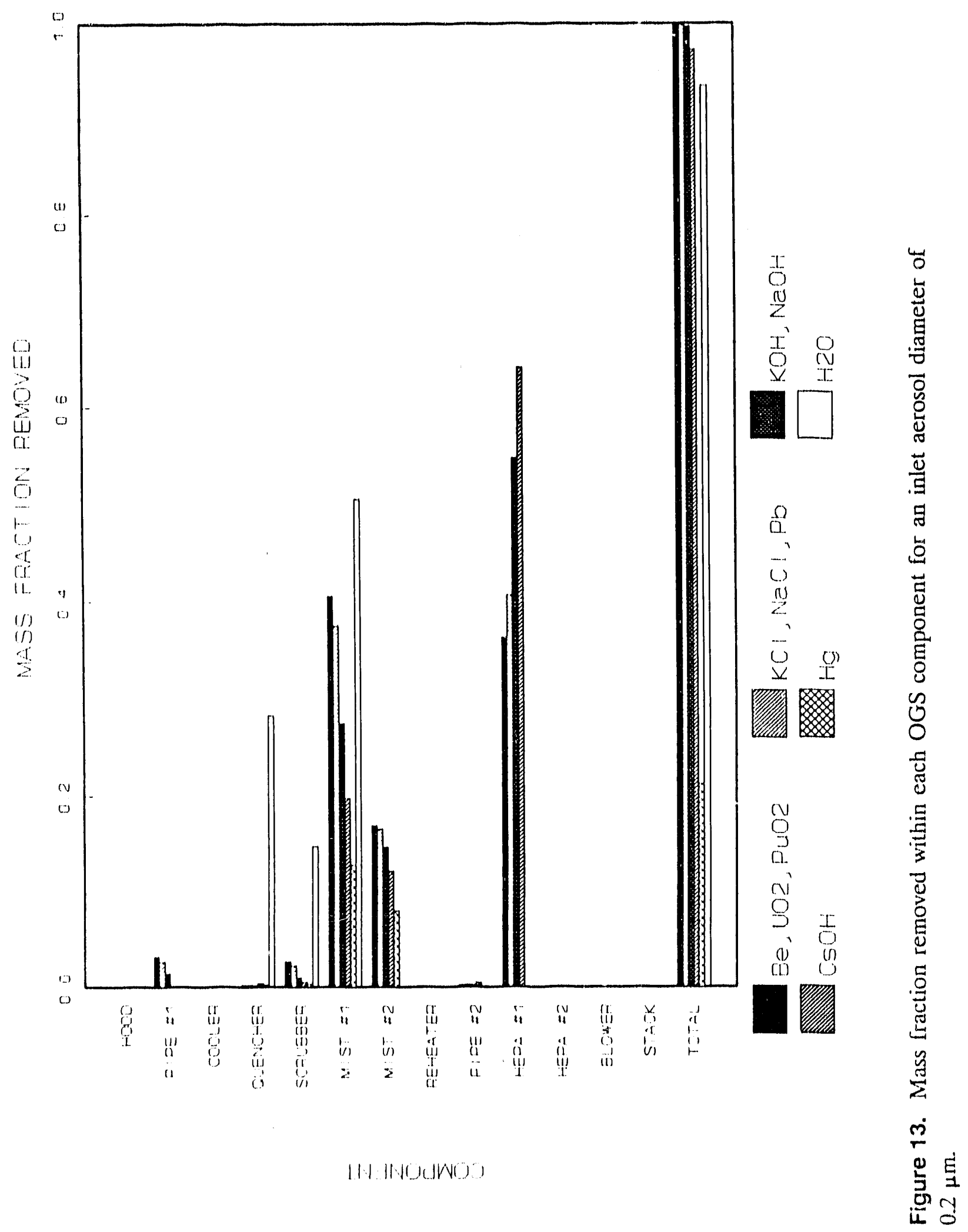




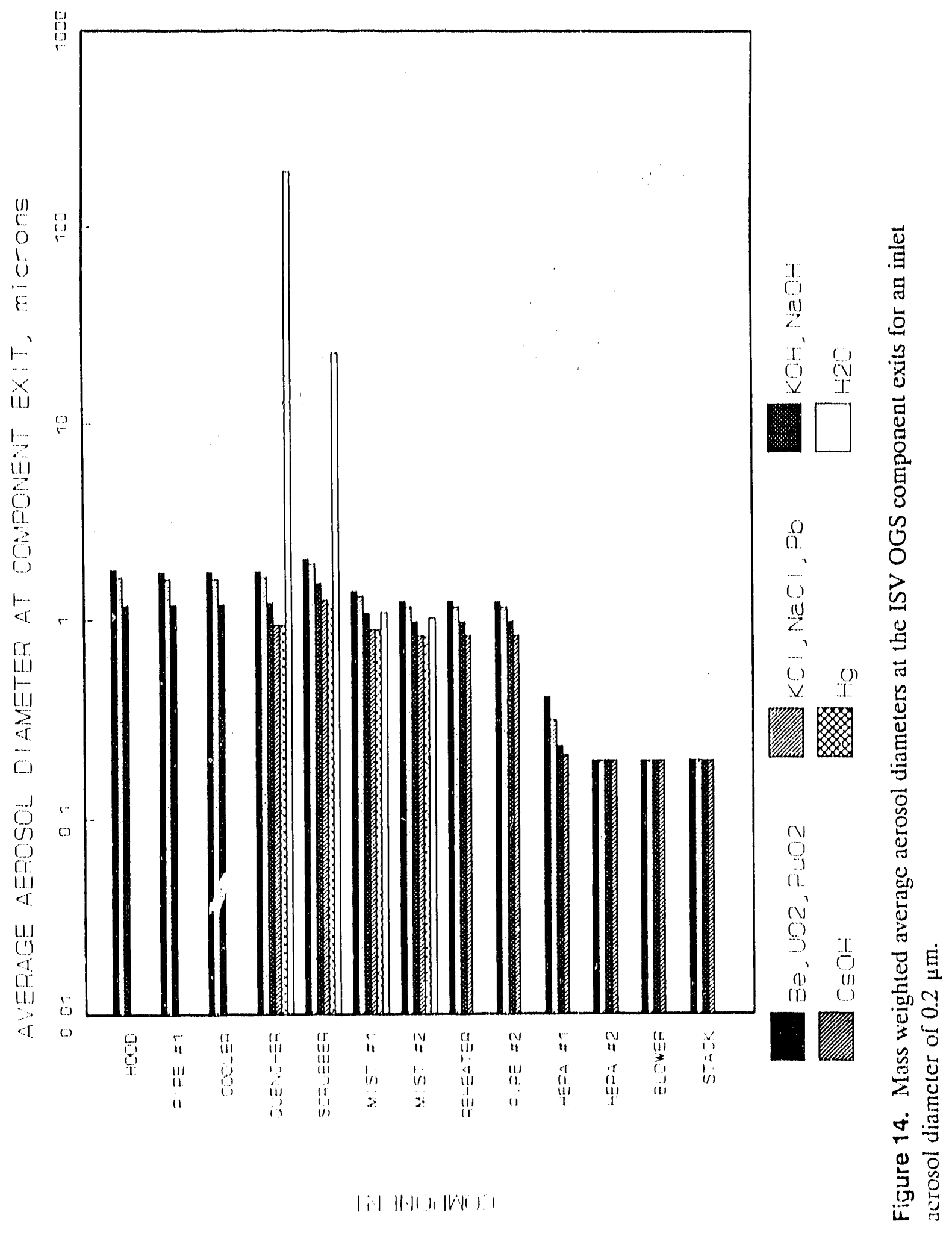




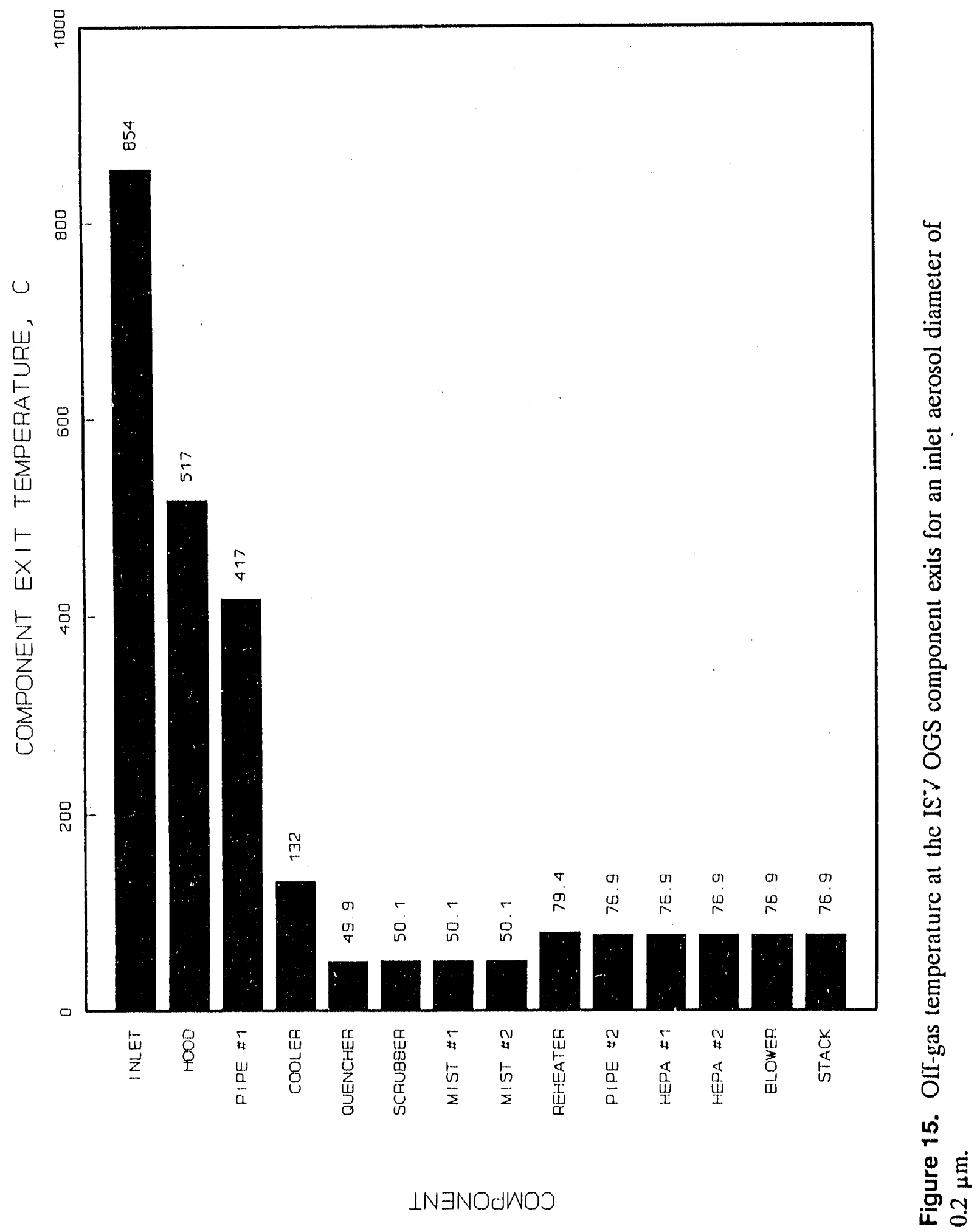


Table 12. Predicted OGS exit mass flow rates, decontamination fractions, and release fractions for an inlet aerosol diameter of $2.0 \mu \mathrm{m}$.

\begin{tabular}{lcccc}
\hline $\begin{array}{c}\text { Condensible } \\
\text { species }\end{array}$ & $\begin{array}{c}\text { Mass flow rate } \\
\text { entering OGS } \\
\mathrm{kg} / \mathrm{s}\end{array}$ & $\begin{array}{c}\text { Mass flow rate } \\
\text { exiting OGS } \\
\mathrm{kg} / \mathrm{s}\end{array}$ & $\begin{array}{c}\text { Decontamination } \\
\text { fraction }\end{array}$ & $\begin{array}{c}\text { Release } \\
\text { fraction }\end{array}$ \\
\hline $\mathrm{Be}$ & $9.4 \times 10^{-4}$ & $8.6 \times 10^{-11}$ & $1.0000 \times 10^{0}$ & $9.1 \times 10^{-8}$ \\
$\mathrm{CsOH}$ & $1.9 \times 10^{-11}$ & $3.8 \times 10^{-13}$ & $9.8032 \times 10^{-1}$ & $2.0 \times 10^{-2}$ \\
$\mathrm{H}_{2} \mathrm{O}^{\mathrm{a}}$ & $2.8 \times 10^{0}$ & $1.8 \times 10^{-1}$ & $9.3593 \times 10^{-1}$ & $6.4 \times 10^{-2}$ \\
$\mathrm{Hg}$ & $8.7 \times 10^{-4}$ & $3.9 \times 10^{-4}$ & $5.5060 \times 10^{-1}$ & $4.5 \times 10^{-1}$ \\
$\mathrm{KCl}$ & $6.9 \times 10^{-3}$ & $8.2 \times 10^{-9}$ & $1.0000 \times 10^{0}$ & $1.2 \times 10^{-6}$ \\
$\mathrm{KOH}$ & $1.8 \times 10^{-3}$ & $2.7 \times 10^{-9}$ & $1.0000 \times 10^{0}$ & $1.5 \times 10^{-6}$ \\
$\mathrm{NaCl}$ & $9.3 \times 10^{-3}$ & $1.4 \times 10^{-9}$ & $1.0000 \times 10^{0}$ & $1.5 \times 10^{-7}$ \\
$\mathrm{NaOH}$ & $5.3 \times 10^{-3}$ & $7.9 \times 10^{-8}$ & $9.9999 \times 10^{-1}$ & $1.5 \times 10^{-5}$ \\
$\mathrm{~Pb}$ & $1.2 \times 10^{-2}$ & $5.0 \times 10^{-9}$ & $1.0000 \times 10^{0}$ & $4.2 \times 10^{-7}$ \\
$\mathrm{PuO}{ }_{2}$ & $2.8 \times 10^{-7}$ & $2.6 \times 10^{-14}$ & $1.0000 \times 10^{0}$ & $9.1 \times 10^{-8}$ \\
$\mathrm{UO}{ }_{2}$ & $2.0 \times 10^{-4}$ & $1.9 \times 10^{-11}$ & $1.0000 \times 10^{0}$ & $9.1 \times 10^{-8}$ \\
& & & \\
a. Entering mass flow rate composed of the vapor that enters the hood and the spray injected \\
in the quencher and scrubber components.
\end{tabular}




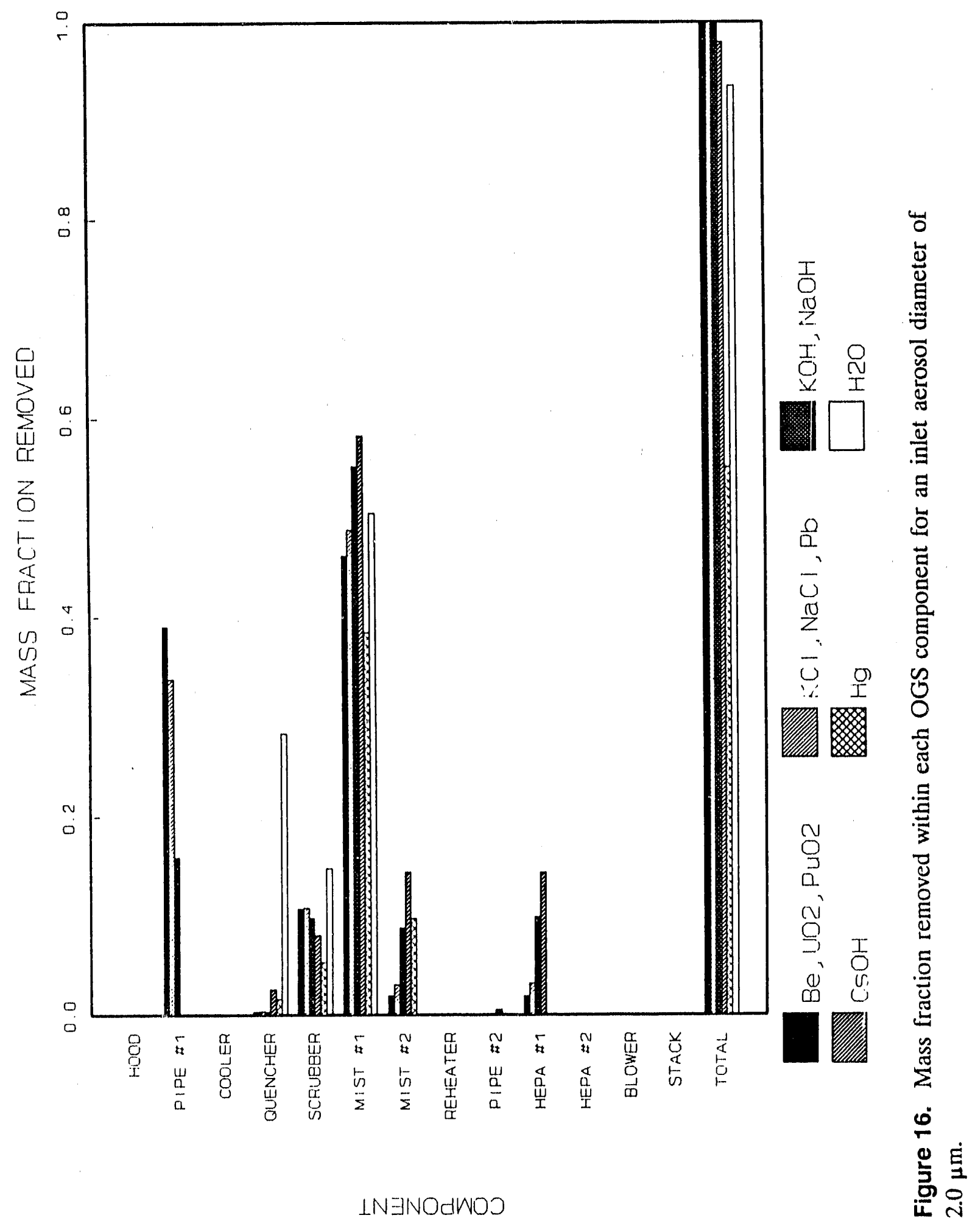




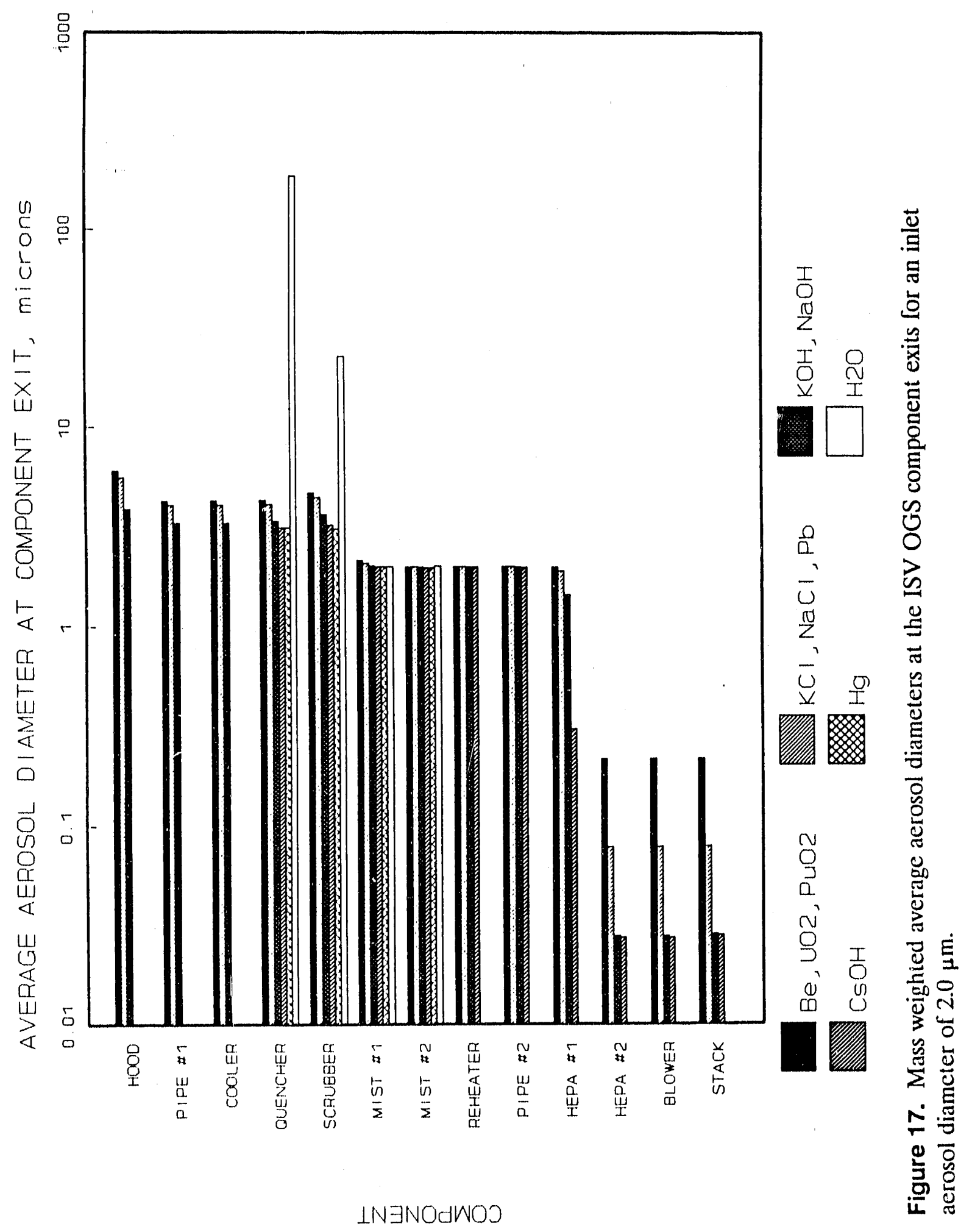




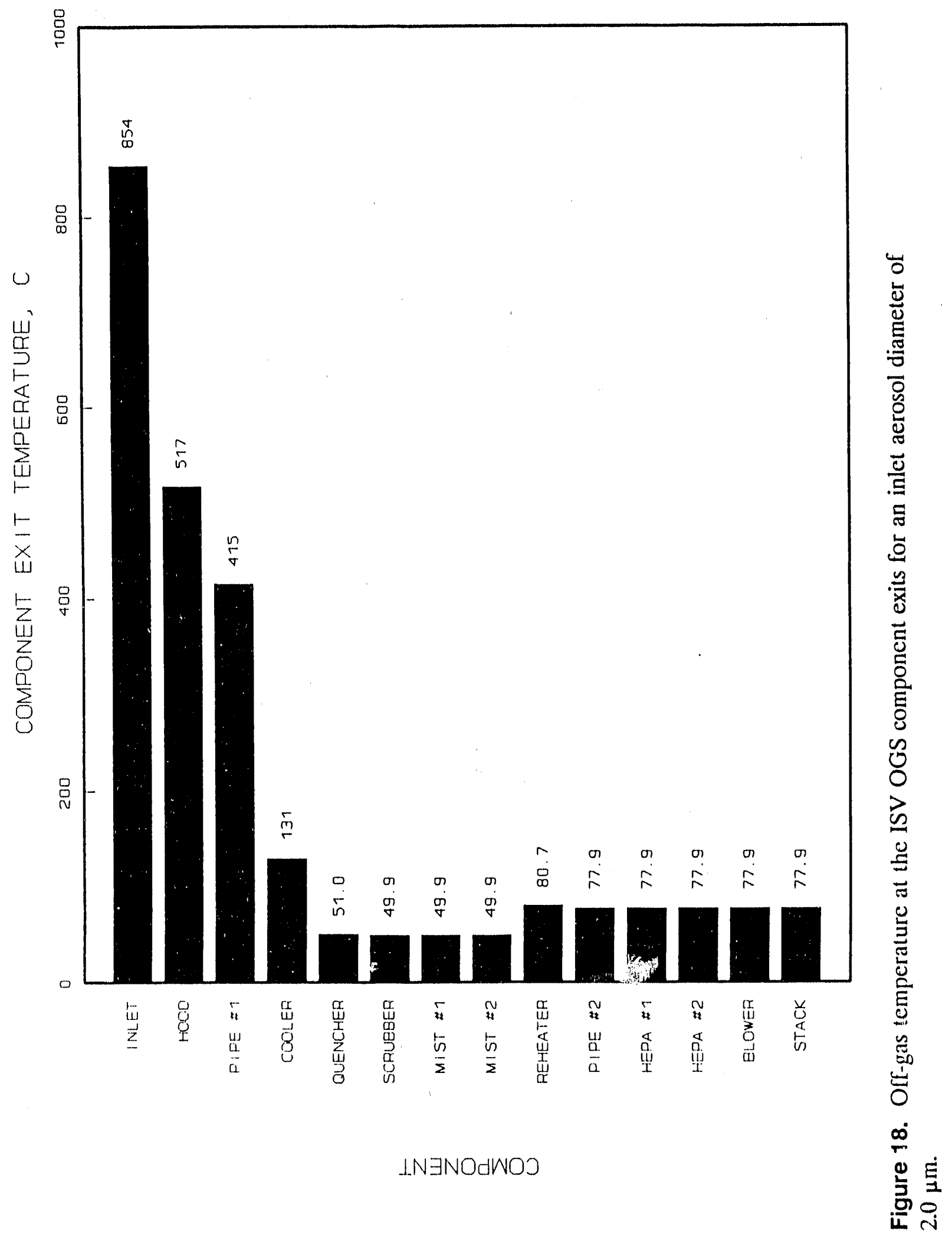


Table 13. Predicted OGS exit mass flow rates, decontamination fractions, and release fractions for an inlet aerosol diameter of $9.3 \mu \mathrm{m}$.

\begin{tabular}{lcccc}
\hline $\begin{array}{c}\text { Condensible } \\
\text { species }\end{array}$ & $\begin{array}{c}\text { Mass flow rate } \\
\text { entering OGS } \\
\mathrm{kg} / \mathrm{s}\end{array}$ & $\begin{array}{c}\text { Mass flow rate } \\
\text { exiting OGS } \\
\mathrm{kg} / \mathrm{s}\end{array}$ & $\begin{array}{c}\text { Decontamination } \\
\text { fraction }\end{array}$ & $\begin{array}{c}\text { Release } \\
\text { fraction }\end{array}$ \\
\hline $\mathrm{Be}$ & $9.4 \times 10^{-4}$ & $4.8 \times 10^{-15}$ & $1.0000 \times 10^{0}$ & $5.2 \times 10^{-12}$ \\
$\mathrm{CsOH}$ & $1.9 \times 10^{-11}$ & $8.7 \times 10^{-12}$ & $5.5295 \times 10^{-1}$ & $4.5 \times 10^{-1}$ \\
$\mathrm{H}_{2} \mathrm{O}^{\mathrm{a}}$ & $2.8 \times 10^{0}$ & $1.8 \times 10^{-1}$ & $9.3769 \times 10^{-1}$ & $6.2 \times 10^{-2}$ \\
$\mathrm{Hg}$ & $8.7 \times 10^{-4}$ & $7.4 \times 10^{-4}$ & $1.5145 \times 10^{-1}$ & $8.5 \times 10^{-1}$ \\
$\mathrm{KCl}$ & $6.9 \times 10^{-3}$ & $1.4 \times 10^{-7}$ & $9.9998 \times 10^{-1}$ & $2.0 \times 10^{-5}$ \\
$\mathrm{KOH}$ & $1.8 \times 10^{-3}$ & $6.1 \times 10^{-6}$ & $9.9652 \times 10^{-1}$ & $3.5 \times 10^{-3}$ \\
$\mathrm{NaCl}$ & $9.3 \times 10^{-3}$ & $2.6 \times 10^{-8}$ & $1.0000 \times 10^{0}$ & $2.8 \times 10^{-6}$ \\
$\mathrm{NaOH}$ & $5.3 \times 10^{-3}$ & $4.7 \times 10^{-6}$ & $9.9911 \times 10^{-1}$ & $8.9 \times 10^{-4}$ \\
$\mathrm{~Pb}$ & $1.2 \times 10^{-2}$ & $8.1 \times 10^{-8}$ & $9.9999 \times 10^{-1}$ & $6.8 \times 10^{-6}$ \\
$\mathrm{PuO}_{2}$ & $2.8 \times 10^{-7}$ & $1.5 \times 10^{-18}$ & $1.0000 \times 10^{0}$ & $5.1 \times 10^{-12}$ \\
$\mathrm{UO}_{2}$ & $2.0 \times 10^{-4}$ & $1.1 \times 10^{-15}$ & $1.0000 \times 10^{0}$ & $5.1 \times 10^{-12}$
\end{tabular}

a. Entering mass flow rate composed of the vapor that enters the hood and the spray injected in the quencher and scrubber components. 


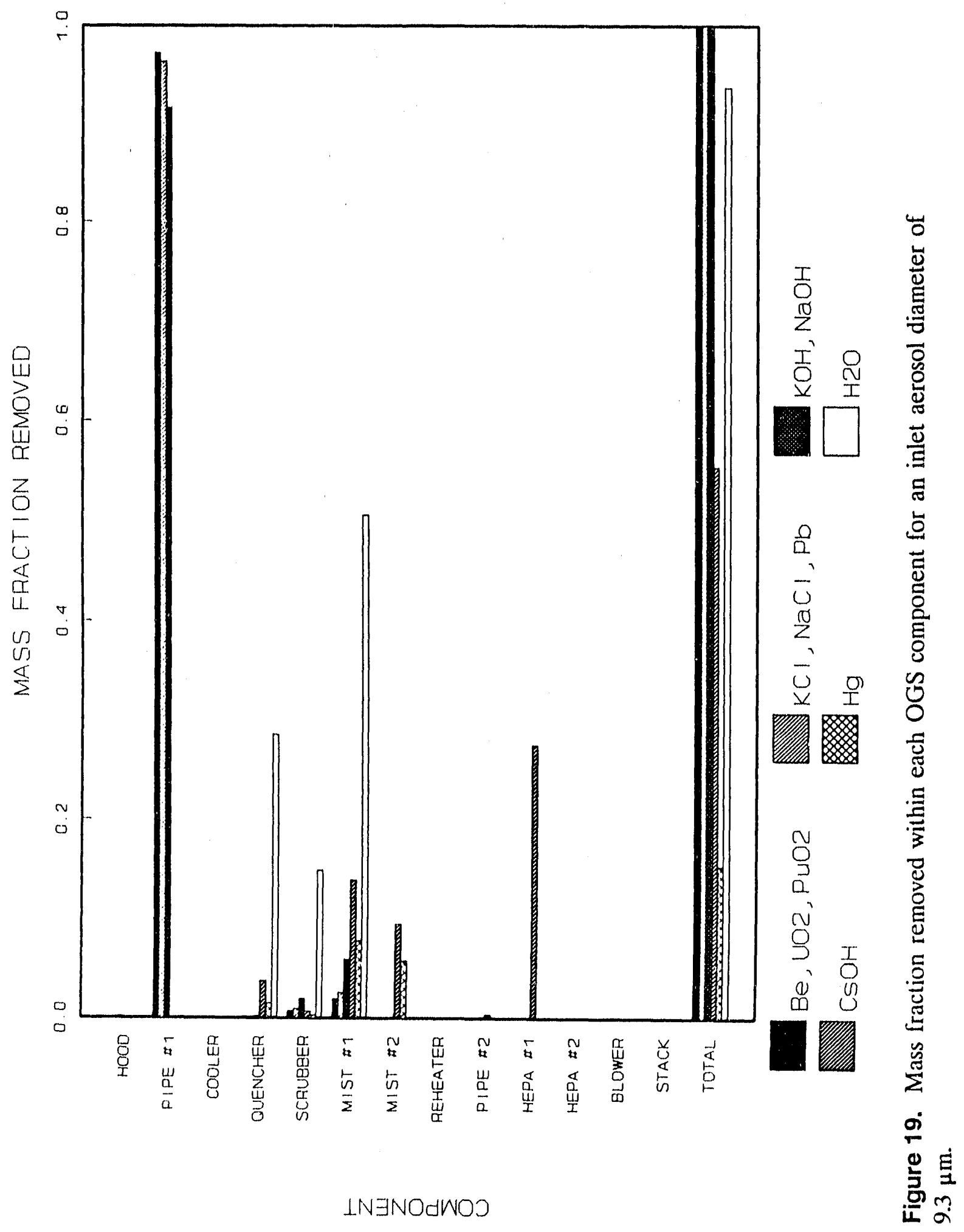




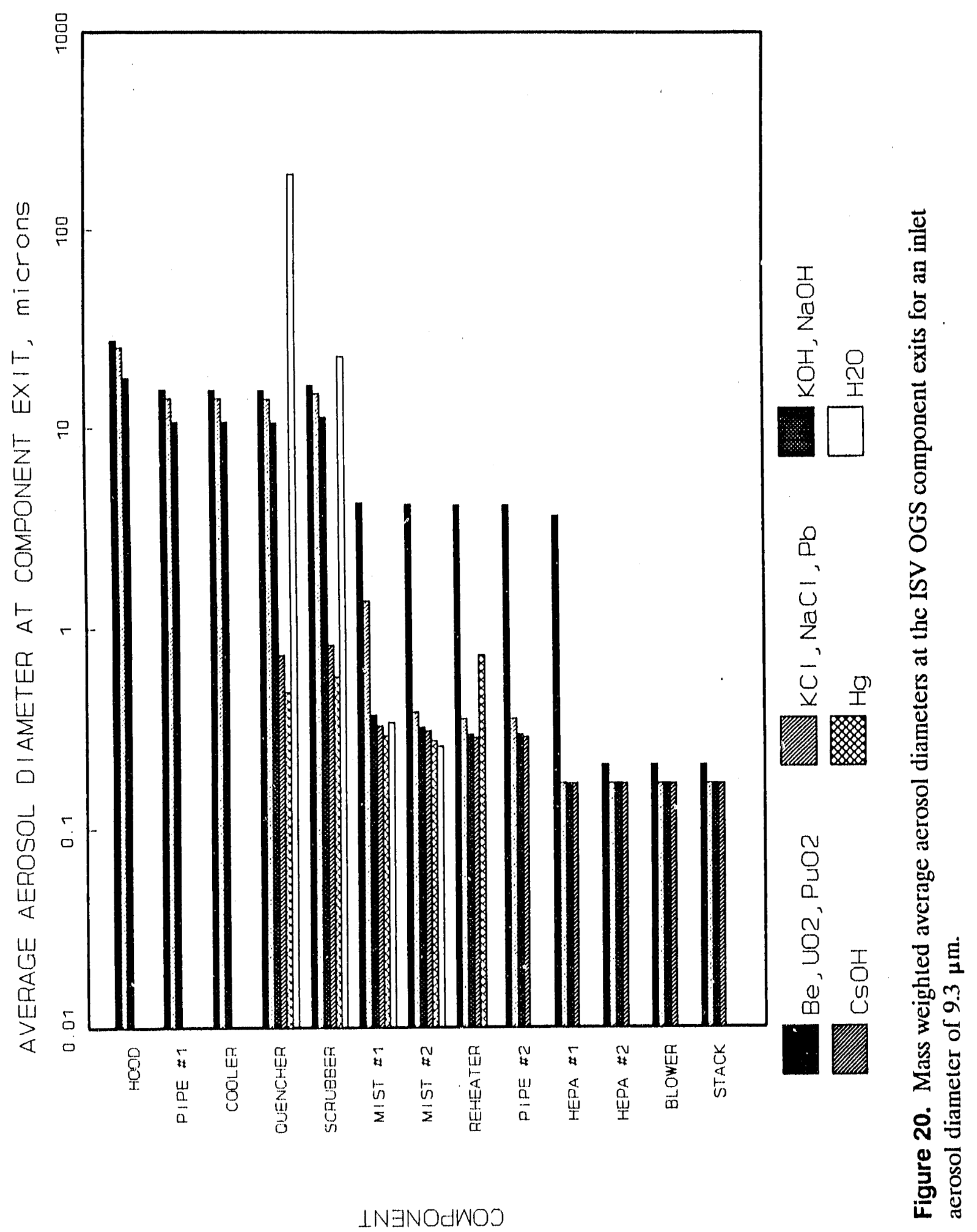




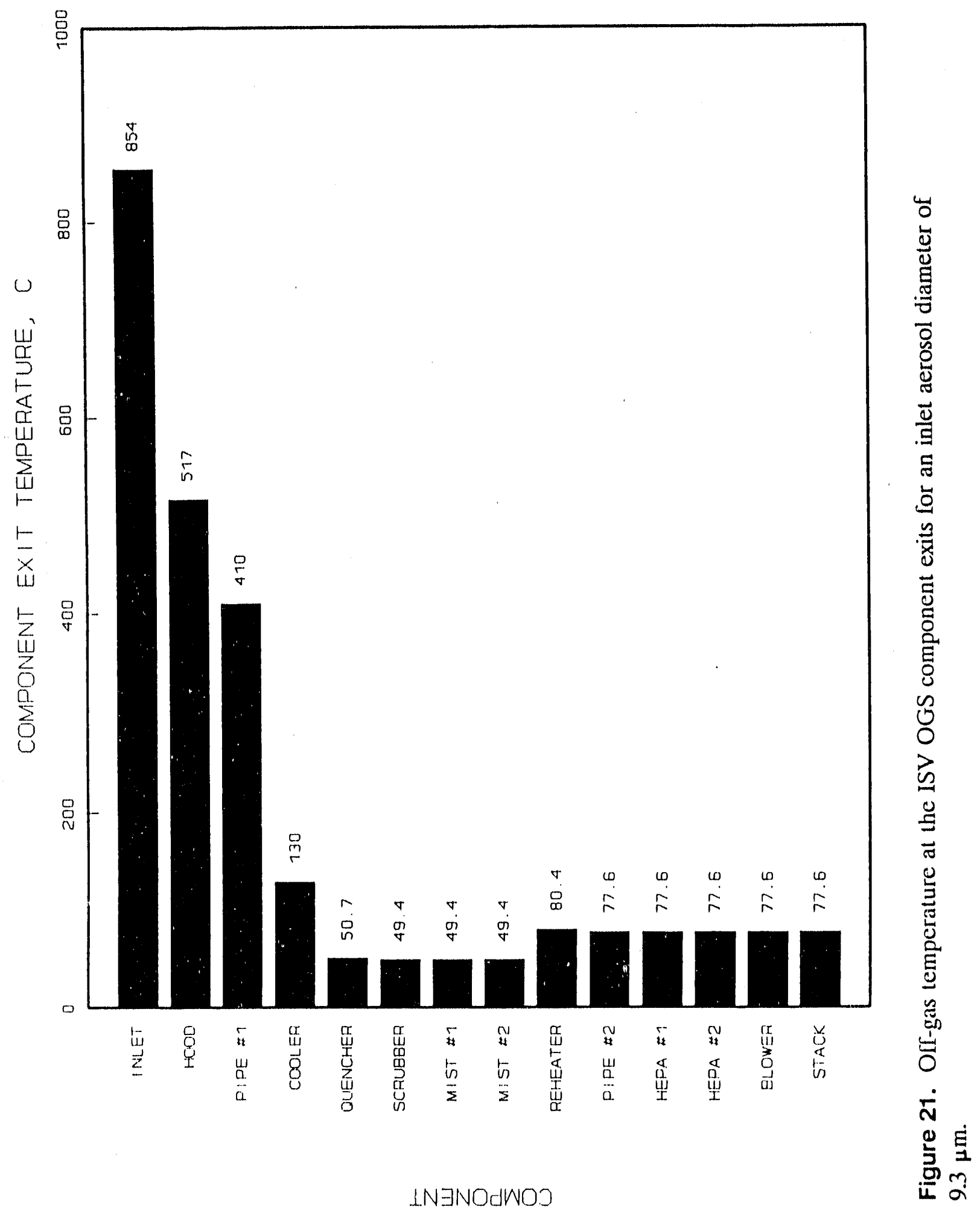


Cooler-In the off-gas cooler, additional heat was removed and the off-gas exited at approximately $131^{\circ} \mathrm{C}\left(268^{\circ} \mathrm{F}\right)$. At this temperature, the remaining vapor mass for species groups two and three condensed onto aerosols and the cooler surfaces, but the cesium hydroxide, mercury, and water remained in vapor form. Very little mass was removed and the average acrosol diameter at the exit remained unchanged.

Quencher-In the quencher, water spray injected at $52^{\circ} \mathrm{C}\left(126^{\circ} \mathrm{F}\right)$ cooled the off-gas by both sensible and latent effects. The temperature at the quencher exit was $49.9,51.0$, and $50.7^{\circ} \mathrm{C}$ $\left(122,124,123^{\circ} \mathrm{F}\right)$ for the three inlet aerosol sizes, respectively. These temperatures were less than for the entering water spray due to evaporative cooling. The slight variation in the exit temperature was due to a combination of differences in the thermal mass entering the quencher and the evaporative cooling effect. At these lower temperatures, almost all of the cesium hydroxide and twothirds of the mercury was condensed onto aerosols. For all species except water, the mass removed in the quencher was small. For water, a large fraction of the injected water aerosols were removed by gravity deposition. For the species' that entered the quencher as aerosols, the mass average aerosol diameters remained virtually unchanged in the quencher. The exit diameters for the cesium hydroxide and mercury were in general smaller than the other species' aerosols because they were formed by condensation of vapor onto smaller aerosols. The mass averaged aerosol diameter for the water aerosols decreased from the injected size of $200 \mu \mathrm{m}$ to an exit value of approximately $190 \mu \mathrm{m}$. This decrease was due to a combination of evaporation and to deposition of the larger aerosols. At the quencher exit, the water vapor was slightly subsaturated.

Tandem Nozale Scrubber-In the scrubber, agglomeration of the aerosols with additional injected water aerosols increased the aerosol sizes and deposition of the larger aerosols occurred. At the exit, the mass averaged aerosol diameter for the water aerosols was approximately $23 \mu \mathrm{m}$. This value was less than the entering size of $190 \mu \mathrm{m}$ because of deposition of the larger aerosols, but was greater than the injected spray size of $20 \mu \mathrm{m}$ because of agglomeration. The mass of water removed was dominated by the large injected acrosols being removed by gravitational and turbulent deposition mechanisms. Additional evaporative cooling of the off-gas occurred as additional water aerosols were evaporated and the water vapor exited the scrubber at saturation. The off-gas exit temperature was $50.1,49.9$, and $49.4^{\circ} \mathrm{C}\left(122.2,121.8\right.$, and $\left.120.9^{\circ} \mathrm{F}\right)$ for Runs 1,2 , and 3 , respectively.

Mist Eliminators-In the mist eliminators, the dominant aerosol removal mechanism was the centrifugal force mechanism in the vane plate bends. The mass fraction removed was a function of both the aerosol size distribution and the amount of mass that enters. For the three inlet aerosol sizes, the mass fraction removed was a maximum for the $2.0 \mu \mathrm{m}$ aerosol size. For the $0.2 \mu \mathrm{m}$ inlet aerosol size, the average aerosol size at the mist eliminator entrance was smaller so that the removal efficiency was also reduced and less mass was removed. For the $9.3 \mu \mathrm{m}$ inlet aerosol size, the average aerosol sizes for species' groups one, two, and three were larger than for the other two runs, and the removal efficiency was increased. However, the mass fraction removed was less because most of the inlet mass was already removed in the off-gas jumper piping. For groups four and five, the average aerosol size was sinaller than for the previous two runs, so that the removal efficiency was reduced and less mass removed. The smaller acrosol sizes for groups four and five were due to most of the large aerosols being removed prior to the quencher. This resulted in the cesium hydroxide and mercury vapor condensing onto the remaining smaller aerosols. 
In the second mist eliminator, for species' groups one, two, and three, the mass removed was greatest for Run 1 and smallest for Run 3. That is, for these species, the removal decreased with increasing inlet aerosol size. Also, the fraction removed in the second mist eliminator was less than in the first mist eliminator since most of the mass was already removed. For groups four and five, the mass removed was greatest for Run 2. In Run 1, the removal efficiency for these species was reduced because of the small aerosol sizes that enter and less mass was removed than for Run 2 . in Run 3, the average aerosol size that entered was even smaller than for Run 1, thus the removal efficiency was smaller, and again less mass was removed than for Run 2.

The mass averaged aerosol diameters at the second mist eliminator exit decreased slightly for all three runs and all of the species' groups.

Reheater-In the reheater, the surface heat flux increased the off-gas temperature to approximately $80^{\circ} \mathrm{C}\left(176^{\circ} \mathrm{F}\right)$. A small variation in the exit temperature for the three runs was due to variations in the thermal mass entering the reheater. However, for all three runs, the increased gas temperature evaporated the remaining mercury and water aerosols. (An exception to this occurred for Run 3 in which a very small number of large mercury aerosols remained. However, shortly after exiting the reheater, these remaining mercury aerosols also evaporated.) For species' groups two, three, and four, a small fraction of the remaining aerosols were deposited on the reheater walls. Because of the very high surface temperature of the reheater, most of this deposited mass evaporated from the surface and returned to the off-gas where it either condensed onto other aerosols or remained in the off-gas as supersaturated vapor.

Piping Connecting the Reheater with the HEPA Filters-Upon entering the piping, the off-gas temperature decreased to approximately $78^{\circ} \mathrm{C}\left(172^{\circ} \mathrm{F}\right)$ due to heat transferred to the cooler pipe wall. In Run 2, species' groups two, three, and four entered this piping at supersaturated conditions. The supersaturated vapor then condensed onto either the piping wall or the small number of remaining aerosols, but most nucleated into very small aerosols $(<0.02 \mu \mathrm{m}$ in diameter). The diameter of these nucleated aerosols were more than two orders of magnitude smaller than the mass averaged aerosol diameter of $2 \mu \mathrm{m}$. Agglomeration of the smaller aerosols with the mass dominant larger ones was limited because of the small number of large aerosols available.

HEPA Filters-Upon entering the first HEPA filter, $99.7 \%$ of the remaining aerosols larger than $0.2 \mu \mathrm{m}$ were removed. In this HEPA filter, for species' groups one, two, and three, the mass removed was greatest for Run 1 and smallest for Run 3. For Run 1, the mass fraction removed was large because a large fraction of the inlet mass had not been removed and most was in aerosol form with a diameter greater than $0.2 \mu \mathrm{m}$. The fraction of mass removed was less for Runs 2 and 3 because a larger fraction of the inlet mass was removed in prior components. For the cesium hydroxide, the release fraction was smallest for Run 2 , because most of the inlet mass was removed in prior components.

The mass fraction removed by the second HEPA filter was very small for all species and all three inlet aerosol sizes. However, the small amount of mass that was removed had large effects on the exit mass average aerosol size. This was particularly apparent for Run 2 , in which the exit aerosol sizes for species' groups two, three, and four were $0.08,0.03$, and $0.03 \mu \mathrm{m}$, respectively. These small aerosols originated in the reheater and piping that followed. As discussed above, for Run 2 the 
supersaturated vapor exiting the reheater nucleated into very small aerosols $(<0.02 \mu \mathrm{m})$ which did not agglomerate with the small number of larger aerosols $(\sim 2 \mu \mathrm{m}$ in diameter). Prior to this second HEPA filter, the small number of larger aerosols dominated the mass average aerosol size distribution. However, in the first and second HEPA filters, $99.999 \%$ these larger aerosols were removed; the smaller aerosols passed through toth. At the second HEPA filter exit, these smaller aerosols remained and dominated the mass average aerosol size distribution.

Blower and Stack-The mass fractions removed by the blower and stack were very small $\left(<1 \times 10^{-6}\right)$ for all species' and inlet aerosol sizes. The off-gas temperature at the stack exit was $76.9,77.9$, and $77.6^{\circ} \mathrm{C}\left(170.4,172.2\right.$, and $\left.171.7^{\circ} \mathrm{F}\right)$ for Runs 1,2 , and 3 , respectively. The slight variation in the exit temperature for the three runs was due to the variation in the removal rates and thus the thermal mass passing throughout the OGS.

Summary. The results preiented in Figure 11 and Figure 12 indicate that the overall DF and RF for the ISV OGS is a function of the species' properties and the inlet aerosol diameter. For species' group one, the DF is essentially 1.0 for all three inlet aerosol diameters. The RF for this group is very small and decreases as the inlet aerosol size increases. This group has a low EVC for the OGS operating temperature 1 ange and entered the OGS as aerosols.

For species' groups two, three, four, and five, a different trend is observed. The DF values for these groups are maximum for the $2.0 \mu \mathrm{m}$ inlet aerosol size. Conversely, the RF values are minimum at this inlet aerosol size. These species' groups have relatively moderate to high EVCs and entered the OGS as either all vapor or a mixture of vapor and aerosol.

In general, the RF is highest for the mercury and lowest for species' group one. That is, the OGS RF is lower for species with lower EVCs. Furthermore, for those species that enter the OGS as aerosols, the OGS RF decreases with inlet aerosol size because the mass removal is dominated by gravitational and centrifugal deposition mechanisms. The efficiency of these mechanisms increase with increased aerosol size.

For those species that enter as either all vapor or a combination of aerosol and vapor, the OGS RF is minimum for the $2.0 \mu \mathrm{m}$ inlet acrosol size case. This result is due to the vapor condensing onto small aerosols as the off-gas is cooled. The size of the aerosols that the vapor condenses on is a complex function of the acrosol sizes available at the location that the vapor condenses. The location at which this occurs is a function of the species EVC. The aerosol size distribution at any location is a function of the removal characteristics of the OGS and the inlet aerosol size. For example, for the $0.2 \mu \mathrm{m}$ inlet aerosol size case, very little of the inlet aerosols are removed prior to the vapor condensing onto the aerosols, so that most of the vapor condenses onto aerosols not much larger than at the inlet (or slightly larger due to agglomeration). For an inlet aerosol size of $9.3 \mu \mathrm{m}$, most of the inlet aerosols are removed in the off-gas jumper piping, so that the vapor nucleates into and condenses onto relatively small aerosols. For the $2.0 \mu \mathrm{m}$ inlet aerosol case, the aerosol removal rate in the off-gas jumper pipe is less than for the $9.3 \mu \mathrm{m}$ inlet size. This results in sufficient aerosols remaining aloft that the vapor is able to condense onto larger aerosols than in either of the other two cases. These larger aerosols are then more effectively removed by the OGS, resulting in the minimum overall RF. 
The removal of water is virtually independent of the inlet aerosol size. This result is primarily due to the water mass removed being dominated by the water injected into the quencher and scrubber components. The mass flow rate of the water vapor entering the hood was $8.7 \times 10^{-2} \mathrm{~kg} / \mathrm{s}$. The total mass flow rate for the water injected into the quencher and scrubber was $2.8 \mathrm{~kg} / \mathrm{s}$. The inlet aerosols sizes for the water injected into the quencher and scrubber were 200 and $20 \mu \mathrm{m}$, respectively, and remained unchanged for all of the calculations. The removal of these large injected water aerosols occurs in the quencier, scrubber, and first mist eliminator.

Examination of the results as a function of the OGS components reveals additional effects of the species' properties and inlet aerosol size. For example, the components which remove the mass is also dependent on the inlet aerosol size and species' group. As shown in Figure 13, for an inlet diameter of $0.2 \mu \mathrm{in}$, the removal of species' groups one, two, and three was dominated by the first and second mist eliminators and the first HEPA filter. For an inlet diameter of $2.0 \mu \mathrm{m}$, the removal occurred earlier in the OGS. For this case, the removal was dominated by the off-gas jumper piping, scrubber, first and second mist eliminator, and the first HEPA filter. For an inlet diameter of $9.3 \mu \mathrm{m}$, the removal was dominated by the off-gas jumper piping.

For species' groups four and five, the variation of the component's removal characteristics is not as pronounced as with groups one, two, and three. However, as discussed previously, the magnitude of the removal is a strong function of the inlet aerosol size. The removal of cesium hydroxide primarily occurred in the scrubber, mist eliminators, and first HEPA filter. For mercury, the first and second mist eliminators dominated in removing mercury that condensed onto aerosols. The HEPA filters did not remove any because the mercury was vaporized in the reheater prior to the HEPA filters. Neither cesium hydroxide or mercury was removed prior to the quencher because both were in vapor form. Similarly, no water was removed prior to the quencher nor after the reheater because it was in vapor form. 


\section{CONCLUSIONS}

A conceptual model of the vapor and aerosol transport and deposition in the in situ vitrification (ISV) large-field test (LFT) off-gas system (OGS) has been developed. This model can be used to predict OGS process emissions under normal operating conditions and for postulated accidents. These predictions can be used in support of safety and risk assessments of the ISV LFT program. The model can also be used to evaluate design and/or procedural modifications, define tests, and predict test results.

The OGS vapor and aerosol transport and deposition has been modeled using the PULSE/MOD-ISV/VER 1.0.0 developmental computer code. Input data requirements include the specific geometries of the OGS components; the composition, rate, and temperature of the vapors and aerosols entering the OGS; and the OGS component surface temperatures or heat fluxes. Not all of these model inputs were available. Therefore, conceptual input parameters were developed. Using this input data, preliminary analyses of the OGS model were performed with the code. These analyses included a demonstration that the code predicts convergent results for the hood component, a comparison of code predictions with performance data for the OGS mist eliminator, and a preliminary sensitivity study of the complete OGS model to the inlet aerosol size. It should be noted that the calculations are preliminary. The results were obtained with a developmental code, which has not been verified or validated, using conceptual input data and parameters.

The preliminary model analyses have demonstrated:

- The code PULSE/MOD-ISV code predicts convergent results for the hood component. As the iteration tolerances are decreased, the precision of the results increases. Similarly, as the subsegmenting of the hood is increased, the results become more precise.

- $\quad$ Predicted performance efficiencies โor the mist eliminator component compare quite well with performance data.

- The preliminary sensitivily study of the overall OGS model indicate that, in general, the OGS decontamination fractions (DFs) and release fractions (RFs) are dependent upon the inlet aerosol sizes and the off-gas species properties.

The mass removal in the OGS is dominated by deposition of aerosols by centrifugal, gravitational, and, to a lesser degree, turbulent deposition mechanisms.

The dominant species property observed to affect the overall OGS DF and RF was the equilibrium vapor concentration (EVC). The OGS RF was lower for species with lower EVC. For example, those species that enter as aerosols have smaller RFs than those with higher EVCs that enter as vapor or a combination of vapor and aerosol. Also, for species that entered as either all vapor or a combination of vapor and aerosol, the amount of material released from the OGS was minimized for an inlet aerosol size of $2.0 \mu \mathrm{m}$. For species that entered as all aerosol, the mass released decreased with increasing inlet acrosol size. 
Future work on this project should include efforts to upgrade the PULSE/MOD-ISV code from developmental status, efforts to update OGS component models as revised information Lecomes available, and additional efforts to obtain more accurate estimates of the off-gas flow conditions entering the OGS. Upgrading of the PULSE/MOD-ISV code should include a thorough verification and validation program, the development of a users guide and code manual, improved phenomenon models, and improved input and output capabilities. Whether the code models need improvement should be determined by comparison of predicted results with experimental data. Proposed improvements should also be balanced with the required predictive accuracy. 


\section{REFERENCES}

1. D. A. Arrenholz and J. L. Knight, A Brief Analysis and Description of Transuranic Wastes in the Subsurface Disposal Area of the Radioactive Waste Management Complex at INEL, EGG-WTD-9438, February 1991.

2. D. A. Arrenholz, S. O. Bates, R. A. Callow et al., In Situ Vitrification Program Treatability Investigation Workplan, Draft, EGG-WM-9072, Junc 1990.

3. D. A. Arrenholz, In Situ Vitrification Program Treatability Investigation Progress Report, EGG-WTD-9383, Revision 1, February 1991.

4. D. L. Hagrman, TRAPMELT/PULSE Users' Manual, EGG-NE-8896, February 1990.

5. R. A. Callow et al., In Situ Vitrification Application to Buried Waste: Final Report of Intermediate Field Tests at Idaho National Engineering Laboratory, EGG-WTD-9807, August 1991.

6. D. A. Petti, et al., Power Burst Facility (PBF) Severe Fuel Damage Test 1-4 Test Results Report, NUREG/CR-5163, EGG-2542, April 1989.

7. H. Jordan and M. R. Kuhlman, TRAP-MELT2 User's Manual, NUREG/CR-4205, BMI-2124, May 1985.

8. F77L-EM/32, Version 4.00, Incline Village, Nevada: Lahey Computer Systems, Inc., 1990.

9. R. B. Bird, W. E. Stewart, and E. N. Lightfoot, Transport Phenomena, New York: John Wiley and Sons, 1960.

10. B. S. Petukhov, "Heat and Friction in Turbulent Pipe Flow with Variable Physical Properties," Advances in Heat Transfer, J. P. Harthett and T. F. Irvine, Jr., (eds.), Volume 6, New York: Academic Press, 1970.

11. D. A. Petti, Silver-Indium-Cadmium Control Rod Behavior and Aerosol Formation in Severe Reactor Accidents, NUREG/CR-4876, EGG-2501, April 1987.

12. W. C. Hinds, Aerosol Technology, New York: John Wiley and Sons, 1982.

13. P. G. Saffman and J. S. Turner, "On the Collision of Drops in Turbulent Clouds," Journal of Fluid Mechanics 1, 1956, pp. 16-30.

14. M. A. Delichasios and R. F. Probstein, Coagulation in Turbulent Flow - Theory and Experiment, AD-A031 297, 1974, p. 22.

15. P. C. Gormley and M. Kennedy, "Diffusion from Steam Flowing Through a Cylinder Tube," Proc. Royal Irish Academy, A52, pp. 163-169. 
16. N. B. Wood, "A Simple Method for the Calculation of Turbulent Deposition to Smooth and Rough Surfaces," Journal Aerosol Science, 12, 1981, pp 275-288.

17. N. A. Fuchs, The Mechanics of Aerosols, Oxford: Pergamon Press, 1964.

18. J. R. Brock, "On the Theory of Thermal rurces Acting on Aerosol Particles," Journal Colloid Science, 17, 1962, pp 768-780.

19. R. M. Elrick, D. A. Powers, and R. A. Sallach, Reactor Safety Research Semiannual Report January - June 1986 Volume 35, NUREG/CR-4805, SAND86-2752, Part 1, May 1987, pp. 204-218.

20. J. K. Hohorst (ed.), SCDAP/RELAP5/MOD2 Code Manual Volume IV: MATPRO-- A Library of Material Properties for Light-Water-Reactor Accident Analysis, NUREG/CR-5273 and EGG. 2555 Volume IV, Revision 3, February 1990.

21. V. X. Tung, V. K. Dhir, F. Chang, A. R. Karagozian, and F. Zhou, Enhancement of Forced Convection Heat Transfer in Tubes Using Staged Tangential Flow Injection, GRI 89/0020, 1989.

22. Marlo Coil, Nuclear Cooling, Inc., High Ridge, Missouri, 63049, Bulletin No. MC-6-870501.

23. TS-5 Series Horizontal Flow Mist Eliminators, TS-5/9-89/DP 3000, The Munters Corporation, Gas Cleaning Division, P.O. Box 6428, Fort Myers, FL 33911. 
Appendix A

Bulk Gas Temperature Model Derivation 
A-2 


\section{Appendix A}

\section{Bulk Gas Temperature Model Derivation}

This appendix presents the derivation of the equations used in calculating the gas temperature in the PULSE/MOD-ISV/VER 1.0.0 code. The calculation of the gas temperature is dependent upon the surface boundary condition of the channel. For a channel segment with a specified wall temperature boundary condition, the gas temperature is calculated using Equation (23) in the main report. For a wall heat flux boundary condition, Equation (24) is used. The derivation of these equations follows.

\section{A.1 Wall Temperature Boundary Condition}

The basis for estimating the temperature change of the gas is formulated with an energy balance on a packet of gas of volume $\mathrm{V}$. The increase in enthalpy of the gas packet is equal to the heat added by internal sources plus that transferred from the wall surface to the gas packet for a period of time $\Delta t$. For the PULSE/MOD-ISV code, the internal heat generation, $\mathrm{Q}$, is limited to the latent heat released by condensation and removed by evaporation of the condensible species. In the case of evaporation, the heat generation term is negative. The heat transferred at the wall surface is formulated as the product of the heat transfer coefficient, the wall surface area, and the temperature potential difference. This energy balance can be stated as:

$$
\left(T_{t+\Delta t}-T_{t}\right) \cdot \rho_{g} c_{p} V=Q \Delta t+h A_{w} \cdot\left(T_{w}-T_{t}\right) \Delta t
$$

where

$\begin{array}{lll}\mathrm{T}_{1+\Delta t} & = & \text { gas temperature at time } \mathrm{t}+\Delta \mathrm{t}(\mathrm{K}) \\ \mathrm{T}_{1} & = & \text { gas temperature at time } \mathrm{t}(\mathrm{K}) \\ \rho_{\mathrm{g}} & = & \text { density of the gas packet }\left(\mathrm{kg} / \mathrm{m}^{3}\right) \\ \mathrm{c}_{\mathrm{p}} & = & \text { specific heat capacity at constant pressure of the gas packet }[\mathrm{J} /(\mathrm{kg} \mathrm{K})] \\ \mathrm{V} & = & \text { volume of the gas packet }\left(\mathrm{m}^{3}\right) \\ \mathrm{Q} & = & \text { internal heat generation rate }(\mathrm{W}) \\ \mathrm{h} & = & \text { wall heat transfer coefficient }\left(\mathrm{W} / \mathrm{m}^{2}-\mathrm{K}\right) \\ \mathrm{A}_{\mathrm{w}} & = & \text { wall surface area of the channel }\left(\mathrm{m}^{2}\right) \\ \mathrm{T}_{\mathrm{w}} & = & \text { wall temperature }(\mathrm{K})\end{array}$

In the limit that $\Delta \mathrm{t}$ goes to zero, Equation (A-1) can be rewritten as

$$
\frac{d T}{d t}=\frac{Q}{\rho_{g} c_{p} V}+\frac{h A_{w}}{\rho_{g} c_{p} V} \cdot\left(T_{w}-T\right)
$$


$\frac{d \theta}{d t}=\frac{Q}{\rho_{g} c_{p} V}-\lambda \theta$

where

$$
\begin{array}{lll}
\theta & = & \mathrm{T}-\mathrm{T}_{\mathrm{w}},(\mathrm{K}) \\
\lambda & = & \left(\mathrm{h} \mathrm{A}_{\mathrm{w}}\right) /\left(\rho \mathrm{c}_{\mathrm{p}} \mathrm{V}\right),\left(\mathrm{s}^{-1}\right) .
\end{array}
$$

Equation (A-3) can be rearranged as

$\frac{\mathrm{d} \theta}{\mathrm{dt}}+\lambda \theta=\frac{\mathrm{Q}}{\rho_{\mathrm{g}} \mathrm{c}_{\mathrm{p}} \mathrm{V}}$

Multiplying boik sides by $\mathrm{e}^{\lambda t}$ and rearranging one obtains

$$
\frac{d}{d t}\left(\theta e^{\lambda t}\right)=\frac{Q}{\rho_{g} c_{p} V} e^{\lambda t}
$$

Multiplying both sides by $\mathrm{dt}$ and integrating the left hand side from $\theta_{1} \mathrm{e}^{\lambda t 1}$ to $\theta_{2} \mathrm{e}^{\lambda t 2}$ and the right hand side from $t_{1}$ to $t_{2}$ yields

$\int_{\theta_{1} \mathrm{e}^{\lambda t_{1}}}^{\theta_{2} \mathrm{e}^{\lambda t_{2}}} \mathrm{~d}\left(\theta \mathrm{e}^{\lambda t}\right)=\frac{Q}{\rho_{\mathrm{g}} \mathrm{c}_{\mathrm{p}} \mathrm{V}} \cdot \int_{\mathrm{i}_{1}}^{t_{2}} \mathrm{e}^{\lambda t^{\prime}} \mathrm{dt} \mathrm{t}^{\prime}$

or

$\theta_{2} e^{\lambda t_{2}}-\theta_{1} e^{\lambda t_{1}}=\frac{Q}{h A_{w}}\left(e^{\lambda t_{2}}-e^{\lambda t_{1}}\right)$

where

$$
\begin{array}{lll}
\theta_{1} & = & \mathrm{T}_{1}-\mathrm{T}_{\mathrm{w}} \\
\theta_{2} & = & \mathrm{T}_{2}-\mathrm{T}_{\mathrm{w}} \\
\mathrm{t}^{\prime} & = & \text { dummy variable of integration. }
\end{array}
$$

This equation can be rearranged as 
$\theta_{2}=\theta_{1} \mathrm{e}^{-\lambda\left(t_{2}-t_{1}\right)}+\frac{\mathrm{Q}}{\mathrm{hA}}\left(1-\mathrm{e}^{\left.-\lambda\left(I_{2}-t_{1}\right)\right)}\right)$

Substituting for $\theta_{1}, \theta_{2}$, and $\lambda$ and rearranging one obtains

$\left(T_{2}-T_{1}\right)=\left(T_{w}-T_{1}+\frac{Q}{h A_{w}}\right)\left(1-e^{-\frac{A_{w} h}{\rho_{g} c_{p}} \nabla^{\left(t_{2}-t_{1}\right)}}\right)$.

Letting

$$
\begin{array}{lll}
t_{1} & = & t \\
t_{2} & = & t_{1}+8 t
\end{array}
$$

and substituting into Equation (A-9) one obtains the change in gas temperature over a time step of $8 \mathrm{t}$ :

$\left(T_{t+\delta 1}-T_{1}\right)=\left(T_{w}-T_{1}+\frac{Q}{h A_{w}}\right)\left(1-e^{-\frac{A_{w h t}}{\rho_{g} c_{p} \nabla} \cdot \delta 1}\right)$.

\section{A.2 Wall Heat Flux Boundary Condition}

The basis for estimating the temperature change of the gas is formulated with an energy balance similar to that for the wall temperature boundary condition case described above. However for this case, the heat transferred from the wall surface is formulated as the product of the wall heat flux and the surface area. This energy balance can be stated as:

$\rho_{g} c_{p} V \cdot \Delta T=\left(Q+Q_{w} A_{w}\right) \Delta t$

where

$\begin{array}{ll}\mathrm{T}_{1} & = \\ \mathrm{T}_{1+\Delta 1} & = \\ \mathrm{Q}_{\mathrm{w}} & = \\ \mathrm{A}_{\mathrm{w}} & = \\ \mathrm{Q} & = \\ \mathrm{V} & = \\ \rho & = \\ \mathrm{c}_{\mathrm{p}} & =\end{array}$

gas temperature at time $\mathrm{t}(\mathrm{K})$

gas temperature at time $t+\Delta t(K)$

wall heat flux $\left(\mathrm{W} / \mathrm{m}^{2}\right)$

wall surface area of the channel $\left(\mathrm{m}^{2}\right)$

internal heat generation rate $(\mathrm{W})$

volume of the gas packet $\left(\mathrm{m}^{3}\right)$

density of the gas packet $\left(\mathrm{kg} / \mathrm{m}^{3}\right)$

specific heat capacity at constant pressure of the gas packet $[\mathrm{J} /(\mathrm{kg} \mathrm{K})]$. 
In the limit as $\Delta t$ approaches zero, Equation (A-11) can be rewritten as

$$
\frac{d T}{d t}=\frac{\left(Q+Q_{w} A_{w}\right)}{\rho_{g} c_{p} V}
$$

Multiplying both sides by dt and integrating the left hand side from $T_{1}$ to $T_{2}$ and the right hand side from $t_{1}$ to $t_{2}$ yields

$\int_{T_{1}}^{T_{2}} d T^{\prime}=\frac{\left(Q+Q_{w} A_{w}\right)}{\rho_{g} c_{p} V} \cdot \int_{t_{1}}^{t_{2}} d t^{\prime}$

or

$T_{2}-T_{1}=\frac{\left(Q+Q_{w} A_{w}\right)}{\rho_{g} c_{p} V}\left(t_{2}-t_{1}\right)$

where

$$
\mathrm{T}^{\prime}, \mathrm{t}^{\prime}=\text { dummy variables of integration. }
$$

Letting

$$
\begin{array}{lll}
t_{1} & = & t \\
t_{2} & = & t_{1}+8 t
\end{array}
$$

and substituting into Equation (A-14) one obtains the change in gas temperature over a time step of $8 \mathrm{t}$ :

$$
\left(T_{t+\Delta t}-T_{t}\right)=\frac{\left(Q+Q_{w} A_{w}\right)}{\rho_{g} c_{p} V} \delta t
$$


Appendix B

\section{Pulse/MOD-ISV Material Property Models}




$$
\text { B-2 }
$$




\section{Appendix B}

\section{Pulse/MOD-ISV Material Property Models}

A list of the condensible and non-condensible species that can be modeled with the PULSE/MOD-ISV/VER 1.0.0 code is given in Table B-1. The condensible species have been modified from those modeled by the TRAPMELT/PULSE code. 'The revised species are those that might be encountered in the ISV process. The non-condensible gases have not been modified from those used in the TRAPMELT/PULSE code. A total of fifteen material properties are required by the PULSE/MOD-ISV code. Six of these are non-condensible gas properties and the remaining eight are condensible species properties. Each property is provided by a function or data statement. In this section, the material property data and functions used in PULSE/MOD-ISV are described. First, the non-condensible gas properties will be presented and then be followed by the condensible species.

\section{B.1 Non-condensible Gas Properties}

For the non-condensible gases, the properties and associated subcodes are the gas thermal conductivity (GASCON), the gas specific heat capacity at constant pressure (GCP), gas density (GDENS), gas molecule mean free path (GMFP), gas effective emissivity (GMISS), and gas viscosity (GVISCO). All of these functions are identical to those in the TRAPMELT/PULSE code and all are described in detail in the MATPRO materials properties package documentation. ${ }^{\text {B-1 }}$

\section{B.1.1 Gas Thermal Conductivity}

The thermal conductivity of the non-condensible gas mixture is required to calculate the temperature of the gas packet proceeding down a channel with wall temperatures different from gas. The thermal conductivity of the mixture is calculated for the ten non-condensible components listed in Table B-1. It is calculated with the expression (see Reference B-1)

$$
k_{\text {mix }}=\sum_{i=1}^{n}\left(\frac{k_{i} x_{i}}{x_{i}+\sum_{\substack{j=1 \\ j \neq i}}^{n} \psi_{i j} x_{j}}\right)
$$

where

$$
\psi_{i j}=\phi_{i j}\left[1+2.41 \frac{\left(M_{i}-M_{j}\right)\left(M_{i}-0.142 M_{j}\right)}{\left(M_{i}+M_{j}\right)^{2}}\right]
$$


Table B-1. Condensible and non-condensible species modeled in the PULSE/MOD-ISV VER 1.0.0 code.

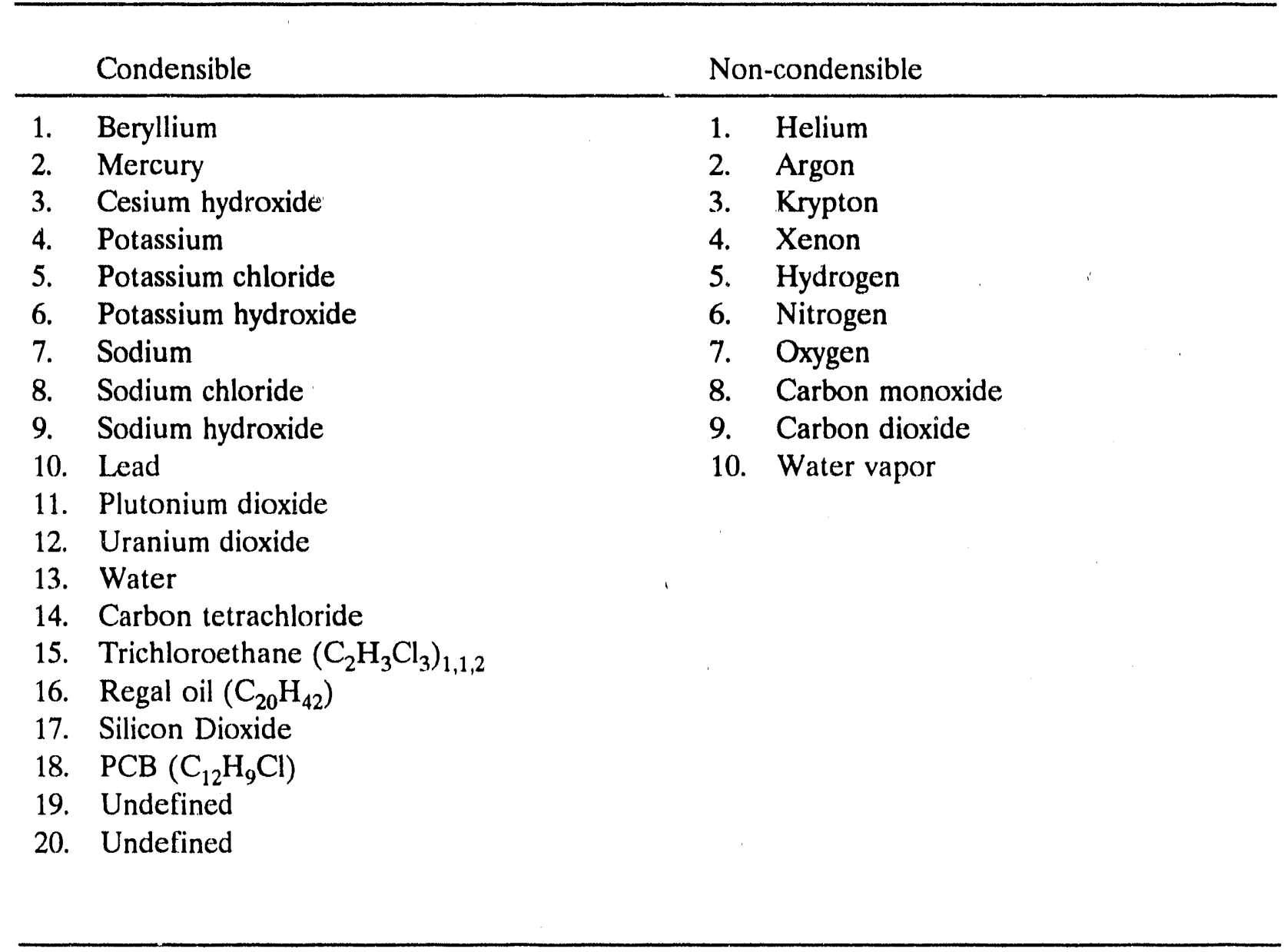


and

$$
\phi_{i j}=\frac{\left[1+\left(\frac{k_{i}}{k_{j}}\right)^{1 / 2} \cdot\left(\frac{M_{i}}{M_{j}}\right)^{1 / 4}\right]^{2}}{2^{3 / 2}\left(1+\frac{M_{i}}{M_{j}}\right)^{1 / 2}}
$$

and

$$
\begin{array}{lll}
n & = & \text { number of components in mixture (unitless) } \\
\mathrm{M}_{\mathrm{i}} & = & \text { molecular mass of component } \mathrm{i}(\mathrm{kg} / \mathrm{kg}-\text { mole) } \\
\mathrm{x}_{\mathrm{i}} & = & \text { mole fraction of the component } \mathrm{i} \text { (unitless) } \\
\mathrm{k}_{\mathrm{i}} & = & \text { thermal conductivity of the component } \mathrm{i}[\mathrm{W} /(\mathrm{m} \mathrm{K})]
\end{array}
$$

The thermal conductivities for the ten gases are obtained as follows. For the pure noble or diatomic gases, the correlation as a function of temperature is given by Equation (B-4):

$k_{i}=A_{i} \cdot T^{B_{i}}$

where

$$
\begin{array}{lll}
\mathbf{k}_{\mathrm{i}} & = & \text { thermal conductivity of the ith gas component }[\mathrm{W} /(\mathrm{m} \mathrm{K})] \\
\mathrm{T} & = & \text { gas temperature }(\mathrm{K})
\end{array}
$$

and $A_{i}$ and $B_{i}$ are coefficients for each noble or diatomic gas. The coefficient values are listed in Table B-2.

For water vapor, the thermal conductivity is calculated using the following equations.

For $\mathrm{T} \leq 973.15 \mathrm{~K}$

$$
\begin{aligned}
k_{w} & =\left(-2.243 \times 10^{-7}+9.096 \times 10^{-10} \cdot \mathrm{T}-6.004 \times 10^{-14} \cdot \mathrm{T}^{2}\right) \cdot \frac{\mathrm{P}}{\mathrm{T}} \\
& +\frac{1.009 \cdot \mathrm{P}^{2}}{\mathrm{~T}^{2} \cdot \mathrm{T}_{\mathrm{c}}^{4.2}}+1.76 \times 10^{-2}+5.87 \times 10^{-5} \mathrm{~T}_{\mathrm{c}}+1.04 \times 10^{-7} \mathrm{~T}_{\mathrm{c}}^{2} \\
& -4.51 \times 10^{-11} \mathrm{~T}_{\mathrm{c}}{ }^{3}
\end{aligned}
$$


Table B-2 Coefficients used in Equation (B-4) to calculate the thermal conductivity for the non-condensible gases modeled in the PULSE/MOD-ISV VER 1.0.0 code (see Reference B-1).

\begin{tabular}{llc}
\hline Non-condensible & $\begin{array}{c}\mathrm{A}_{\mathrm{i}} \\
\mathrm{W} /(\mathrm{m} \mathrm{K})\end{array}$ & $\begin{array}{c}\mathrm{B}_{\mathrm{i}} \\
\text { unitless }\end{array}$ \\
\hline 1. Helium & $2.639 \times 10^{-3}$ & 0.7085 \\
2. Argon & $2.986 \times 10^{-4}$ & 0.7224 \\
3. Krypton & $8.247 \times 10^{-5}$ & 0.8363 \\
4. Xenon & $4.351 \times 10^{-5}$ & 0.8616 \\
5. Hydrogen & $1.097 \times 10^{-3}$ & 0.8785 \\
6. Nitrogen & $5.314 \times 10^{-4}$ & 0.6898 \\
7. Oxygen & $1.853 \times 10^{-4}$ & 0.8729 \\
8. Carbon monoxide & $1.403 \times 10^{-4}$ & 0.9090 \\
9. Carbon dioxide & $9.460 \times 10^{-6}$ & 1.3120 \\
10. Water vapor & Alternative correlation used. \\
\hline
\end{tabular}

and for $\mathrm{T}>973.15 \mathrm{~K}$,

$k_{w}=4.44 \times 10^{-6} \mathrm{~T}^{1.45}+9.5 \times 10^{-5}\left(\frac{2.1668 \times 10^{-9}}{\mathrm{~T}} \mathrm{P}\right)^{1.3}-1.283668 \times 10^{-3}$

where

$$
\begin{array}{lll}
\mathrm{T}_{\mathrm{c}} & = & \text { gas temperature }\left({ }^{\circ} \mathrm{C}\right) \\
\mathrm{P} & = & \text { gas pressure }(\mathrm{Pa}) .
\end{array}
$$

\section{B.1.2 Gas Specific Heat Capacity at Constant Pressure}

The specific heat capacity of the non-condensible gas mixture at constant pressure is required to calculate the temperature of the gas packet. The function GCP calculates the specific heat capacity at constant pressure for a mixture of the ten gases listed in Table B-1. The specific heat is a function of the mole fractions of each component and the gas temperature. It is determined by dividing the molar heat capacity of the mixture by the molecular weight of the mixture. The molar heat capacity of the mixture is calculated using a mole-weighted average of the molar heat capacities (see Reference B-1)

$$
C_{p, \text { mix }}=\sum_{i=1}^{n} C_{p, i} x_{i}
$$


where

$$
\begin{aligned}
& \mathrm{C}_{\mathrm{p}, \text { mix }}=\quad \begin{array}{l}
\text { molar specific heat capacity of the mixture at constant pressure } \\
{[\mathrm{J} /(\mathrm{kg}-\text { mole } \mathrm{K})] .}
\end{array} \\
& \mathrm{C}_{\mathrm{p}, \mathrm{l}}=\quad \begin{array}{l}
\text { molar specific heat capacity at constant pressure of a pure sample of } \\
\text { component } \mathrm{i}[\mathrm{J} /(\mathrm{kg} \text {-mole } \mathrm{K})] .
\end{array}
\end{aligned}
$$

The molecular weight of the mixture is given by

$$
M_{\operatorname{mix}}=\sum_{i=1}^{n} M_{i} x_{i}
$$

The molar specific heat capacity at constant pressure of a pure sample of the monatomic gases helium, argon, krypton, and xenon is calculated using the ideal gas expression

$$
\begin{aligned}
\mathrm{C}_{\mathrm{p}, \mathrm{i}} \text { (monatomic) } & =2.5 \cdot \mathrm{R} \\
& =2.0786 \times 10^{4} \mathrm{~kg} \mathrm{\textrm {m } ^ { 2 }} /(\mathrm{s} \cdot \mathrm{kg} \text {-mole } \cdot \mathrm{K})
\end{aligned}
$$

where

$$
\mathrm{R} \quad=\quad \text { ideal gas constant, } 8314 \mathrm{~kg}-\mathrm{m}^{2} /(\mathrm{s} \mathrm{kg} \text {-mole } \mathrm{K}) \text {. }
$$

For hydrogen, nitrogen, oxygen, carbon monoxide, carbon dioxide, and water vapor, the molar specific heat capacity is calculated using a second degree polynomial correlation in temperature given by Equation (B-10):

$$
C_{p, i}(\text { non monatomic })=A_{i}+B_{i} T+C_{i} T^{2}
$$

where $A_{i}, B_{i}$, and $C_{i}$ are coefficients obtained from Reference 20 and listed here in Table B-3.

\section{B.1.3 Gas Density}

The density of the non-condensible gas mixture is required to calculate the temperature and velocity of the gas packet. The function GDENS calculates the density for a mixture of the ten gases listed in Table B-1. The density is a function of the mole fractions of each component and the gas temperature and pressure. The density of the mixture is determined from van der Waals' equation of state for a gas mixture (see Reference B-1). The correlation used to calculate the density is given by Equation (B-11):

$$
\rho_{\text {mix }}=\frac{\sum_{i=1}^{n} x_{i} M_{i}}{\frac{R T}{P}+\sum_{i=1}^{n} x_{i} b_{i}-\sum_{i=1}^{n} \frac{x_{i}^{2} a_{i}}{R T}}
$$


Table B-3. Coefficients used in Equation (B-10) to calculate the non-monatomic gas molar heat capacities at constant pressure (see Reference B-1).

\begin{tabular}{llll}
\hline & \multicolumn{1}{c}{$\mathrm{A}_{\mathrm{i}}$} & & $\mathrm{B}_{\mathrm{i}}$ \\
Non-condensible & $\mathrm{J} /(\mathrm{kg}$-mole $\mathrm{K})$ & $\mathrm{J} /\left(\mathrm{kg}\right.$-mole $\left.\mathrm{K}^{2}\right)$ & $\mathrm{J} /\left(\mathrm{kg}\right.$-mole K $\left.\mathrm{K}^{3}\right)$ \\
\hline Hydrogen & $2.88 \times 10^{4}$ & $2.76 \times 10^{-1}$ & $1.17 \times 10^{-3}$ \\
Nitrogen & $2.64 \times 10^{4}$ & $7.913 \times 10^{0}$ & $-1.44 \times 10^{-3}$ \\
Oxygen & $2.62 \times 10^{4}$ & $1.150 \times 10^{1}$ & $-3.22 \times 10^{-3}$ \\
Carbon monoxide & $2.62 \times 10^{4}$ & $8.755 \times 10^{0}$ & $-1.92 \times 10^{-3}$ \\
Carbon dioxide & $2.87 \times 10^{4}$ & $3.573 \times 10^{1}$ & $-1.036 \times 10^{-2}$ \\
Water vapor & $2.88 \times 10^{4}$ & $1.375 \times 10^{1}$ & $-1.436 \times 10^{-3}$ \\
\hline
\end{tabular}

where $a_{1}$ and $b_{1}$ are the van der Waals' coefficients listed in Table B-4.

Table B-4. Van der Waals' coefficients used in Equation (B-11) to calculate the non-condensible gas density (see Reference B-1).

\begin{tabular}{|c|c|c|}
\hline Non-condensible & $\frac{a_{i}}{J /(k g-\text { mole } K)}$ & $\begin{array}{c}\mathrm{b}_{1} \\
\mathrm{~J} /\left(\mathrm{kg} \text {-mole } \mathrm{K}^{2}\right)\end{array}$ \\
\hline Helium & 0 & $3.17 \times 10^{-2}$ \\
\hline Argon & 0 & $2.85 \times 10^{-2}$ \\
\hline Krypton & 0 & $3.22 \times 10^{-2}$ \\
\hline Xenon & 0 & $4.29 \times 10^{-2}$ \\
\hline Hydrogen & 0 & $2.84 \times 10^{-2}$ \\
\hline Nitrogen & 0 & $3.46 \times 10^{-2}$ \\
\hline Oxygen & 0 & 0 \\
\hline Carbon monoxide & 0 & 0 \\
\hline Carbon dioxide & () & 0 \\
\hline Water vapor & $5.536 \times 10^{5}$ & $3.05 \times 10^{-2}$ \\
\hline
\end{tabular}

\section{B.1.4 Gas Viscosity}

The viscosity of the gas mixture is used in many relations to describe the flow conditions. The function GVISCO calculates the viscosity for a mixture of the ten gases listed in Table B-1. The viscosity is a function of the mole fractions and viscosities of each component and the gas temperature. The viscosity of the mixture is calculated as ${ }^{\mathrm{B} \cdot 2}$ 


$$
\mu_{\mathrm{mix}}=\sum_{i=1}^{n} \frac{x_{i} \mu_{1}}{\sum_{j=1}^{n} x_{j} \Phi_{j j}}
$$

where $\Phi_{i j}$ is a dimensionless parameter given as

$$
\Phi_{\mathrm{j}}=\frac{\left[1+\left(\frac{\mu_{i}}{\mu_{j}}\right)^{1 / 2} \cdot\left(\frac{M_{i}}{M_{j}}\right)^{1 / 4}\right]^{2}}{2^{3 / 2}\left(1+\frac{M_{i}}{M_{j}}\right)^{1 / 2}}
$$

and

$$
\mu_{i}=\quad \text { viscosity of the component } \mathrm{i}(\mathrm{kg} / \mathrm{m} \mathrm{s}) \text {. }
$$

The viscosities for the ten gases are determined as follows. The correlations used for pure monatomic gases (helium, argon, krypton, xenon, hydrogen, nitrogen, oxygen, carbon monoxide, and carbon dioxide) are all of the form

$\mu_{\mathrm{i}}($ monatomic $)=8.4411 \times 10^{-24} \frac{\left(\mathrm{M}_{\mathrm{i}} \cdot \mathrm{T}_{\mathrm{i}}\right)^{1 / 2}}{\mathrm{\sigma}^{2} \mathrm{kT} / \epsilon_{\mathrm{a}}}$

where

$$
\begin{array}{lll}
\sigma & = & \text { the collision diameter }(\mathrm{m}) \\
\epsilon_{\mathrm{a}} & = & \text { the maximum energy of attraction between a pair of molecules }(\mathrm{J}) \\
\mathrm{k} & = & \text { Boltzmann's constant, } 1.38 \times 10^{-23} \mathrm{~J} / \mathrm{K} .
\end{array}
$$

The intermolecular force parameters $\boldsymbol{\sigma}$ and $\boldsymbol{\epsilon}_{\mathrm{a}}$ are tabulated values (see Reference B-2).

The viscosity of water vapor is calculated as

$$
\mu_{w}=1.851 \times 10^{-6} \frac{T^{1 / 2}}{\left(1+\frac{680}{T}\right)} \text {. }
$$

\section{B.1.5 Gas Molecule Mean Free Path}

The mean free path of the gas mixture is required to calculate the deposition rate due to thermophoresis. The function GMFP calculates the mean free path for a mixture of the ten gases listed in Table B-1. The mean free path is a function of the mole fractions of each component and 
the gas temperature, density, and viscosity. The mean free path of the mixture is approximated using the single component ideal gas relation for viscosity. The single component relation for viscosity is related to the mean free path as (see Reference B-2)

$\mu=\frac{\rho}{3}\left(\frac{8 \mathrm{R}}{\pi \mathrm{M}} \mathrm{T}\right)^{1 / 2} \lambda$

where

$\begin{array}{lll}\mu & = & \text { gas viscosity }[\mathrm{kg} /(\mathrm{m} \mathrm{s})] \\ \rho & = & \text { gas density }\left(\mathrm{kg} / \mathrm{m}^{3}\right) \\ \mathrm{M} & = & \text { molecular weight of the gas }(\mathrm{kg} / \mathrm{kg}-\text { mole }) \\ \lambda & = & \text { mean free path of gas molecules }(\mathrm{m}) .\end{array}$

Generalizing Equation (B-16) for mixtures, the mean free path for the mixture is approximated by solving for $\lambda$, and replacing the single component gas properties, $\mu, \rho$, and $M$, with those for the mixture. The resulting approximation is

$\lambda_{\text {mix }}=\frac{3 \mu_{\text {mix }}}{\rho_{\text {mix }}}\left(\frac{\pi}{8 \mathrm{RT}}\right)^{1 / 2} \cdot\left(\sum_{i=1}^{n} x_{i} \cdot M_{i}\right)^{1 / 2}$

where $\rho_{\text {mix }}$ and $\mu_{\text {mix }}$ are given by Equations (B-11) and (B-12), respectively.

\section{B.1.6 Gas Effective Emissivity}

The effective emissivity of the non-condensible gas mixture is used to approximate the radiative heat transfer between the gas packet and the channel with surface. Use of the effective emissivity assumes the gas packet to be an opaque source. This simplification avoids solving the detailed differential equations for energy transport in a nontransparent media (see Reference B-2).

The function GMISS calculates the effective emissivity for a mixture of the ten gases listed in Table B-1. The correlation assumes that water vapor is the only nontransparent species present and that the packet is cylindrical. The emissivity is a function of the mole fraction of water vapor; the gas temperature and pressure; and the effective diameter of the packet. The simplification that the gas mixture is transparent to all of the gases except water vapor is not accurate for all problems. First, the nonsymmetrical molecules like $\mathrm{CO}_{2}$ and $\mathrm{CO}$ also absorb infrared irradiation. When more than trace amounts of these components are present, the correlation will give incorrect results. Second, radiation from the suspended aerosols is neglected. For the relatively low temperatures expected to occur in the ISV OGS, these simplifications are reasonable. However, for high temperature applications, this gas emissivity model may require modifications. 
The correlations used to calculate the eflective emissivity of the waier vapor are based on Figures 6-10 and 6-11 of Hottel and Sarofim. ${ }^{13-3}$ The effective emissivity is calculated as

$$
\epsilon=\epsilon_{1} \cdot C_{w}
$$

where

$$
\begin{array}{lll}
\epsilon & = & \text { effective emissivity of a gas packet } \\
\epsilon_{1} & = & \text { effective emissivity of a gas packet at } 1.01 \times 10^{5} \mathrm{~Pa} \\
\mathrm{C}_{\mathrm{w}} & = & \begin{array}{l}
\text { correction factor to convert emissivity at } 1.01 \times 10^{5} \mathrm{~Pa} \text { to that for system } \\
\text { pressure, } \mathrm{P} .
\end{array}
\end{array}
$$

The effective emissivity at $1.01 \times 10^{5} \mathrm{~Pa}$ is calculated as

$$
\epsilon_{1}=\exp (a+b T)
$$

where $a$ and $b$ are coefficients calculated as

$$
\begin{aligned}
& a=-7.715+\ln (\mathrm{L}) \cdot\left[1.016-3.339 \times 10^{-2} \cdot \ln (\mathrm{L})\right], \quad(\text { dimensionless }) \\
& \mathrm{b}=-3.798 \times 10^{-3}+\ln (\mathrm{L}) \cdot\left[4.652 \times 10^{-4}-1.611 \times 10^{-5} \cdot \ln (\mathrm{L})\right], \quad\left(\mathrm{K}^{-1}\right)
\end{aligned}
$$

and

$$
\mathrm{L}=\quad \text { the equivalent beam path length }(\mathrm{m}) \text {. }
$$

The equivalent beam path length is calculated as

$L=P \cdot x_{w} \cdot D_{h}$

where

$$
\begin{array}{lll}
\mathrm{x}_{\mathrm{w}} & = & \text { mole fraction of water vapor in the gas } \\
\mathrm{D}_{\mathrm{h}} & = & \text { hydraulic diameter of the flow channel. }
\end{array}
$$

The pressure correction factor for water $\mathrm{C}_{\mathrm{w}}$ is calculated with a second degree polynomial that is a function of the total pressure expressed in units of two atmospheres and the equivalent beam length:

$$
C_{w}=c+d x+e x^{2}
$$


where

$x=9.872 \times 10^{-6} \cdot \frac{P}{2}$

and the coefficients $\mathrm{c}, \mathrm{d}$, and e of Equation (B-23) are listed in Table B-5 as a function of the equivalent beam length.

Table B-5. Coefficients used in Equation (B-23) to calculate the effective emissivity pressure correction factor for water vapor, $C_{w}$ (see Reference $B-1$ ).

Equivalent beam length

$\mathrm{L} \leq 1.54380 \times 10^{3}$

$1.5438 \times 10^{3}<\mathrm{L} \leq 1.15785 \times 10^{4}$

$1.15785 \times 10^{4}<\mathrm{L} \leq 2.31570 \times 10^{4}$

$2.3157 \times 10^{4}<\mathrm{L} \leq 5.40330 \times 10^{4}$

$5.4033 \times 10^{4}<\mathrm{L} \leq 1.15785 \times 10^{5}$

$1.15785 \times 10^{5}<\mathrm{L} \leq 2.31570 \times 10^{5}$

$2.3157 \times 10^{5}<\mathrm{L}$

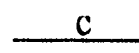

$1.2 \times 10^{-1}$

$2.0 \times 10^{-1}$

$2.7 \times 10^{-1}$

$3.6 \times 10^{-1}$

$4.5 \times 10^{-1}$

$5.3 \times 10^{-1}$

$6.0 \times 10^{-1}$

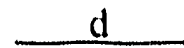

$2.07660 \times 10^{0}$

$1.88570 \times 10^{0}$

$1.74100 \times 10^{0}$

$1.55738 \times 10^{0}$

$1.33210 \times 10^{0}$

$1.17100 \times 10^{0}$

$1.00240 \times 10^{0}$ e

$6.3330 \times 10^{-1}$

$5.7143 \times 10^{-1}$

$5.6190 \times 10^{-1}$

$5.5476 \times 10^{-1}$

$4.6430 \times 10^{-1}$

$4.6190 \times 10^{-1}$

$4.0480 \times 10^{-1}$ 


\section{B.2 Condensible Specles}

For the condensible species, the properties and associated subcodes are the species equilibrium vapor concentration (GCEQ), the vapor deposition speed duc to chemisorbtion (GCHMI), the aerosol thermal conductivity (PCON), the aerosol density (PDENS), the surface tension of condensed species (PSTEN), the vapor specilic heat capacity at constant pressure (CPVAPR), the aerosol specific heat capacity at constant pressure (CPAERO), the latent heat of condensation/evaporation (HLATNT), and the species molecular weight and molar volume (INCLUDE files MOLEWT.H and MOLEVOL.H, respectively). Functions were GCEQ, GCHMI, PCON, PDENS, and PSTEN obtained from the TRAPMELT/PULSE code and the property values were changed to model the condensible species listed in Table B-1. The remaining functions were developed as part of this project.

\section{B.2.1 Equilibrium Vapor Concentration}

The equilibrium vapor concentration is used to calculate the rate of condensation or evaporation onto fixed wall surfaces or mobile aerosols. Also, it is used in modeling the nucleation of aerosols from vapor.

The function GCEQ calculates the equilibrium vapor concentration for the eighteen condensible species listed in Table B-1. The equilibrium vapor concentration is a function of the system temperature and pressure and the equilibrium vapor pressures of the species. The equilibrium vapor concentration is related to the equilibrium vapor pressure using an approximation based upon van der Waals' equation of state for a gas (see Reference B-1):

$$
C_{1}=\frac{M_{1} \cdot P_{1}}{R T+b_{i} P-\frac{a_{1} P}{R T}}
$$

where

$$
\begin{aligned}
& \mathrm{C}_{\mathrm{i}}=\text { equilibrium vapor concentration for the ith species }\left(\mathrm{kg} / \mathrm{m}^{3}\right) \\
& \mathrm{M}_{1}=\text { molecular mass of ith species }(\mathrm{kg} / \mathrm{kg} \cdot \mathrm{mole}) \\
& \mathrm{P}_{1}=\text { vapor partial pressure of ith species at the reference pressure } \mathrm{P}_{0}(\mathrm{~Pa}) \text {, } \\
& \text { (equilibrium vapor pressure in a confined volume.) } \\
& \mathrm{R}=\text { gas law constant, } 8314.4 \mathrm{~J} /(\mathrm{kg} \text {-mole } \mathrm{K}) \\
& \mathrm{T}=\quad \text { system temperature }(\mathrm{K}) \\
& \mathrm{P} \quad=\quad \text { system pressure }(\mathrm{Pa}) \\
& a_{1}=\quad \text { van der Waals' constant that accounts for the intermolecular forces of } \\
& \text { attraction }\left\{\left[\mathrm{kg} \mathrm{m}^{5}\right] /\left[\mathrm{s}^{2}(\mathrm{~kg} \text {-mole })^{2}\right]\right\} \\
& b_{1}=\text { van der Waals' constant to correct for the volume occupied by the } \\
& \text { molecules }\left(\mathrm{m}^{3} / \mathrm{kg}\right. \text {-mole). }
\end{aligned}
$$

The partial pressures, $P_{1}$, at the system pressure, $P$, are related to the partial pressures at the reference pressure using an approximation based upon van der Waals' equation of state (see Reference B-1): 
$\ln \left[\frac{P_{1}(P)}{P_{1}\left(P_{0}\right)}\right] \approx \frac{b_{1}}{R T}\left(P-P_{0}\right)$

where

$$
\mathrm{P}_{0} \quad=\quad \text { the reference pressure }(\mathrm{Pa}) \text {. }
$$

For all species except water, the correction for the intermolecular forces of attraction is neglected by specifying the $a_{1}$ 's in Equation (B-25) as zero. Also, for all species except water, the $b_{1}$ 's, are approximated as the species molecular weight divided by the condensed phase mass density. For water vapor, $a_{w}$ and $b_{w}$ have values of $5.536 \times 10^{5}\left(\mathrm{~kg} \mathrm{~m}^{5}\right) /\left[\mathrm{s}^{2}(\mathrm{~kg} \text {-mole })^{2}\right]$ and $3.05 \times 10^{-2} \mathrm{~m}^{3} / \mathrm{kg}$-mole, respectively. ${ }^{\text {B.4 }}$ Table B-6 lists the molecular weights, mass densities, and van der waals' coefficients used in Equations (B-25) and (B-26).

Finally, the equilibrium vapor pressure over a surface of the ith specie at the reference pressure of one atmosphere is calculated with an expression of the form (see Reference B-1):

$$
\ln \left(P_{1}\right)=A_{1} \cdot T^{-1}+B_{1}+C_{1} \log (T)+D_{1} \cdot T
$$

where $A_{i}, B_{1}, C_{1}$, and $D_{1}$ are coefficients for the ith species and are listed in Table B-7. ${ }^{13 \cdot 5, B \cdot 6,13 \cdot 7}$

Equation (B-27) is used for all species except water. For water vapor, the equilibrium vapor pressure was determined using a morc complex relation. For temperatures less than the critical temperature, $647.2 \mathrm{~K}\left(374^{\circ} \mathrm{C}\right)$, the following expression is usc d:

$$
\mathrm{P}_{\mathrm{w}}=\mathrm{P}_{\mathrm{c}} \cdot \frac{\exp \left\{\frac{\frac{1}{\theta} \cdot\left[-7.691 \cdot(\Delta \theta)-26.08 \cdot(\Delta \theta)^{2}-168.2 \cdot(\Delta \theta)^{3}+64.32 \cdot(\Delta \theta)^{4}-119.0 \cdot(\Delta \theta)^{5}\right]}{1.0+4.167 \cdot(\Delta \theta)+20.98 \cdot(\Delta \theta)^{2}}\right\}}{\exp \left[\frac{(\Delta \theta)}{1.0 \times 10^{9} \cdot(\Delta \theta)^{2}+6.0}\right]}
$$

where

$$
\begin{aligned}
& \mathrm{P}_{\mathrm{c}} \quad=\quad \text { equilibrium vapor pressure of water at the critical temperature, 221.55 } \\
& \times 10^{5} \mathrm{~Pa} \\
& \theta \quad=\quad \mathrm{T} / 647.2 \\
& \Delta \theta=(1-\theta) \text {. }
\end{aligned}
$$

If the temperature is above $647.2 \mathrm{~K}$, then $\mathrm{P}_{1}$ is limited to the critical value of $221.55 \times 10^{5} \mathrm{~Pa}$. 
'Table B-6. Van der Waals' coefficients used in Equations (B-25) and (B-26) to calculate the equilibrium vapor concentrations for the condensible species modeled in the PULSE/MOD-ISV VER 1.0.0 code.

\begin{tabular}{|c|c|c|c|}
\hline \multicolumn{2}{|c|}{ Specie } & $\begin{array}{r}\text { van dor W } \\
\left(\mathrm{kg} \mathrm{m}^{5}\right) /\left[\mathrm{s}^{2}(\mathrm{~kg} \cdot \mathrm{molc})^{2}\right]\end{array}$ & $\begin{array}{c}b_{1} \\
m^{3} / \mathrm{kg}-\mathrm{mole}\end{array}$ \\
\hline 1. & Beryllium & 0.0 & 4.87()$\times 10^{-3}$ \\
\hline 2. & Mercury & 0.0 & $1.476 \times 10^{-2}$ \\
\hline 3. & Cesium hydroxide & 0.0 & $4.080 \times 10^{-2}$ \\
\hline 4. & Potassium & 0.0 & $4.547 \times 10^{-2}$ \\
\hline 5. & Potassium chloride & 0.0 & $3.758 \times 10^{-2}$ \\
\hline 6. & Potassium hydroxide & 0.0 & $2.745 \times 10^{.2}$ \\
\hline 7. & Sodium & 0.0 & $2.370 \times 10^{-2}$ \\
\hline 8. & Sodium chloride & 0.0 & $2.699 \times 10^{-2}$ \\
\hline 9. & Sodium hydroxide & 0.0 & $1.878 \times 10^{-2}$ \\
\hline 10. & Lead & 0.0 & $1.826 \times 10^{-2}$ \\
\hline 11. & Plutonium dioxide & 0.0 & $2.391 \times 10^{-2}$ \\
\hline 12. & Uranium dioxide & 0.0 & $2.464 \times 10^{-2}$ \\
\hline 13. & Wuter & $5.536 \times 10^{5}$ & $3.050 \times 10^{-2}$ \\
\hline 14. & Carbon tetrachloride & 0.0 & $9.653 \times 10^{-2}$ \\
\hline 15. & Trichloroethane $_{1,1,2}$ & 0.0 & $9.265 \times 10^{-2}$ \\
\hline 16. & Regal oil $\left(\mathrm{C}_{20} \mathrm{H}_{42}\right)^{1,1,}$ & 0.0 & $3.216 \times 10^{-1}$ \\
\hline 17. & Silicon Dioxide & 0.0 & $2.731 \times 10^{-2}$ \\
\hline 18. & $\operatorname{PCB}\left(\mathrm{C}_{12} \mathrm{H}_{9} \mathrm{Cl}\right)$ & 0.0 & $1.640 \times 10^{-1}$ \\
\hline
\end{tabular}




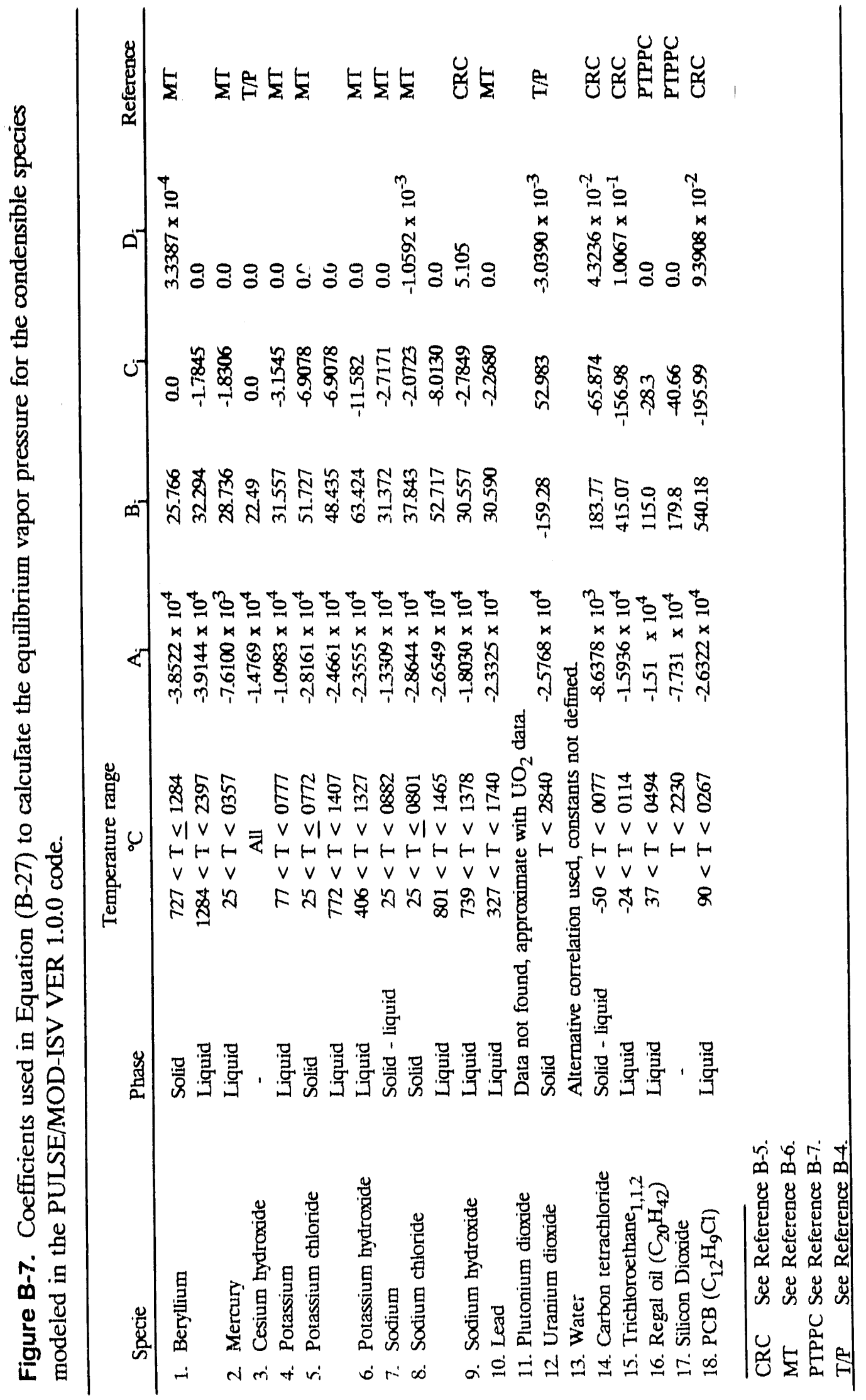




\section{B.2.2 Vapor Deposition Speed Due to Chemisorbtion}

The vapor deposition speed is used to calculate the rate of chemisorbtion onto fixed wall surfaces. Of the species listed in Table B-1, only the chemisorbtion of cesium hydroxide by stainless steel surfaces is modeled.

The function GCHMI calculates the vapor deposition speed for use in Equation (21). The vapor deposition speed for cesium hydroxide on to stainless steel is a function of the system temperature and is modeled using the following correlation: ${ }^{3-8}$

$k_{r}=\exp \left(-2.4563778-\frac{7284.8555}{T}\right)(\mathrm{m} / \mathrm{s})$

\section{B.2.3 Aerosol Thermal Conductivity}

The thermal conductivity of suspended aerosols is used in calculating the deposition rate of aerosols due to thermophoresis. The function PCON is used to calculate the thermal conductivities for the eighteen condensible species listed in Table B-1. When more than one species is present, the conductivities for each specie are combined as though the species are slabs conducting in parallel. The effective conductivity of the mixture is expressed as (see Reference B-4):

$k_{\text {eff }}=\sum_{j=1}^{n} k_{j} \cdot v_{j}$

where

$$
\begin{aligned}
& \mathrm{k}_{\mathrm{eff}}=\quad \text { effective thermal conductivity of a mixture of } \mathrm{n} \text { aerosol species }[\mathrm{W} /(\mathrm{m} \\
& \begin{array}{lll}
k_{j} & = & \\
V_{j} & = & \text { conductivity of the } j \text { th species }[\mathrm{W} /(\mathrm{m} \mathrm{K})]
\end{array}
\end{aligned}
$$

The conductivities for the condensible species are approximated as constant values and are listed in Table B-8.

\section{B.2.4 Aerosol Density}

The density of the condensed phase of the species is used in many of the aerosol deposition models to calculate the van der Waals' coefficients listed in Table B-6, and is used to determine the volume fraction of each species. The function PDENS is used to specify the densities for the eighteen condensible species listed in Table B-1. The densities are approximated as constant values and are listed in Table B-9. ${ }^{\mathrm{B} .9}$ 
Table B-8. Aerosol thermal conductivities for the condensible species modeled in the PULSE/MOD-ISV VER 1.0.0 code.

\begin{tabular}{|c|c|c|}
\hline Specie & $\begin{array}{c}k_{i} \\
W /(m ~ K)\end{array}$ & Reference \\
\hline 1. Beryllium & 1680 & MT \\
\hline 2. Mercury & 10 & MT \\
\hline 3. Cesium hydroxide & 6.7 & $\mathrm{~T} / \mathrm{P}$ \\
\hline 4. Potassium & 49 & PTPPC \\
\hline 5. Potassium chloride & 0.81 & PTPPC \\
\hline 6. Potassium hydroxide & $6.7^{\mathrm{a}}$ & \\
\hline 7. Sodium & 86 & PTPPC \\
\hline 8. Sodium chloride & 0.99 & PTPPC \\
\hline 9. Sodium hydroxide & $6.7^{\mathrm{a}}$ & \\
\hline 10. Lead & 34 & MT \\
\hline 11. Plutonium dioxide & $3.5^{\mathrm{b}}$ & \\
\hline 12. Uranium dioxide & 3.5 & $\mathrm{~T} / \mathrm{P}$ \\
\hline 13. Water & 10 & $T / P$ \\
\hline 14. Carbon tetrachloride & 0.0977 & PTPPC \\
\hline 15. Trichloroethane $e_{1,1,2}$ & 0.129 & PTPPC \\
\hline 16. Regal oil $\left(\mathrm{C}_{20} \mathrm{H}_{42}\right)$ & 0.05 & PTPPC \\
\hline 17. Silicon Dioxide & 2.0 & PTPPC \\
\hline 18. $\mathrm{PCB}\left(\mathrm{C}_{12} \mathrm{H}_{9} \mathrm{Cl}\right)$ & $0.12^{c}$ & $\mathrm{CRC}$ \\
\hline \multicolumn{3}{|c|}{$\begin{array}{l}\text { a. Property value not found; conductivity of cesium hydroxide was used. } \\
\text { b. Property value not found; conductivity of uranium dioxide was used. } \\
\text { c. Property value not found; conductivity of diphenyl at } 200^{\circ} \mathrm{C} \text { was used. }\end{array}$} \\
\hline See Reference B-5. & & \\
\hline See Reference B-6. & & \\
\hline PTPPC See Reference B-7. & & \\
\hline T/P See Reference B-4. & & \\
\hline
\end{tabular}


Table B-9. Aerosol dersities for the condensible species modeled in the PULSE/MOD-ISV VER 1.0 .0 code.

\begin{tabular}{lll}
\hline Specie & $\begin{array}{c}\text { Density } \\
\mathrm{kg} / \mathrm{m}^{3}\end{array}$ & Reference \\
\hline 1. Beryllium & 1850 & $\mathrm{MT}$ \\
2. Mercury & 13590 & PTPPC \\
3. Cesium hydroxide & 3680 & T/P \\
4. Potassium & 860 & PTPPC \\
5. Potassium chloride & 1984 & PTPPC \\
6. Potassium hydroxide & 2044 & PTPPC \\
7. Sodium & 970 & PTPPC \\
8. Sodium chloride & 2165 & PTPPC \\
9. Sodium hydroxide & 2130 & PTPPC \\
10. Lead & 11340 & MT \\
11. Plutonium dioxide & 11460 & MT \\
12. Uranium dioxide & 10960 & T/P \\
13. Water & 1000 & T/P \\
14. Carbon tetrachloride & 1594 & PTPPC \\
15. Trichloroethane & PTPPC \\
16. Regal oil $\left(\mathrm{C}_{20} \mathrm{H}_{42}\right)$ & 1440 & PTPPC \\
17. Silicon Dioxide & 877 & PTPPC \\
18. PCB ( $\left.{ }_{12} \mathrm{H}_{9} \mathrm{Cl}\right)$ & 2200 & PCB \\
\hline MT See Reference B-6. & 1150 & \\
PTPPC See Reference B-7. & & \\
PCB See Reference B-9. & & \\
T/P See Reference B-4. & & \\
& & \\
\hline
\end{tabular}

\section{B.2.5 Surface Tension of Condensed Species}

The surface tension of the condensed species is used in modeling the nucleation of aerosols from vapor. The function PSTEN is used to calculate the surface tension as a function of temperature for the condensible species listed in Table B-1. The surface tension correlation is given by Equation (B-31) (see Reference B-6):

$\sigma_{i}=A_{i}-B_{i} \cdot T$

where

$$
\sigma_{i}=\quad \text { surface tension of the ith species }(\mathrm{N} / \mathrm{m})
$$

and $A_{i}$ and $B_{i}$ are coefficients listed in Table B-10. 
Table B-10. Coefficients used in Equation (B-31) to calculate the surface tension for the condensible species modeled in the PULSE/MOD-ISV VER 1.0.0 code.

\begin{tabular}{|c|c|c|c|}
\hline Specie & $\begin{array}{c}\mathrm{A}_{\mathrm{i}} \\
\mathrm{N} / \mathrm{m}\end{array}$ & $\begin{array}{c}\mathrm{B}_{1} \\
\mathrm{~N} /(\mathrm{m} \mathrm{K})\end{array}$ & Reference \\
\hline 1. Beryllium & 1.10 & 0.0 & MT \\
\hline 2. Mercury & 0.541 & $2.3 \times 10^{-4}$ & PTPPC \\
\hline 3. Cesium hydroxide & 0.15 & 0.0 & CRC \\
\hline 4. Potassium & 0.1386 & $6.943 \times 10^{-5}$ & PTPPC \\
\hline 5. Potassium chloride & 0.075 & 0.0 & $\mathrm{CRC}$ \\
\hline 6. Potassium hydroxide & $0.15^{\mathrm{a}}$ & 0.0 & \\
\hline 7. Sodium & 0.2228 & $9.25 \times 10^{-5}$ & PTPPC \\
\hline 8. Sodium chloride & 0.095 & 0.0 & PTPPC \\
\hline 9. Sodium hydroxide & $0.15^{\mathrm{a}}$ & 0.0 & \\
\hline 10. Lead & 0.5665 & $1.62 \times 10^{-4}$ & CRC \\
\hline 11. Plutonium dioxide & $1.0^{\mathrm{b}}$ & 0.0 & \\
\hline 12. Uranium dioxide & $1.0^{\mathrm{b}}$ & 0.0 & \\
\hline 13. Water & 0.1348 & $2.063 \times 10^{-4}$ & $\mathrm{~T} / \mathrm{P}$ \\
\hline 14. Carbon tetrachloride & 0.0173 & 0.0 & P'TPPC \\
\hline 15. Trichloroethane $e_{1,1,2}$ & 0.0239 & 0.0 & PTPPC \\
\hline 16. Regal oil $\left(\mathrm{C}_{20} \mathrm{H}_{42}\right)$ & 0.0224 & 0.0 & P'ГРPC \\
\hline 17. Silicon Dioxide & $1.0^{\mathrm{b}}$ & 0.0 & \\
\hline 18. $\mathrm{PCB}\left(\mathrm{C}_{12} \mathrm{H}_{9} \mathrm{Cl}\right)$ & $0.0377^{\mathrm{c}}$ & 0.0 & CRC \\
\hline See Reference B-5. & & & \\
\hline MT $\quad$ See Reference B-6. & & & \\
\hline PTPPC See Reference B-7. & & & \\
\hline $\mathrm{T} / \mathrm{P} \quad$ See Reference B-4. & & & \\
\hline
\end{tabular}

\section{B.2.6 Condensible Vapor Specific Heats at Constant Pressure}

The specific heat at constant pressure for the condensible species in the vapor phase is used in determining the total thermal mass in the gas packet. This information is then used to calculate the temperature of the gas packet. For this model, the condensible species listed in Table B-1 are assumed to behave as ideal gases when in the vapor phase. Therefore, the vapor specific heats are approximated as constants. This approximation is valid for small concentrations of the species. The specific heat values are specified by the function CPVAPR and are listed in Table B-11.

\section{B.2.7 Condensed Phase Specific Heats at Constant Pressure}

Similar to the vapor specific heats, the specific heats for the condensed phase are used to calculate the temperature of the gas packet. The function CPAERO calculates the specific heat as a function of temperature for the condensible species listed in Table B-1. The specific heat correlation is given by Equation (B-32) (see Reference B-7): 
$\left(c_{p_{1},}\right)_{1}=A_{i}+B_{1} \cdot T+C_{1} \cdot T^{-2}+D_{1} \cdot T^{2}+E_{i} \cdot T^{3}$

where

$$
\left(c_{p, 1}\right)_{i}=\quad \text { specific heat of the ith species in condensed phase, }(\mathrm{J} /(\mathrm{kg} \mathrm{K})
$$

and $A_{i}, B_{i}, C_{i}, D_{i}$, and $E_{i}$ are coefficients listed in Table B-12.

Table B-11. Vapor specific heats at constant pressure for the condensible species modeled in the PULSE/MOD-ISV VER 1.0.0 code.

\begin{tabular}{|c|c|c|c|}
\hline & Specie & $\begin{array}{r}c_{p, v} \\
J /(k g ~ K)\end{array}$ & Reference \\
\hline 1. & Beryllium & 2100 & MT \\
\hline 2. & Mercury & 137 & MT \\
\hline 3. & Cesium hydroxide & $1200^{\mathrm{A}}$ & \\
\hline 4. & Potassium & 512 & PTPPC \\
\hline 5. & Potassium chloride & 502 & MT \\
\hline 6. & Potassium hydroxide & 1010 & PTPPC \\
\hline 7. & Sodium & 909 & PTPPC \\
\hline & Sodium chloride & 792 & PTPPC \\
\hline & Sodium hydroxide & 1420 & PTPPC \\
\hline & Lead & $1200^{\mathrm{a}}$ & \\
\hline & Plutonium dioxide & $1200^{\mathrm{a}}$ & \\
\hline & Uranium dioxide & $1200^{\mathrm{a}}$ & \\
\hline & Water & 1200 & $\mathrm{CRC}$ \\
\hline & Carbon tetrachloride & 6770 & MT \\
\hline & Trichloroethane $_{1,1,2}$ & 761.3 & PTPPC \\
\hline & Regal oil $\left(\mathrm{C}_{20} \mathrm{H}_{42}\right)$ & 1700 & PTPPC \\
\hline & Silicon Dioxide & $1200^{\mathrm{a}}$ & \\
\hline & $\operatorname{PCB}\left(\mathrm{C}_{12} \mathrm{H}_{9} \mathrm{Cl}\right)$ & $1840^{\mathrm{b}}$ & $\mathrm{CRC}$ \\
\hline
\end{tabular}

a. Property value could be found; heat capacity of water vapor was used.

b. Property value could be found; heat capacity of biphenyl vapor $\left(\mathrm{C}_{12} \mathrm{H}_{10}\right)$ was used.

CRC See Reference B-5.

MT See Reference B-6.

PTPPC See Reference B-7. 


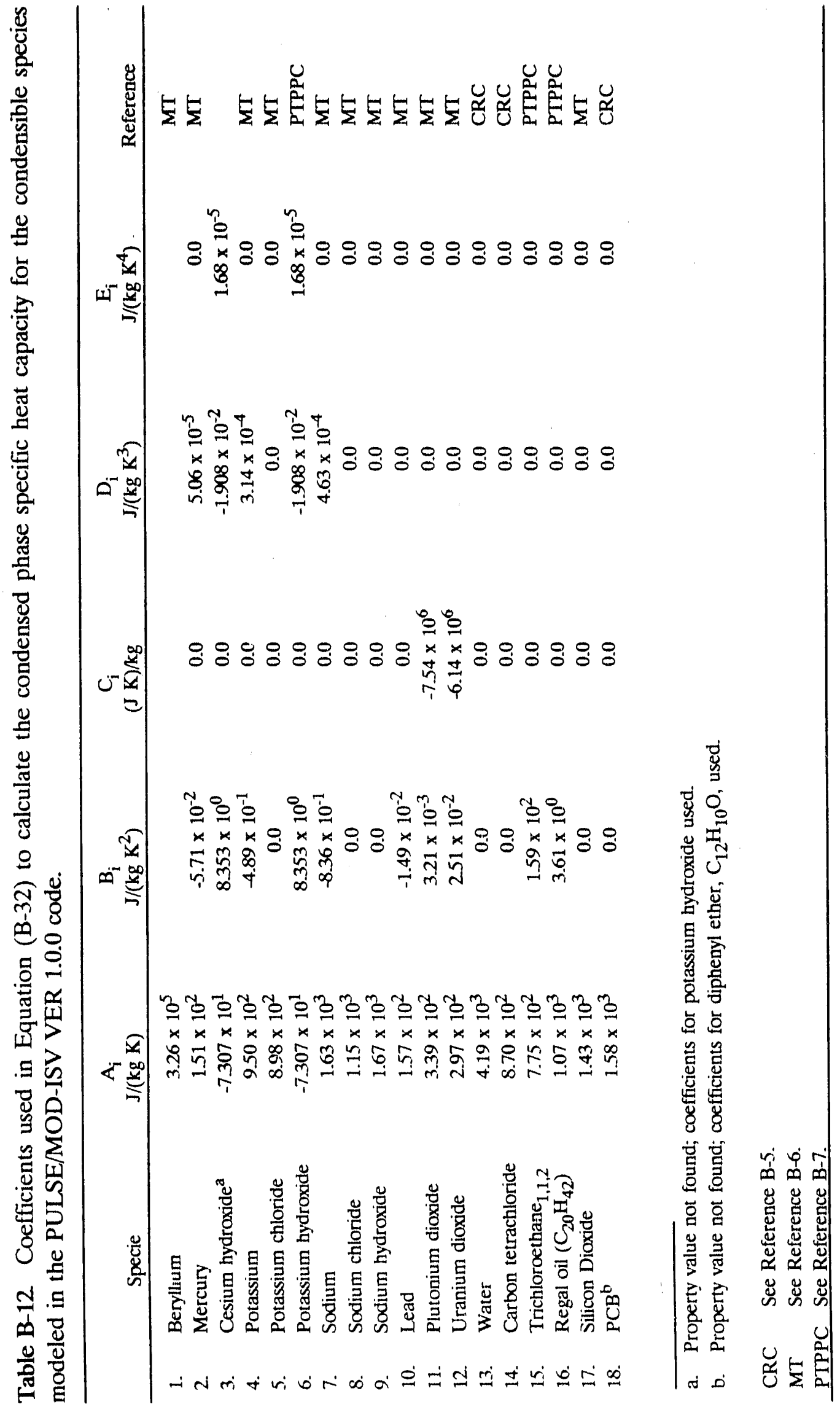




\section{B.2.8 Latent Heats}

The latent heat of evaporation/condensation for the condensible species is used in calculating the temperature of the gas packet. The latent heats are specified as constant values by the function HLATNT and are listed in Table B-13.

Table B-13. Vapor specific heats at constant pressure for the condensible species modeled in the PULSE/MOD-ISV VER 1.0 .0 code.

\begin{tabular}{|c|c|c|c|}
\hline & Specie & $\begin{array}{c}\mathrm{h}_{\mathrm{fg}} \\
\mathrm{J} / \mathrm{kg}\end{array}$ & Reference \\
\hline 1. & Beryllium & $3.24 \times 10^{7}$ & MT \\
\hline 2. & Mercury & $2.95 \times 10^{5}$ & MT \\
\hline 3. & Cesium hydroxide ${ }^{a}$ & $2.28 \times 10^{6}$ & \\
\hline 4. & Potassium & $2.02 \times 10^{6}$ & MT \\
\hline 5. & Potassium chloride & $2.19 \times 10^{6}$ & MT \\
\hline 6. & Potassium hydroxide & $2.543 \times 10^{6}$ & PTPPC \\
\hline 7. & Sodium & $4.31 \times 10^{6}$ & $\mathrm{MT}$ \\
\hline 8. & Sodium chloride & $2.91 \times 10^{6}$ & $\mathrm{MT}$ \\
\hline 9. & Sodium hydroxide & $3.61 \times 10^{6}$ & MT \\
\hline 10 . & Lead & $8.58 \times 10^{5}$ & MT \\
\hline 11. & Plutonium dioxide ${ }^{a}$ & $2.28 \times 10^{6}$ & \\
\hline 12. & Uranium dioxide $\mathrm{a}^{\mathrm{a}}$ & $2.28 \times 10^{6}$ & \\
\hline 13. & Water & $2.28 \times 10^{6}$ & CRC \\
\hline 14. & Carbon tetrachloride & $1.98 \times 10^{5}$ & PTPPC \\
\hline 15. & Trichloroethane $_{1.12}$ & $2.87 \times 10^{5}$ & CRC \\
\hline & Regal oil $\left(\mathrm{C}_{20} \mathrm{H}_{42}\right)$ & $2.10 \times 10^{5}$ & PTPPC \\
\hline & Silicon Dioxide ${ }^{\mathrm{a}}$ & $2.28 \times 10^{6}$ & \\
\hline & $\mathrm{PCB}^{\mathrm{b}}$ & $3.09 \times 10^{5}$ & CRC \\
\hline
\end{tabular}

a. Property value not found; latent heat of water was used.

b. Property value not found; latent heat of biphenyl, $\mathrm{C}_{12} \mathrm{H}_{10}$, was used.

CRC See Reference B-5.

MT See Reference B-6.

PTPPC See Reference B-7. 


\section{B.2.9 Molecular Weights and Molar Volumes}

The molecular weights and molar volumes for the condensible species listed in Table B-1 are used in many of the property correlations described above. The values used in the PULSE/MOD-ISV code are specified by data statements. Data statements A and B contain the molecular weights and molar volumes, respectively. A list of the values is presented in Table B-14.

Table B-14. Molecular weights and molar volumes for the condensible species modeled in the PULSE/MOD-ISV VER 1.0.0 code.

\begin{tabular}{lclc}
\hline Specie & $\begin{array}{c}\text { Molecular } \\
\text { weight } \\
\mathrm{kg} /(\mathrm{kg} \mathrm{mole})\end{array}$ & $\begin{array}{l}\text { Molar volume } \\
\mathrm{m}^{3} /(\mathrm{kg} \mathrm{mole})\end{array}$ & Reference \\
\hline 1. Beryllium & 9.01 & $4.87 \times 10^{-3}$ & CRC \\
2. Mercury & 201 & $1.48 \times 10^{-2}$ & $\mathrm{CRC}$ \\
3. Cesium hydroxide & 150 & $4.08 \times 10^{-2}$ & $\mathrm{CRC}$ \\
4. Potassium & 39.1 & $4.55 \times 10^{-2}$ & $\mathrm{CRC}$ \\
5. Potassium chloride & 74.6 & $3.76 \times 10^{-2}$ & $\mathrm{CRC}$ \\
6. Potassium hydroxide & 56.1 & $2.75 \times 10^{-2}$ & CRC \\
7. Sodium & 23.0 & $2.37 \times 10^{-2}$ & CRC \\
8. Sodium chloride & 58.4 & $2.70 \times 10^{-2}$ & CRC \\
9. Sodium hydroxide & 40.0 & $1.88 \times 10^{-2}$ & CRC \\
10. Lead & 207 & $1.83 \times 10^{-2}$ & CRC \\
11. Plutonium dioxide & 274 & $2.39 \times 10^{-2}$ & CRC \\
12. Uranium dioxide & 270 & $2.46 \times 10^{-2}$ & CRC \\
13. Water & 18.0 & $1.80 \times 10^{-2}$ & CRC \\
14. Carbon tetrachloride & 154 & $9.65 \times 10^{-2}$ & CRC \\
15. Trichloroethane & & CRC \\
16. Regal oil $\left(\mathrm{C}_{20} \mathrm{H}_{42}\right)$ & 133 & $9.27 \times 10^{-2}$ & CRC \\
17. Silicon $\mathrm{Dioxide}_{12}$ & 282 & $3.22 \times 10^{-1}$ & CRC \\
18. PCB $\left(\mathrm{C}_{12} \mathrm{H}_{9} \mathrm{Cl}\right)$ & 60.1 & $2.73 \times 10^{-2}$ & CRC
\end{tabular}

CRC See Reference B-5. 


\section{REFERENCES}

B-1. J. K. Hohorst (ed.), SCDAP/RELAP5/MOD2 Code Manual Volume IV: MATPRO--A Library of Material Properties for Light-Water-Reactor Accident Analysis, NUREG/CR5273 and EGG-2555 Volume IV, Kevision 3, February 1990.

B-2. R. B. Bird, W. E. Stewart, and E. N. Lightfoot, Transport Phenomena, New York: John Wiley and Sons, 1960.

B-3. H. C. Hottel and A. F. Sarofim, Radiative Transfer, New York: McGraw-Hill, 1967.

B-4. W. H. Hamill and R. R. Williams, Principles of Physical Chemistry, New York: Prentice Hall, 1959.

B-5. R. C. Weast, S. M. Selby, and C. D. Hodgman (eds.), Handbook of Chemistry and Physics, 56th edition, Cleveland, Ohio: The Chemical Rubber Company, 1975.

B-6. O. Kubaschewski and C. B. Alcock, Metallurgical Thermochemistry, 5th edition, New York: Pergamon Press, 1979.

B-7. T. E. Daubert and R. P. Danner, Physical and Thermodynamic Properties of Pure Chemicals: Data Compilation, Part 1, New York: Hemisphere Publishing Corporation, 1991.

B-8. R. M. Elrick, D. A. Powers, and R. A. Sallach, Reactor Safety Research Semiannual Report January - June 1986 Volume 35, NUREG/CR-4805, SAND86-2752, Part 1, May 1987, pp. 204-218.

B-9. Toxicological Profile for Selected PCBs, ATSDR/TP-88/21, June 1989. 

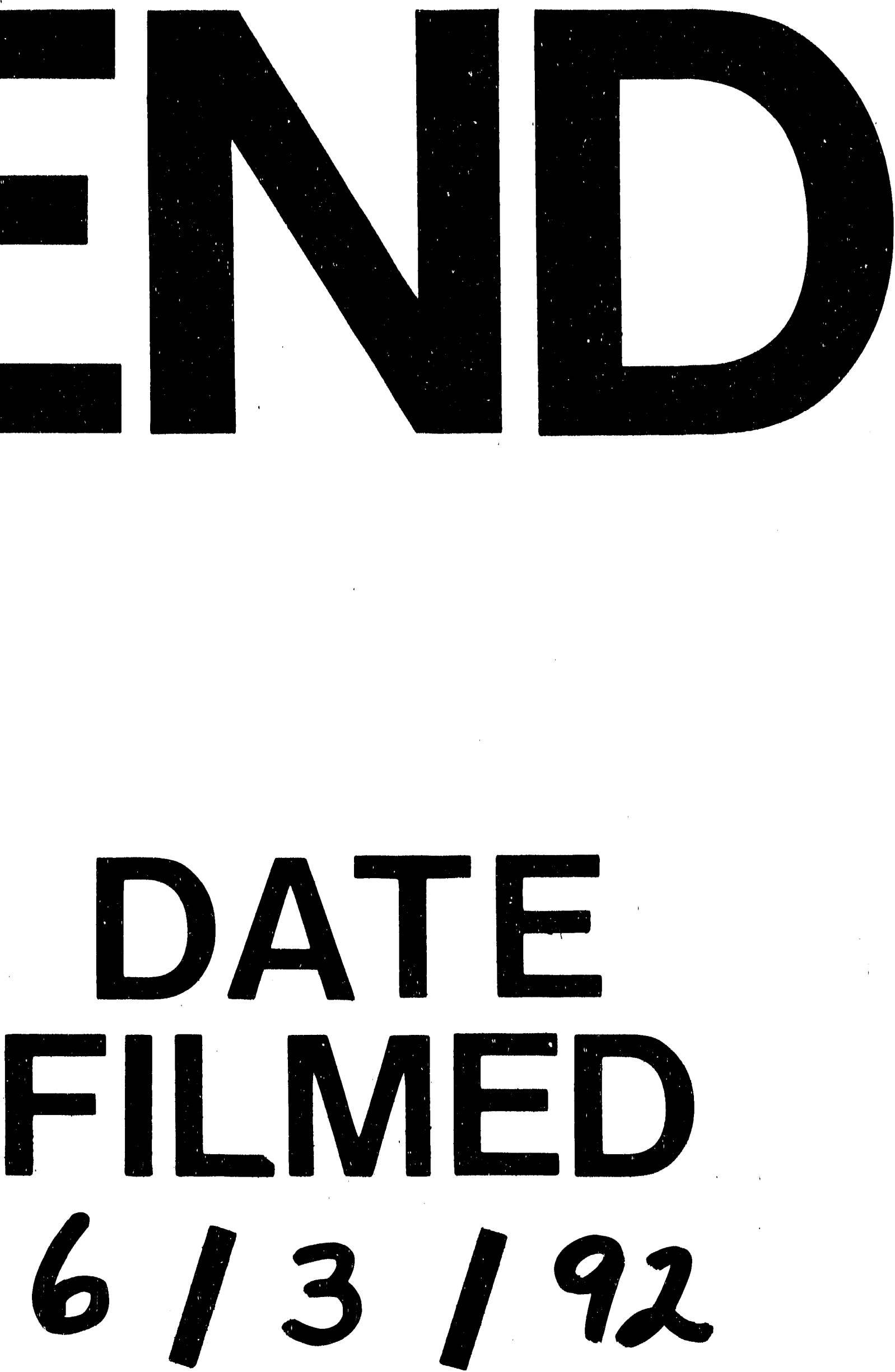
